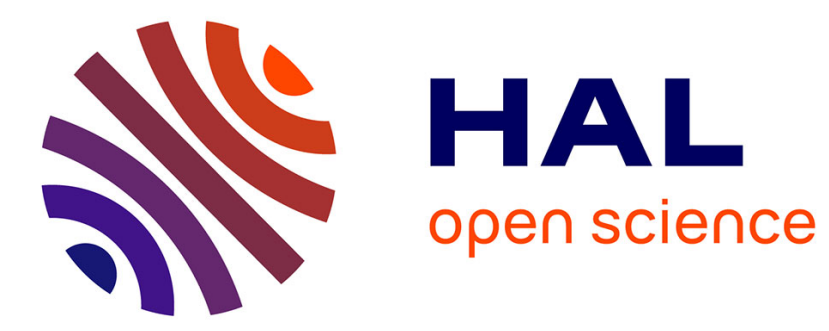

\title{
Consequences of progressive eclogitization on crustal exhumation, a mechanical study
}

Hugues Raimbourg, Laurent Jolivet, Yves Leroy

\section{To cite this version:}

Hugues Raimbourg, Laurent Jolivet, Yves Leroy. Consequences of progressive eclogitization on crustal exhumation, a mechanical study. Geophysical Journal International, 2007, 168 (1), pp.379-401. 10.1111/j.1365-246X.2006.03130.x . hal-00144471

\section{HAL Id: hal-00144471 https://hal.science/hal-00144471}

Submitted on 26 Nov 2012

HAL is a multi-disciplinary open access archive for the deposit and dissemination of scientific research documents, whether they are published or not. The documents may come from teaching and research institutions in France or abroad, or from public or private research centers.
L'archive ouverte pluridisciplinaire HAL, est destinée au dépôt et à la diffusion de documents scientifiques de niveau recherche, publiés ou non, émanant des établissements d'enseignement et de recherche français ou étrangers, des laboratoires publics ou privés. 


\section{Consequences of progressive eclogitisation on crustal exhumation, a mechanical study}

Hugues Raimbourg (a)

Laurent Jolivet (a)

Yves Leroy (b)

(a): Laboratoire de Tectonique, Université Pierre et Marie Curie, Paris, France

(b) : Laboratoire de Géologie, Ecole Normale Supérieure, Paris, France

Abbreviated title : Consequences of eclogitization on exhumation

Corresponding author :

hugues.raimbourg@1gs.jussieu.fr

Tel : +33144275260

Fax : +33144275085 


\section{Summary}

The very low water content of the granulitic unit of Holsnøy, in the Bergen Arcs, Norway, caused its partial metastable preservation throughout Caledonian burial end exhumation, leading to the observed mixture of completely eclogitized and uneclogitized rocks. Largescale eclogite-facies fracturing enabled fluid penetration into the granulite and subsequent eclogitization, and resulted in a very anisotropic geometry of eclogitized volumes. The eclogite fraction, denser than its granulite-facies protolith, was also weaker and localized all deep ductile deformation.

We address the consequences on subduction dynamics of the concomitant evolution of density and large-scale average rheology during progressive eclogitization of crust by comparing the behaviour of buried crust of various properties in a simple channel-flow model. We define the "exhumation number" $\alpha$ that depends upon buoyancy and viscosity and describes the capacity of a crust to exhume. For a crust whose eclogitization causes more weakening than density increase (high exhumation number), the maximum possible downward flow in the partially-eclogitized zone is very low. This zone acts as a bottleneck and all incoming crust in excess is forced backward and starts exhuming. The conditions for this return flow to reach shallow levels are studied in the case of alternating subduction of crust with low- and high exhumation numbers. We also demonstrate that large exhumation rates reached by certain UHP units are incompatible with any stationnary flow regime and can only occur in the transitionary regime from subduction of low to high exhumation number crust. The additional presence of a weak layer on top of the channel favors burial for narrow channels and exhumation for large ones, but does not qualitatively changes the dynamics of the subduction channel.

\section{Keywords: eclogitization, exhumation, subduction channel}

\section{Introduction}

The presence in former or present collision zones of coesite (Chopin 1984; Smith 1984) or microdiamonds (Dobrzhinetskaya et al. 1995) in crustal rocks now at the surface evidences their former burial to large depths $(>100 \mathrm{~km})$ and subsequent exhumation. The geodynamical context that allows to reach such depths is subduction: crust attached to the dense subducting lithosphere is dragged down into the mantle, and at some point starts its way up. The second part of this evolution is problematic: which mechanism does trigger movement reversal, what 
are the conditions of exhumation? The main purpose of this study is to explore the consequences of metamorphic reactions and phase changes on this process.

Large-scale analogue (Chemenda et al. 1996; Chemenda et al. 1995) as well as numerical modelling (Burov et al. 2001) of subduction zones highlight the major forces at stake: vertical movements at large depths of subducted crust are prescribed by the balance between buoyancy of buried crust and downpull drag by lithospheric mantle. In the second type of model, exhumation of HP rocks is driven by crustal convective instability, while in the first type it results from the formation of one crustal-scale thrust. In both cases exhumation starts when buoyancy overcomes downward pull. Additionally, in corner-flow models (Shreve \& Cloos 1986), the fixed wedge shape of the subduction channel induces a forced return-flow of crust independent of density contrasts. Such rigid geometries of the subduction channel lead to large overpressures (Mancktelow 1995). However when using realistic rocks rheologies it can be shown that the walls of the subduction channel permanently adjust to pressure variations and that no significant overpressure can accumulate (Burov et al. 2001; Toussaint et al. 2004).

The effects of metamorphic transformations on the behaviour of the subduction channel have seldom been explored although variations in material properties and particularly in density and rheology are likely to bring about large modifications of geometry and dynamics of subduction zones. These variations stem first from the evolving nature of involved lithospheric plates, as in the transition from oceanic to continental lithosphere subduction. The difference in radiogenic heat production between oceanic and continental crust has strong consequences on the thermal regime of convergent zones (Bousquet et al. 1997; Goffé et al. 2003). Additionnally, the buoyancy differences between continental and oceanic crust are often invoked to explain the differences between subduction and collision regimes (Beaumont et al. 1996; Regard et al. 2003).

Metamorphic reactions also affect rocks physical properties and have geodynamical consequences: hydration of the mantle above the subducting slab causing serpentinization of peridotites induces the formation of a low viscosity wedge whose internal circulation enables crust exhumation (De Sigoyer et al. 2004; Gerya et al. 2002b; Guillot et al. 2000). The subducted crust also undergoes phase changes as it is buried, and eclogite-facies metamorphic reactions cause a well defined density increase (e.g. Austrheim (1987), Bousquet et al. (1997)) and rheological changes that are still not well constrained. The ongoing controversy over the dominant deformation of omphacite, one of the main eclogite-facies minerals, either dislocation creep (Bascou et al. 2002) or diffusion creep (Godard \& van Roermund 1995; 
Mauler et al. 2001), illustrates the lack of data on mechanical behaviour of high-pressure minerals. As a result, when accounted for, crustal eclogitization reactions are only integrated in numerical models through the density variation (Burov et al. 2001; Doin \& Henry 2001).

Preservation of successive parageneses in a single rock evidences the complex progress of metamorphic reactions, which are neither instantaneous nor spatially homogeneous. A large fraction of the anhydrous Precambrian granulitic unit of the Bergen Arc underwent Caledonian burial and exhumation without any sign of reworking (Austrheim 1987; Austrheim \& Griffin 1985), while the rest was in average strongly eclogitized. The kilometerscale rheology of partially eclogitized units, such as Holsnøy high-pressure unit, depends on the small-scale rheology of un- and eclogitized materials, but also on the geometries of unand transformed volumes.

The first objective of this paper is to gain better insight into the possible physical mechanisms underlying the propagation of the eclogitized zones into a subducted dry granulitic basement, and to explore their consequences on the rheology of a partially eclogitized crust. The second objective is to analyse the consequences of such partial metamorphic transformations on deep circulation in subduction channels. The framework of this mechanical study is the channelflow model (England \& Holland 1979; Shreve \& Cloos 1986) that enables to understand the interplay between buoyancy and viscosity variations in the flow of progressively eclogitizing rocks.

\section{Geological settings}

\section{The Lindås Nappe, a Caledonian high-pressure unit}

The Lindås Nappe belongs to the Bergen Arcs, a series of arcuate thrust sheets centered around Bergen, Norway. The protolith is considered as a portion of lower crust and contains abundant mafic material (Kolderup \& Kolderup 1940).

The northwestern part of Holsnøy (Fig. 1) belongs to The Lindås Nappe and is constituted of gabbroic to anorthositic rocks. The geology and metamorphic history of the area is well constrained by numerous prior studies (Austrheim 1987; Austrheim 1990a; Austrheim 1990b; Austrheim 1994; Austrheim \& Engvik 1995; Austrheim \& Griffin 1985; Austrheim \& Mørk 1988; Boundy et al. 1992). The protolith was pervasively recrystallised and deformed under granulite-facies conditions during the Grenvillian orogenesis ( $900 \mathrm{Ma}$ (Austrheim \& Griffin 1985; Bingen et al. 2001; Cohen et al. 1988)). It was then involved in the Caledonian orogen 
and experienced successive eclogite-, amphibolite- and greenschist-facies metamorphism around 400-460 Ma (Austrheim 1990b; Bingen et al. 2004; Bingen et al. 1998; Bingen et al. 2001; Boundy et al. 1997b). Maximum burial conditions, recorded by the eclogite-facies metamorphism, were estimated by thermobarometric studies as $\sim 15-20$ kbars and $700-800^{\circ} \mathrm{C}$ (Austrheim \& Griffin 1985; Boundy et al. 1992; Jamtveit et al. 1990; Mattey et al. 1994; Raimbourg et al. submitted). Caledonian metamorphic reactions heterogeneously affected northwestern Holsnøy; as a result a large fraction of the granulite-facies unit was metastably preserved throughout Caledonian history and the successive Caledonian metamorphic stages only partially overprinted each other.

\section{Role of eclogitization in Holsnøy exhumation}

The analysis of eclogitic deformation and its comparison with regional kinematics reveal that eclogitic shear zones (Fig. 1b) enabled deep thrusting of crustal sliver onto each other (Raimbourg et al. in press). The age of eclogite-facies metamorphism (460-420 Ma), albeit controversial, is by large older than the onset of Caledonian large-scale extension driven by plate divergence ( 400-405 Ma, (Fossen 1992; Fossen 2000; Roberts 2003)). Both burial and exhumation of Holsnøy occurred therefore during convergence and collision. The general structure of the Caledonian orogen is interpreted as resulting from the subduction of Baltica under Laurentia (Krogh 1977). This asymmetrical geometry of the convergent zone is inferred from nappe-thrust kinematics and spatial variations in metamorphic grade (Griffin et al. 1985). Continental subduction is also the only widely accepted framework where crustal rocks reach depths $>100 \mathrm{~km}$, like coesite-bearing units in the Western Gneiss Region (WGR) (Carswell et al. 2001; Smith 1984; Wain 1997). Within this subduction, we interpreted the deep eclogitic thrusts as the first step towards exhumation (Raimbourg et al. in press). Eclogitization reactions and the consequent viscosity drop enabled mechanical decoupling within the subducting slab between light crust and dense mantle and triggered the buoyant ascent of buried crust.

\section{P-T paths and exhumations rates within Bergen Arcs and WGR}

Amphibolite-facies retrogression of Holsnøy occurred at $690^{\circ} \mathrm{C}$ and 8-12 kbars (Boundy et al. 1992), or $600^{\circ} \mathrm{C}$ and $8 \mathrm{kbars}$ (Kühn 2002). If the timing of eclogite-and amphibolite-facies events are too much debated to give reliable exhumation rates, the shape of return P-T paths shows nevertheless two distinct tendencies: first a nearly isothermal decompression followed by a return to the surface along a geothermal gradient around $15^{\circ} \mathrm{C} / \mathrm{km}$. 
The P-T-t paths from the Western Gneiss Region high-pressure and ultrahigh-pressure units, compiled by Labrousse et al. (2004), show the same division of uplift paths in two successive phases, first a large pressure drop with little temperature variations, down to roughly 5-10 kbars and $\sim 600{ }^{\circ} \mathrm{C}$, then a return to the surface. Dating the successive metamorphic events confirms the division exhumation in two phases, exhumation rates within the first phase being much faster than in the second one.

\section{Rheological changes associated to eclogitization}

\section{Sample scale rheology: experimental and natural data}

The Holsnøy eclogite paragenesis is composed of omphacite, garnet, kyanite and minor phengite, +/- rutile, +/- quartz, +/- amphibole (Boundy et al. 1992), and the volumetric dominant mineral is omphacite. Whereas the metastable granulite-facies fraction was not deformed during Caledonian subduction, most eclogitized zones show pervasive deformation, attesting to the much higher ductility of eclogite than granulite (Austrheim \& Griffin 1985). This rheological softening is the most obvious in narrow transition zones between granulite and eclogite, where the partially eclogitized granulitic foliation is bent to merge into eclogitic foliation (Fig. 2).

The unambiguous localization of deformation in omphacite-dominated fraction (eclogite) and respective undeformability of plagioclase-dominated fraction (granulite) do nevertheless not match experimentally derived rheological laws. Diopside is 10 times stronger than anorthite under similar thermodynamic conditions (Dimanov et al. 2003), what is confirmed by the very strong behaviour of dry calcic clinopyroxene aggregates (Bystricky \& Mackwell 2001). The yet much weaker rheology of natural omphacite seen on Holsnøy is also documented in the Western Alps (Piepenbreier \& Stöckhert 2001). The presence of $\mathrm{Na}$ in the high-pressure pyroxene may significantly soften it (Jin et al. 2001), but these experiments were carried out at very high temperatures $(1500 \mathrm{~K})$ and their extrapolation to real deformation conditions may be difficult. Furthermore, beside discrepancies in creep rates of omphacite, even deformation mechanisms are debated: Anisotropic omphacite crystallographic preferred orientations in natural samples, studied by Electronic Backscatter Diffraction, have been interpreted as resulting either from diffusion creep (Godard \& van Roermund 1995; Mauler et al. 2001) or dislocation creep (Bascou et al. 2002). Bystricky \& Mackwell (2001) have concluded to the coexistence of both processes, their relative contribution depending on the differential stress 
applied. As a result of this variance in natural and experimental data, and given the very strong strain partitioning on Holsnøy, we shall consider in the following that eclogite is much weaker than granulite, without quantifying the rheological difference.

\section{Decameter-scale rheology of the mixture eclogite-granulite}

At decameter-scale, the rheology of the partially eclogitized granulite depends on eclogite and granulite rheologies and on the spatial organization of un- and eclogitized volumes. The volumetric fraction of eclogite is highly variable within Holsnøy unit (Fig. 1b): in the least transformed areas, eclogite is present only in cm-wide bands along sparse fractures, while in the most transformed areas the only relics of granulite are scarce m-scale boudins embedded in eclogitic shear zones. A large continuous range of rheology, from granulite-supported to eclogite-supported, is spanned on Holsnøy (Fig. 3).

\section{Decameter-scale propagation of eclogitization}

The geometry of eclogitized zones is constrained by the processes driving the spatial propagation of metamorphic reactions. As stated above, the anhydrous granulite is metastably preserved unless provided with fluid input, therefore fluid penetration controlled the spreading of metamorphic transformation.

At mineral-scale, fluid diffused along grain boundaries, but also within newly formed mmlong fractures. The volume reduction associated to eclogitization (up to $\sim 10 \%$ for complete eclogitization (Austrheim \& Griffin 1985)) caused stress development that eventually resulted in granulitic garnet fracturing (Erambert \& Austrheim 1993; Raimbourg et al. submitted). Eclogitic fractures behave as new pathways for fluid, enhancing the metamorphic reaction and diffusion kinetics (see for example the simulation in Jamtveit et al. (1990)). At mineral-scale the transformation propagation is not driven solely by simple diffusion but rather by coupled diffusion-microfracturing.

The efficiency of this microfracturing-assisted diffusion at meter-scale is questionable. In little-transformed areas, showing the first stages of eclogitization, some finger-shaped eclogitized volumes do not have any visible central macroscopic fracture (Fig. 4, right side). In this case, small-scale diffusion is responsible for the eclogitization of the whole volume. But the quantitatively prominent structure, descriptive of eclogitization inception, is macroscopic planar fracture filled with hydrous minerals surrounded by two parallel bands of eclogite (Austrheim 1987; Austrheim \& Mørk 1988). In this case the meter-scale fluid 
transportation was carried out within the decametric fracture, and then microfracturingassisted diffusion enabled fluid penetration into the host granulite (Fig. 4, left side).

\section{Geometry of the damage zone}

The propagation of eclogitized zones at scales > meter is controlled by the formation of macroscopic fractures that channelize fluids. The volume containing these fractures (around the outer border of the "Breccia zone" on Fig. 1b) can be seen as a damage zone, intermediate between eclogite and granulite (Fig. 5). Within this damage zone, fluid diffuses within and away from macroscopic fractures and the local fraction of eclogite increases until the whole volume is eclogitized; in parallel the damage zone extends further away from the fluid source. The distribution of eclogitized zones is highly anisotropic: the most eclogitized zones are 100m-wide but km-long shear zones, which have similar orientations, trending roughly N90120 with a gentle dip to the North (Fig. 1b). The formation of macroscopic fractures and the associated geometry of damage zones, that drive the spatial propagation of eclogitization, must therefore be anisotropic.

\section{Propagation of eclogitisation and large-scale rheological consequences}

If the mechanisms underlying macroscopic fracturing have never been precisely defined, they must nevertheless account for the anisotropic geometry of the eclogitized zones. The kinematics of eclogite-facies are consistent all over the high-pressure unit, attesting for the influence of large-scale stresses (Raimbourg et al. in press). Besides, stresses resulting from the reaction-induced volume change constitute the other candidate for fracturing the granulite. Both phenomena can be accounted for by solving the matrix-inclusion class of problems, such as Eshelby's problem (e.g. Nemat-Nasser \& Hori (1993), section 11). It is out of the scope of this paper to analyze in detail such a problem, we can nevertheless outline the method and some qualitative conclusions. Let us assume that eclogitization is confined within an ellipsoidal inclusion, embedded in an infinite granulitic matrix (Fig. 6). The damage zone can be determined as the zone within the granulite undergoing large stresses. As the inclusion is softer, shear stresses applied at infinity will concentrate in the granulite next to the sharp tip of the inclusion (shown as scalar equivalent stress). Additionally the inclusion can undergo the volume change linked to eclogitization, introduced in the problem as a field of residual deformation, null outside the inclusion and constant inside. The highest stresses aroused in the granulite to accommodate this initial and discontinuous deformation are also located near the sharp tip of the inclusion. 
The value of large-scale stresses is unknown, and eclogite and granulite rheologies are poorly constrained, precluding to assess the intensity of both localizing mechanisms. They nevertheless both result in anisotropic geometry of damage zones, and eventually of eclogitized zones. The anisotropic propagation of eclogitized volumes differ much from the pattern obtained from diffusion-like processes, smoothing anisotropies (Fig. 7).

The physical process controlling the propagation of eclogitized volumes also determines the evolution of the large-scale rheology of Holsnøy unit during its progressive eclogitization. In particular, when a volume of eclogite crosscuts the granulitic unit, all the subsequent strain is localized within the eclogite, and under prescribed strain rate, applied stress drops. The volume change associated to this drastic rheological change -i.e., the critical rheological fraction (CRF)- is all the smaller if the propagation of eclogitized zones is anisotropic because the formation of connected eclogitic shear zones occurs sooner.

The behaviour after the CRF differs between the volume-change and the rheology-difference localizing mechanisms. In the latter, the granulite macroscopic fracturing is related to largescale stresses; the stress drop resulting from the rheological weakening after the CRF prevents any posterior fracturing and damage zone propagation (Bjørnerud et al. 2002). In the volumechange mechanism, eclogitization is a self-propagating phenomenon that proceeds even after the large-scale rheology change.

\section{Exhumation of partially eclogitized crust}

The physical processes controlling the propagation of eclogitized zones consequently determine the evolution of large-scale rheology during progressive eclogitization. In parallel to these complex rheological variations, the density of a partially eclogitized unit varies proportionally to the proportions of protolith and eclogite. Eclogitization results in a density increase hindering the capacity to exhume. On the other hand, in Holsnøy granulites, the large rheological softening induced by eclogitization enabled mechanical decoupling from the subducting lithospheric mantle and subsequent exhumation (Raimbourg et al. in press). The “channel flow" model (England \& Holland 1979; Shreve \& Cloos 1986) is a powerful analytical framework to study this equivocal effect of eclogitization on exhumation. Its simplicity enables to study the interplay between buoyancy and viscous drag, two major forces controlling burial and exhumation.

\section{The subduction channel model}




\section{General geometry and boundary conditions}

The subduction channel model has been defined to analyse the movements of sediments on top of a subducting plate (England \& Holland 1979; Shreve \& Cloos 1986). We apply here the model not to the sediments but to the crust overlying the subducting slab and we ignore the thin layer of sediments, in a first approach. Accretionary prisms, which can be as deep as 30-40 km (e.g. Bousquet et al. (1997), Chi et al. (2003), Rubio et al. (2000)) are not described by the channel flow model, whose upper vertical limit is therefore below such structures. Its lower limit is not constrained, as a certain amount of lower crust within the subducting slab is assumed to disappear into the mantle (Jolivet et al. 2003; Le Pichon et al. 1988).

The bottom boundary of the channel, in the $y$ direction (Fig. 8), is the subducting lithospheric mantle; the roof is either the overriding mantle wedge or the thickened crustal orogen, depending on the depth. The velocity is prescribed as the plate velocity $U$ at the bottom, and null velocity at the top. The width channel gradient $\frac{\partial h(x)}{\partial x}$ and the transverse pressure gradient $\frac{\partial P(x, y)}{\partial y}$ are assumed to be small, material properties being constant in $y$ direction. As a result the velocity $\vec{u}$ is everywhere parallel to $\vec{x}$-i.e., the flow is laminar.

\section{Velocity profiles}

Under the above assumptions, Stokes equations with neglectible acceleration are reduced to $\frac{\partial \tau_{x y}}{\partial y}=\frac{\partial \phi}{\partial x}$

where $\phi=P-\rho_{\text {crust }} g z$ is the hydraulic potential, $\tau_{x y}$ the shear stress, $\mathrm{P}$ the pressure, $\rho_{\text {crust }}$ the crustal density, $\mathrm{g}$ the vertical component of acceleration within the gravity field and $\mathrm{z}$ the depth. The pressure at depth is approximated as $P=\rho_{\text {mantle }} g z$, so that the hydraulic potential gradient is proportional to the density difference between crust and mantle:

$\frac{\partial \phi}{\partial x}=\left(\rho_{\text {mantle }}-\rho_{\text {crust }}\right) g \sin \alpha=\Delta \rho g \sin \alpha$, where $\alpha$ is the dip of subduction

Crustal constitutive equations under a large range of P-T conditions, relating stress and strain rate, are the last ingredient to derive the flow field from the stress balance equations. Monomineralic flow laws are often used to approximate rock rheologies; as stated above, omphacite rheology is unfortunately not well constrained. In particular the deformation mechanism, either by diffusion or dislocation creep, corresponding respectively to Newtonian or non-Newtonian rheologies, highly influence the flow pattern within the channel (Gerya \& 
Stöckhert 2002a). Resulting exhumation rates, as well as natural evidences described in Stöckhert (2002), Stöckhert et al. (1999) and Stockhert et al. (1997), led the authors to prefer a Newtonian rheology for high pressure crust in their numerical model (Gerya et al. 2002b). For the same reasons and for the sake of simplicity we use a Newtonian rheology defined by $\tau_{x y}=\eta \frac{\partial u}{\partial y}$

where $\eta$ is the viscosity.

For a given channel width $\mathrm{h}$, the velocity profile is given by $\bar{u}=-\frac{\alpha}{2} \bar{h}^{2}\left(\bar{y}-\bar{y}^{2}\right)+(1-\bar{y})$

where $\bar{u}=\frac{u}{U}, \bar{y}=\frac{y}{h}(0<\bar{y}<1)$ are adimensional variables, $\bar{h}=\frac{h}{h^{*}}$ and $\alpha=\frac{\frac{\partial \phi}{\partial x} h^{* 2}}{\eta U}$ are adimensional parameters, $h^{*}$ an arbitrary width and $\mathrm{U}$ the plate velocity.

The velocity field is the sum of two terms (Fig. 8): one parabolic field generated by the hydraulic potential gradient and one linear field resulting from the velocity of the lower boundary. The latter is always directed downwards and represents the dragging by the subducting lithospheric mantle, while the former has a sign given by the density difference between crust and mantle, which varies according to the crustal phase changes, and represents the buoyancy-driven movements, which can be directed either downward or upward.

\section{Effect of $\alpha$ value on flow pattern}

The parameter $\alpha$ integrates all relevant material properties and thus completely determines the flow pattern within the channel. In particular, density and viscosity variations associated to eclogitization control the value of $\alpha$,

$$
\alpha=\frac{\frac{\partial \phi}{\partial x} h^{* 2}}{\eta U}
$$

through $\frac{\partial \phi}{\partial x}$ at the numerator and $\eta$ at the denominator, respectively. $\alpha$ is named hereafter the "exhumation number". The sign of $\alpha$ depends on the value of $\frac{\partial \phi}{\partial x}$, thus on crust density.

For a crust heavier than the mantle, the exhumation number is negative, as $\frac{\partial \phi}{\partial x}<0$ Both buoyancy- and lithospheric dragging-driven velocity fields (parabolic and linear flows in Fig. 
8, respectively) are directed downward and no exhumation occurs in this case. Exhumation i.e., upward directed velocities- can occur only when the crust is lighter than the mantle, for $\alpha>0$, under certain conditions.

In the case $\alpha>0$, the possibility of exhumation is controlled by the relative contribution of the buoyancy-driven flow, directed upward, and the lithospheric dragging-driven flow, directed downward. The intensity of the former varies as $\alpha$ and $\bar{h}$ (Fig. 9): for large $\alpha$ and/or $\bar{h}$, the buoyancy-driven flow overtakes its contender and exhumation occurs near the top (in the $y$-direction) of the channel. This can be seen through the evolution of flow pattern, for $a$ given positive exhumation number $\alpha$ : the range of channel widths $\bar{h}$ can be divided in two distincts sets:

for $\bar{h}<\sqrt{\frac{2}{\alpha}}$, everywhere across the channel velocities are directed downward, while for $\bar{h}>\sqrt{\frac{2}{\alpha}}$ the channel is divided into a bottom subducting zone and an top exhuming zone with reverse velocities. Conversely, for a fixed channel width $\bar{h}$, circulation patterns with exhumation are characterized by large exhumation numbers $\alpha$, whereas small $\alpha$ 's imply regimes without exhumation. The physical interpretation of these variations is quite simple in this case: large $\alpha$ result either from large hydraulic gradients $\frac{\partial \phi}{\partial x}$ or from low crust viscosity $\eta$. Large hydraulic gradients imply low density of the crust -i.e. large positive buoyancy of the crust- which favors upward flow. Low crust viscosity decreases the effect of the boundary conditions (velocities imposed on top and bottom of the channel) on the circulation pattern and consequently enhances the upward buoyancy-driven flow.

The effect of density and rheology variations on flow patterns and exhumation are therefore faithfully integrated into the exhumation number and can be summarized as follows: the larger the value of the exhumation number $\alpha$, the greater the material potential to exhume/resistance to burial. This property underlies all the conclusions drawn hereafter.

\section{Channel width variations in steady state regime}

The adimensional net flow across a given section is given by the velocity integral 
$\bar{Q}=\frac{Q}{U h^{*}}=\frac{1}{U h^{*}} \int_{0}^{h} u d y=\int_{0}^{h} \frac{u}{H} \frac{h}{h^{*}} d\left(\frac{y}{h}\right)$

$\bar{Q}=\int_{0}^{1} \overline{u h} d \bar{y}$

$\bar{Q}=\frac{\bar{h}}{2}-\frac{\alpha \bar{h}^{3}}{12}$

Under steady-state regime the mass conservation requires that $\bar{Q}$ is constant all along the channel, i.e.,

$\forall x, \bar{Q}(x)=c s t \Rightarrow \frac{\bar{h}(x)}{2}-\frac{\alpha(x) \bar{h}(x)^{3}}{12}=c s t$

The variations in channel width $\bar{h}(\bar{x})$ are therefore completely constrained by the exhumation number $\alpha(x)$ of the material filling the channel (Fig. 10). In our approach to the subduction channel, the mantle deforms and adapts passively to the flow properties within the channel, it is therefore the material inside the channel that controls the channel width and its time and space variations. This point of view is diametrically opposite to Mancktelow (1995) approach, where the width of the channel is fixed a priori by the rigid mantle that bounds it. There is only one degree of liberty in the system, and either the channel geometry or the pressure variations can be prescribed, but not both. In our model, as we prescribe pressures to be lithostatic, the system fixes itself its geometry; in Mancktelow (1995) model, the prescribed geometry eventually determines the pressure. Their fixed geometry leads to large overpressures (compared to lithostatic pressure) where the channel narrows. Our approach is motivated by large-scale thermo-mechanical models (Burov et al. 2001), showing that mantle cannot sustain large overpressures without deforming; the pressure is therefore always close to lithostatic. The mantle cannot be seen as a rigid framework prescribing a geometry to the subduction channel.

\section{Variations of net flow with $\bar{h}$ for fixed $\alpha$}

If $\alpha>0$, the parametric $\bar{Q}(\bar{h})$ curve, which depends on $\alpha$, has a maximum flow $\bar{Q}_{\max }$ for $\bar{h}=\sqrt{\frac{2}{\alpha}}$ (Fig. 9 bottom left). As explained above, for a fixed positive $\alpha$, the buoyancy-driven flow, directed upward, is favoured by large channel widths. The channel width $\bar{h}=\sqrt{\frac{2}{\alpha}}$ corresponds to the start of the return flow but also to the maximum of net flow $\bar{Q}$. For larger 
$\bar{h}$ 's, the upward buoyancy-driven flow rapidly increases and the net flow $\bar{Q}$ decreases constantly and eventually changes sign (negative $\bar{Q}$ means that in average over the channel section more material is moving upward than downward, which is achieved when the upward buoyancy-driven flow overtakes the downward dragging-driven flow).

\section{Eclogitization modelling in the subduction channel}

To analyse the role of eclogitization in deep crustal movements we have designed a model decomposed in three domains: The shallow domain, made of uneclogitized crust (named hereafter "g", for "granulite"), the deep one where the crust is completely eclogitized ("e"), and an intermediate domain where eclogitization is variably completed ("ge"), from no phase transformation at the boundary with the uneclogitized domain " $\mathrm{g}$ ", to complete transformation at the boundary with eclogitized domain "e". The exhumation number is constant within homogeneous domains "g" and " $\mathrm{e}$ ", and varies with $\mathrm{x}$ in the intermediate domain "ge".

\section{Variations in the exhumation number related to eclogitization - endmember study}

Light, weak and reaction-refractory eclogitic endmember (Holsnøy granulitic unit): high exhumation number crust

The changes in physical properties associated to the eclogitization of the anorthositic unit of Holsnøy are a density increase and a mechanical softening that both affect $\alpha$, respectively through the hydraulic potential gradient and the viscosity.

Density variations

The eclogite density, measured on collected samples (Table 1), is relatively variable around 3.3-3.35 g/ $/ \mathrm{cm}^{3}$, comparable to mantle densities, while the granulite density, also variable, is around 2.8-2.9 $\mathrm{g} / \mathrm{cm}^{3}$, both values in agreement with Austrheim (1987). The density of partially eclogitized granulite "ge" is a linear function of the eclogitized fraction $f_{e}$

$d_{g e}=d_{g}\left(1-f_{e}\right)+d_{e} f_{e}$

\section{Rheology variations}

The mechanical behaviour of a mixture of two Newtonian materials is enclosed between the Voigt and Reuss bounds, which estimate overall properties using uniform strain or stress, respectively (Nemat-Nasser \& Hori 1993). If $\eta_{\mathrm{g}}$ and $\eta_{\mathrm{e}}$ are granulite and eclogite viscosities, the viscosity of partially eclogitized granulite is comprised between 
$\eta_{g e}^{V}=\left(1-f_{e}\right) \eta_{g}+f_{e} \eta_{e} \quad$ (uniform strain - Voigt estimate)

and

$\eta_{g e}^{R}=\left(\frac{1-f_{e}}{\eta_{g}}+\frac{f_{e}}{\eta_{e}}\right)^{-1} \quad$ (uniform stress - Reuss estimate)

The Voigt estimate rheology is stronger than Reuss estimate -i.e., $\eta_{g e}^{V}>\eta_{g e}^{R}$. The variation of $\alpha$ with eclogite fraction $f_{e}$ is shown on Fig.10, with three different eclogite densities: inferior, equal or superior to mantle density, resulting in positive, null or negative $\alpha$ in the eclogite domain. For eclogite as dense as the mantle as in Holsnøy unit (central diagram in Fig. 11), $\alpha$ is constantly decreasing for the Voigt estimate, while it shows a maximum for intermediate $f_{e}$ (close to 0.5 if $\eta_{g}>>\eta_{e}$ ) for the Reuss estimate.

The real large-scale rheology $(5 * 5 \mathrm{~km})$ of the mixture of un- and eclogitized crust depends on eclogite and granulite rheology and on the geometry of un- and eclogitized fractions. This large-scale rheology is highly anisotropic due to the asymmetrical shape of eclogitized volumes. Nevertheless we are not interested in determining the whole set of parameters describing the rheology of the partially eclogitized unit, but rather in the mechanical response to particular boundary conditions, namely non coaxial shear stress, thought to correspond to high-pressure deformation in the subduction channel (Raimbourg et al. in press).

The rheology of the granulite with little eclogite volume, corresponding to the inception of eclogitization, can be roughly approximated by the moduli of randomly distributed diluted spherical inclusions of eclogite within a granulite matrix (François et al. (1995), page 159, Nemat-Nasser \& Hori (1993), page 209). Under prescribed macrostrain, and with the assumption that $\eta_{g} \gg>\eta_{e}$, the overall viscosity $\eta_{g e}$ reduces to

$\eta_{g e} \approx\left(1-\frac{15}{9} f_{e}\right) \eta_{g}$

As the strong phase, granulite, is the coherent and stress-supporting phase, the overall rheology is strong and close to Voigt estimate

$\eta_{g e}^{V}=\left(1-f_{e}\right) \eta_{g}+f_{e} \eta_{e} \approx\left(1-f_{e}\right) \eta_{g}$

As the eclogite fraction increases, it reaches the critical rheological fraction (CRF). Near this point, a continuous shear zone of weak eclogite concentrates a large proportion of the deformation, under the given shear boundary conditions, resulting in a drastic change in rheology (Fig. 12). For higher $f_{e}$, the rheology is controlled by the weak phase, and the $\alpha$ of partially eclogitized unit evolves near the $\alpha$-curve built with Reuss rheology. The $f_{e}$ 
corresponding to the real $\alpha$-curve maximum is either equal to Reuss $\alpha$-curve maximum (near $\left.f_{e}=0.5\right)$ for low $C R F$, or higher for high $C R F$.

\section{Dense, strong, and reaction-compliant eclogitic end-member : low exhumation number crust}

We now consider, as an alternative candidate to eclogitization, a lower crust with a gabbroic composition that reaches the eclogite-facies through blueschist- or amphibolite-facies metamorphism. Eclogitization of this crust is in all respects different from Holsnøy granulitic unit.

\section{Density variations}

The density of a gabbroic crust after complete eclogitization, equal to 3.56 (Bousquet et al. 1997; Goffé et al. 2003), is higher than mantle density. The previous density of the crust, equilibrated on the prograde path in the blueschist- or albite-epidote-amphibolite-facies, is 3.16 or $3.00-3.06$, respectively.

\section{Rheology variations}

Many field occurrences of high-pressure rocks evidence the high strength of eclogite-facies assemblages compared to other metamorphic assemblages. For example, within the Drøsdal mafic body or within Holsnøy the eclogitic foliation is cross-cut by late amphibolite-facies shear zones, attesting of the lower strength of the lower-grade assemblage (Austrheim \& Griffin 1985; Foreman et al. 2005). Similarly, eclogite foliation on Syros and Sifnos is crosscut by weaker blueschist-facies shear bands (Trotet et al. 2001). Although all these examples show the lower strength of retrograde lower pressure parageneses compared to eclogite, we can assume that on the prograde path eclogitization also led to rock strengthening.

The eclogitization-induced large-scale rheology variation is further constrained by the way eclogitized zones propagate. While the eclogitisation of granulitic anorthosite requires hydration, the eclogitization of many terranes subducted and affected by prograde metamorphism is associated to dehydration reactions. This is attested first by the theoretical comparison of the water content of eclogite-facies assemblages with lower-grade assemblages. In barroisite-bearing eclogite-facies metabasites from New Caledonia (Carson $e t$ al. 2000; Carson et al. 1999), the position of the $\mathrm{H}_{2} \mathrm{O}$ saturation line moved away from the fixed composition point in $\mathrm{P}-\mathrm{XH}_{2} \mathrm{O}$ pseudosection during isothermal decompression. $\mathrm{P}-\mathrm{T}$ pseudosections of the south Tianshan glaucophane- and hornblende-bearing eclogites evidence a decrease in $\mathrm{H}_{2} \mathrm{O}$ content in corresponding stable mineral assemblages as $\mathrm{P}$ and $\mathrm{T}$ 
decrease (Wei et al. 2003). In the petrogenetic grid built by Oh \& Liou (1998), the eclogitefacies field is delimited from the blueschist- and epidote-amphibolite-facies fields by two reactions into the eclogite field releasing $\mathrm{H}_{2} \mathrm{O}$. Prograde dehydration reactions are furthermore attested by vein formation, as in the transition from lawsonite- to epidote-eclogite in the Dabie Shan (Castelli et al. 1998). Water-releasing reactions can occur as soon as the P-T conditions enable them and little metastability is to be expected. An hydrous protolith entering the eclogite facies starts therefore to transform everywhere and the resulting eclogitized volumes are more isotropic and homogeneously distributed than Holsnøy anhydrous granulite. The critical rheological fraction associated to the transformation occurs for an higher eclogite fraction $f_{e}$ comparable to the rigid percolation threshold defined in melt crystallisation for $f_{\text {melt }} \approx 45 \%$ (Vigneresse et al. 1996).

\section{$\alpha$ variations}

The complete eclogitization of an amphibolite-facies mafic crust leads to a density increase from 3.16 to 3.56 (Bousquet et al. 1997). All $\alpha$-curves on Fig. 13., built with a large range of rheologies, cross the " $\alpha=0$ " line for $f_{e}=0,5$. When eclogitized crust is stronger than uneclogitized crust, the curves are concave upwards, when both have the same rheology the $\alpha$ curve is a straight line, when eclogitized crust is weaker the curves are convex upwards (Fig. 13-A). As a result, when eclogitized crust is stronger than, as resistant as, or slightly weaker than uneclogitized crust (Fig. 13-A and B), $\alpha$ is always decreasing with eclogite fraction $f_{e}$. When eclogite is significantly weaker than its protolith $(13 \mathrm{C}), \alpha$-curves go through a maximum for $0 \leq f_{e} \leq 0,5$. The influence of the CRF localization on the $\alpha$-curve is shown on figure 13-C: for high $\mathrm{CRF}$, the rheological transition from strong protolith to weak eclogite stress-supported behavior occurs for high $f_{e}$; in this case the maximum of $\alpha$-curve is still for $\alpha=0$.

As a case study, we shall consider a dense and strong eclogitic crust with $\alpha$ maximum for $f_{e}=0$. This crust, whose eclogitization leads to a decrease in exhumation number, is a model of crust "unwilling" to exhume.

\section{Consequences of variations in the exhumation number related to eclogitisation upon steady state flow regime}

Variations of the exhumation number parallel to the subduction channel 
We now consider the subduction of crust with successive low and and high exhumation numbers. The material parameter that drives the circulation in the channel flow model is $\alpha$, but its value is unknown, as it depends on the real rheology. What we are rather interested in are relative variations in the exhumation number along with metamorphic transformation. As a result the $\alpha$ of fully eclogitized/uneclogitized crust is arbitrarily fixed $\left(\alpha_{e}=0 / \alpha_{g}>0\right)$ and for the sake of simplicity it has the same value for both high and low exhumation number endmembers. The difference between them lies in the behaviour of $\alpha$ in the intermediate (ge) domain: $\alpha_{g} \geq \alpha_{g e 1}\left(f_{e}\right) \geq \alpha_{e}$ in low $\alpha$ crust ("ge1"), whereas for some $f_{e}^{\max }$, $\alpha_{g e 2}\left(f_{e}^{\max }\right)=\max (\alpha)$ for high $\alpha$ crust (“ge2”) (Fig. 14 top).

There is therefore a peak in $\alpha$ profile within the partially eclogitized domain of crust 2 , corresponding to material resistant to burial (high exhumation number), which does not exist for crust 1 .

\section{Maximum net flow and necessary return flow - maximum eclogitization}

When $\alpha>0$, the net-flow curve $\bar{Q}(\bar{h})$ is convex upwards and shows a maximum flow $\bar{Q}_{\max }$ for $\bar{h}=\sqrt{\frac{2}{\alpha}}$ (Fig. 9 bottom left). The larger $\alpha$, the smaller this maximum flow $\bar{Q}_{\text {max }}$ : This property is key to analyse the evolution from the subduction of low to high exhumation number material. We consider here steady state regimes, where mass conservation equation requires that flow is constant everywhere,

$$
\forall x, \bar{Q}(x)=\frac{\bar{h}(x)}{2}-\frac{\alpha(x) \bar{h}(x)^{3}}{12}=\text { cst } .
$$

In a first phase (Fig. 14 left), only a crust with a low exhumation number is subducted; the flow $\bar{Q}_{e q}^{1}$ is near the maximum flow in the superficial "g" domain; in the deep domain "e" where the exhumation number is lower, the same flow $\bar{Q}_{e q}^{1}$ is reached with a narrower channel $\left(\bar{h}_{e}<\bar{h}_{g}\right.$, see the left $\bar{Q}(\bar{h})$ curve on fig. 14). In the intermediate domain, as $f_{e}$ increases continuously between "g" and "e" domains, $\alpha$ decreases from $\alpha_{g}$ to $\alpha_{e}$, and $\bar{h}$ decreases from $\bar{h}_{g}$ to $\bar{h}_{e}$. The variations in $\bar{h}(\bar{x})$ reflect the variations in exhumation number along metamorphic transformation of the subducting crust -i.e., the $\bar{h}(\bar{x})$ profile is determined by the $\alpha(\bar{x})$ profile. 
In a second phase, when all the low exhumation number material has been subducted the high- $\alpha$ material (see $\alpha$-profiles on top of Fig. 14) in the partially eclogitized domain, characterized by small maximum net flow, prevents large quantity of crust to be buried. The maximum net flow $\bar{Q}_{2}$ through the intermediate domain, determined by $\alpha_{\max }$, is no longer compatible with the net flow $\bar{Q}_{1}$ arriving from domain "g" (Fig. 14, middle $\bar{Q}(\bar{h})$ curve), domain "ge2" act as a bottleneck for the whole subducting system, which must adapt through $\bar{h}$ evolution, not only within the intermediate domain but also in down- and upstream domains. This evolution implies to force all exceeding material arriving at the bottleneck, where the net flow is very small, to reverse velocity and start exhuming.

After transient evolution, the steady state solutions -i.e., constant $\bar{Q}(x)$ - near the domain "ge2" can be described qualitatively (Fig. 14 right $\bar{Q}(\bar{h})$ curve): within the "ge2" domain, the bottleneck allows the maximum possible flow $\bar{Q}_{2}$. Possible solutions within "g" domain are twofold for $\bar{Q}_{2}$; as too much material was supplied from domain "g" to the bottleneck, the appropriate solution is the larger $\bar{h}$, for which the flow enables the return towards the surface of exceeding material supplied at the bottleneck region $\left(\bar{h}_{g}>\sqrt{\frac{2}{\alpha_{g}}}\right)$. The channel widths variations along $\bar{x}$ (see the particular values $\bar{h}_{g}, \bar{h}_{g e 2}$ and $\bar{h}_{e}$ on the right $\bar{Q}(\bar{h})$ curve) enable the flow to be constant in and around the partially eclogitized zone "ge2".

The match between the steady state solution near the eclogitizing zone "ge2", with net flow $\bar{Q}_{2}$, and the flow far upstream in uneclogitized domain "g", where the flow $\bar{Q}_{1}$ has not been perturbed yet by the modification of the flow pattern at depth, is achieved by a shock wave i.e., a discontinuity in $\bar{h}$ and $\bar{Q}$ (see the circulation pattern Fig. 14 top right).

Physical properties of the partially eclogitized high exhumation number material result in the creation of a bottleneck in the channel circulation, related to the maximum of $\alpha$, which causes the formation of a zone of return flow upstream of the bottleneck, whose upper limit, the shock wave, propagate upwards within domain "g". The movements of this shock wave is prescribed by mass conservation: at the point where the flow $\bar{Q}$ is discontinuous, the balance of in- and outcoming material determines the instantaneous evolution of the channel width and the displacement of the discontinuity. In the example considered (Fig. 14 top right), a positive balance of material is provided at the shock wave. This excess supply is accomodated 
by rapid channel widening upstream of the shock wave, thus the shock wave propagates upward. Once again, this rapid evolution of the channel width is possible only under the assumption that the channel boundary is relatively flexible and passively deforms according to the evolution of the flow within the channel.

This shock wave may be better understood through the analogy with kinematic waves in automobile traffic arriving at a junction with a traffic light (Lighthill et al. 1955a; Lighthill et al. 1955b), where the channel width $\bar{h}$ variable is replaced by the car concentration $c$ (and the $\bar{Q}(\bar{h})$ relation by a similar $\bar{Q}(c)$ relation): when at some time the traffic is stopped as the light gets red (equivalent to the setup of the bottleneck in our model, when high- $\alpha$ material, letting through little flow $\bar{Q}$, is subducted), a traffic jam forms (null net flow $\bar{Q}(c)$, thus null car velocity, maximum $c$, equivalent to our exhuming zone) and propagates backward. The shock wave corresponds to the back limit of the traffic jam, where fast arriving cars must almost stop and are incorporated into the growing traffic jam. This discontinuity between a zone of stopped cars and a zone of fast driving cars propagates backward, as cars are constantly provided to the traffic jam zone.

The maximum of $\alpha$ within the partially eclogitized domain marks the deeper boundary of the return flow zone, which means that crust more eclogitized $\left(f_{e}>f_{e}\left(\alpha_{\max }\right)\right)$ carries on downward. The concomitant evolution of large-scale rheology and density, through exhumation number $\alpha$ evolution, determines precisely the maximum transformation of exhuming crust.

\section{Time evolution of the system - conditions of exhumation}

Crustal exhumation, induced by the introduction of crustal material with a high exhumation number (high $\alpha$ ) within the partially eclogitized domain, is confined within a zone delimited at the bottom by the maximum of $\alpha$ and at the top by the shock wave. If the depth of the former is fixed, the shock wave can move and the size of the exhuming zone can change accordingly. We analyze hereafter the temporal evolution of the system and the movements of the shock wave that determine the evolution of the exhuming zone (Fig. 14 top right).

\section{Kinematic waves}

The evolution of $\bar{h}$ is constrained by the mass conservation equation

$$
\frac{\partial \bar{Q}}{\partial \bar{x}}+\frac{\partial \bar{h}}{\partial \bar{t}}=0
$$


with $\bar{x}=\frac{x}{x^{*}}, \bar{t}=\frac{t}{t^{*}}$ adimensional variables and $t^{*}=\frac{x^{*}}{U}$.

If we assume that

$\bar{Q}=\bar{Q}(\bar{h}, \bar{x})$

The differential equation (2) can be rewritten as

$\frac{\partial \bar{Q}}{\partial \bar{x}}+\frac{1}{c} \frac{\partial \bar{Q}}{\partial \bar{t}}=0$

where $\left.c=\frac{\partial \bar{Q}}{\partial \bar{h}}\right)_{\bar{x} \text { const }}$

The wave motion governed by equation (3), referred to as kinematic waves, is described in detail in Lighthill et al. (1955a) and Lighthill et al. (1955b), which are the base of the following developments. Each wave carries a constant $\bar{Q}$ and travels with a velocity $c$ given by (4). Note the difference between the wave velocity $c$, given by the tangent to the curve $\bar{Q}(\bar{h})$, and the average material velocity at given $\mathrm{x},\langle\bar{u}\rangle=\int_{0}^{1-} \bar{u} d \bar{y}=\frac{\bar{Q}}{\bar{h}}$, given by the slope of the chord (Fig. 9, bottom right). Remark also that backward moving waves coincide with large channel widths, with return flow (Fig. 9, bottom left), while forward moving waves are present in narrow channels, without return flow.

Instead of following material movements, which is more intuitive, we study hereafter the evolution of the circulation within the subduction channel -i.e. $\bar{Q}(x, t)$ - by following constant- $\bar{Q}$-waves movements.

\section{Temporal variations in the nature of subducted crust}

The velocity of a wave, that carries a constant $\bar{Q}$, varies according to the properties of the material it goes through, and determine the wave paths, drawn on space-time diagram (Fig. 15 top). The left side of the diagram shows the steady state subduction of high exhumation number material. Wave velocity is constant within domain "g" (diagram a-b on Fig. 15); as it enters domain "ge1", the decrease in $\alpha$ results for constant $\bar{Q}$ in wave velocity increase, up to a maximum velocity, constant in domain "e". The physical properties and the associated $\alpha$ of a given material volume change along its burial and associated metamorphic transformation. Nevertheless, if the same material is continuously buried, the $\alpha(x)$-profile is constant over time ( $\alpha(x)$ profiles given for high and low $\alpha$ material in Fig. 15 middle). This is no longer 
true in the case of a change in buried material, the size of partially eclogitized domain varies with time, as well as the $\alpha(x)$-profile. In the case where $\alpha$ varies in time, the wave behavior is no longer described by equation (3) and a wave do not carry a constant $\bar{Q}$. To overcome this difficulty, we have prescribed the time variation of $\alpha$ to a vertical line (dashed line on the space-time diagram), as if the transition from one material to another one was instantaneous. This is partially justified by the fact that cross-section averaged material velocity, determining the duration of the transition from one material to the other, is faster than wave velocity. As a result, equation (3) is valid and a wave carries a constant $\bar{Q}$ everywhere but on the material transition line. The flow $\bar{Q}$ carried by each wave located on this line jumps from $\bar{Q}$ $\bar{Q}_{+}$, i.e., from the $\alpha$-curve before material transition to the $\alpha$-curve after transition for constant $\bar{h}$, as the channel width is the physical variable independent on the nature of the material (Fig. 15 bottom left); the wave velocities vary accordingly, and wave propagating forward i.e., to higher $\mathrm{x}$, that is to greater depth- reverse movement when entering domain "ge2".

The value of $\bar{Q}$ is uniquely defined for a fixed point $(x, t)$. The convergence of two waves into a point is permitted by the formation of a shock wave. The mass conservation prescribes the shock wave velocity as $V_{w}=\frac{\bar{Q}_{2}-\bar{Q}_{1}}{\bar{h}_{2}-\bar{h}_{1}}$

where $\bar{Q}_{2}, \bar{h}_{2}, \bar{Q}_{1}, \bar{h}_{1}$ are the discontinuous properties across the shock wave (Fig. 15 bottom middle).

\section{System description}

The subduction for a finite duration of high $\alpha$ crust results in the creation of a bottleneck in the partial eclogitization zone "ge2" (space-time diagram), which is not capable of letting through the incoming flow $\bar{Q}_{g}^{i n}$. After a short transient time, the flow at the bottleneck (corresponding to $\alpha$ maximum) is the maximum flow $\bar{Q}_{g e 2}^{\max }$ (null velocity wave on line c-d on Fig. 15); waves with very close $\bar{Q}$ are accelerated backwards in domain "ge2" up to domain "g" where they keep constant speed. Backwards wave velocities correspond to material velocity field with return flow near the channel top, forward wave velocities correspond to exclusively downward velocity field (Fig. 9). The convergence between these backward waves and forward waves in domain "g" results in the formation of a shock wave, which also 
propagates backward -i.e., upward- with velocity as in bottom middle diagram. The shock waves is the upper limit of the exhuming zone ( $x-y$ material flow pattern on Fig. 15 bottom right figure).

Subsequently, after a short transient period following the transition from "ge2" to "ge1" material, there is no longer bottleneck and the flow $\bar{Q}_{g e 1}^{\max }=\bar{Q}_{g}^{\max }$ is maximum in zone "ge1" (e-f). The wave with null velocity is located at the maximum of $\alpha$, i.e., at the limit between "g" and "ge1".

Waves with decreasing $\bar{Q}\left(\bar{Q}_{g e 1}^{\max } \geq \bar{Q} \geq \bar{Q}_{g e 2}^{\max }\right)$, i.e., with decreasing absolute speed, propagate backwards from the transition "ge1" to "ge2". As a result the shock wave reverses movement and moves forward, as its velocity changes sign progressively (see the difference between points $1-2$, and 1-2').

As done above, the analogy with automobile traffic arriving at a junction with a traffic light can be done: the period of the bottleneck (subduction of high- $\alpha$ material) corresponds to the time when the light is red. No flow through the light is allowed, and a zone of traffic jam, equivalent to the exhuming zone in our problem, propagates backwards. When the light gets green (subduction of low- $\alpha$ material), the flow at the light is maximum, and the cars within the traffic jam (progressively form its front) start over forward. After a certain amount of time of this regime, the back limit of the traffic jam (the shock wave), also moves forward.

\section{Conditions for permanent exhumation}

The low flow allowance of partially eclogitized exhumation-inclined crust triggers the formation of an exhuming zone, with large $\bar{h}$ and return flow, which propagates upward -i.e. backward- with a speed given by the shock wave velocity. The subsequent subduction of low exhumation number material results in the decrease in the size of the exhuming zone indicated by the downward motion of the shock wave.

The shock waves movement are totally transparent to an observer located on an horizontal line at the bottom of the space-time diagram (Fig. 15 top), as the exhuming zone does not expand enough to reach him before shrinking. In fact, alternate subduction of high and low $\alpha$ material leads to cyclical expansion and resorption of the exhuming zone (Fig. 16). The condition for the exhuming zone to reach shallow levels and enable the permanent return of deep rocks to the surface is that through each cycle the exhuming zone expands more than it shrinks. This condition can be coarsely quantified on the space-time diagram by estimating the quantity of material passing through two observers who start at point $b$ and move to point 
g. The first observer passes in $\mathrm{h}$ and stays upstream of the shock wave in domain " $\mathrm{g}$ ". The amount passing through him is

$$
M^{o b s 1}=\bar{Q}_{g}^{i n} T_{t o t}
$$

The second observer follows the path b-c-d-e-f-g. The flow on b-c, d-e and f-g is difficult to assess, but these portions last nevertheless much less time than c-d and e-f, corresponding to steady state solutions. As the observer is immobile on c-d and e-f, the flow passing through him is simply the net flow $\bar{Q}$ on these portions, and the total amount is

$$
M^{\text {obs } 2}=\bar{Q}_{g}^{\max } T_{g e 1}+\bar{Q}_{g e 2}^{\max } T_{g e 2}
$$

and

$$
T_{t o t} \approx T_{g e 1}+T_{g e 2}
$$

The same amount passes through the observers, therefore

$$
M^{o b s 1}=M^{o b s 2} \Rightarrow \frac{T_{g e 2}}{T_{g e 1}}=\frac{\bar{Q}_{g}^{\max }-\bar{Q}_{g}^{i n}}{\bar{Q}_{g}^{i n}-\bar{Q}_{g e 2}^{\max }}
$$

This situation, where both observers start and end up near the shock wave in the partially eclogitized domain, corresponds to a zero net balance of exhuming zone growth. If the duration of exhumation-inclined material subduction is larger, i.e., for

$$
T_{g e 2}>\frac{\bar{Q}_{g e 1}-\bar{Q}_{g}}{\bar{Q}_{g}-\bar{Q}_{g e 1}} T_{g e 1}
$$

then the expansion of the exhuming zone exceeds its shrinkage, and after a certain number of cycles, permanent exhumation to shallow depths can be achieved.

\section{Exhumation rates}

Exhumation rates within the upper part (in the y direction, i.e., near the hanging wall of the model) of the exhuming zone are completely constrained by the width $\bar{h}$ of the channel that determines the material velocity field (Fig. 9). Both average (over upward velocities) and maximum upward velocity are increasing functions of $\bar{h}$, as the balance between upward buoyancy-driven movement and downward viscous drag sways towards the former force with channel widening.

In order to analyse the exhumation rates within the exhuming zone, we have simplified the former problem as it consists now of two materials with constant $\alpha$ (Fig. 17). The high- $\alpha$ material is introduced after a certain time between fixed depths, equivalent to the partially 
eclogitized zone of high exhumation number crust described in Fig. 15. The instantaneous material transition from low- to high- $\alpha$ over the prescribed band propagates downward at a speed given by the low- $\alpha$ material burial rate. This transition line makes an angle with incoming waves, which move more slowly than material. The reaction of the system to the introduction of low- $\alpha$ material can be schematically divided into a short- and long-term phases.

\section{Long-term solution}

The stationnary solution, shown on the right space-time diagram on Fig. 17, is similar to the solution described in preceding section. Long after the material transition line, the waves propagating within the high- $\alpha$ region have almost null velocity corresponding to the largest net flow in this domain (velocity $V_{a} \approx 0$ ). When these waves reach the high- $\alpha$ region they change velocity and propagate backwards (velocity $V_{b}$ ) to form the exhuming zone and merge into the shock wave with forward propagating waves. The shock wave, which delimits the upper limit of the expanding exhuming zone, propagates backwards at constant speed $V_{w \infty}$.

The flow pattern within the exhuming zone is constrained by the channel width $\bar{h}_{\text {out }}$, which itself is dependent on the maximum flow within the bottleneck $\bar{Q}_{\text {out }}$. As exhumation rates increases with $\bar{h}_{\text {out }}$, the highest exhumation rates are achieved when $\bar{Q}_{\text {out }}$ is minimum. Physically, this means that the more the bottleneck resists material burial, the larger the return flow upstream of the bottleneck. Very small maximum net flows within the high- $\alpha$ region, and consequently very small $\bar{Q}_{\text {out }}$, are reached for very large $\alpha$ (e.g. corresponding to very weak eclogite). At most (Fig. 17 bottom), $\bar{Q}_{\text {out }}=0$, and exhumation rates are

$$
\begin{aligned}
& \bar{u}^{-\max }=-\frac{1}{3} \Rightarrow u^{\max }=-\frac{1}{3} U \\
& \left\langle u^{-e x}>=\frac{\bar{Q}^{e x}}{\bar{h}^{e x}} \approx-0,22 \Rightarrow<u^{e x}>=-0,22 U\right.
\end{aligned}
$$

where the average is computed over the portion of the channel were velocities are negative, i.e., for $1 \geq \bar{y} \geq \frac{2}{\alpha \bar{h}^{2}}$ (this portion exists if $\bar{h} \geq \sqrt{\frac{2}{\alpha}}$ ).

\section{Short term solution}


The system reaction at the material transition (Fig. 17, left space-time diagram) can be studied through the evolution of a wave intersecting the line that separates low- from high- $\alpha$ material. The wave carrying a flow $\bar{Q}_{\text {in }}$ arrives with velocity $V_{1}$ to the transition line; then the material properties changes cause for constant $\bar{h}_{\text {in }}$ a drop in the carried flow down to $\bar{Q}_{\text {out }}$, the wave has a large backward velocity $V_{2}$ leading it back into low- $\alpha$ domain. When it gets there, the conservation of $\bar{Q}_{\text {out }}$ determines the channel width $\bar{h}_{\text {out }}$ and associated velocity $V_{3}$; it finally merges with forward-moving waves into the shock wave.

The interesting feature of this transient evolution is that during a short period within low- $\alpha$ domain the flow $\bar{Q}_{\text {out }}$ is negative, the width $\bar{h}_{\text {out }}$ is large and the exhumation rate is therefore high. In fact for a high- $\alpha$ material with infinitely large $\alpha, \bar{Q}_{\text {out }}$ is infinitely negative and resulting exhumation rates are infinitely high. Such high rates are nevertheless confined to a volume of material of the order of the size of the high- $\alpha$ material, equivalent to the length of the partially eclogitized zone "ge2".

This short-term evolution can be physically interpreted as follows: As the crust filling the partially eclogitized zone changes from dense and strong to light and weak material, the width of this zone quickly decreases down to an new steady state, squezzing upward the width difference in a very rapid return flow. The resulting exhuming velocity are much larger than the ones reached in steady state regime, when the width profile of the partially eclogitized zone is close to equilibrium, and when the upward movement is caused only by difference between incoming flow and maximum flow in the bottleneck.

\section{Effect of a weak layer on top of the channel}

The upper boundary of the subduction channel is localized at the limit between subducting and overlying plates, and we applied a null velocity at this boundary. The reasons often invoked for the localization of deep crustal movements in a channel are the presence of a very weak layer on top of the subducting slab. Metasedimentary units can play this role for shallow levels (Shreve \& Cloos 1986), but their occurrences in HP and UHP context (e.g. UHP metasediments in Zermatt-Saas (Lapen et al. 2003; Reinecke 1998), or in the Dabie-Sulu Region (Compagnoni \& Rolfo 1999)) are rather scarce and it is likely that only a small fraction reach the high-pressure field. For deeper levels, a wedge of weak and light serpentinized mantle overlying the subducting crust greatly enhances its exhumation (Gerya $e t$ al. 2002b; Guillot et al. 2000; Schwartz et al. 2001). Partial melting, weakening the crust 
itself, may play some role in its return to the surface (Faure et al. 1999; Labrousse et al. 2004), but it has not been evidenced to our knowledge in the eclogite facies.

\section{Model description}

The presence of a continuous layer of weak material "lubricating" the top of the subduction channel is not incompatible with the model developed above, but the null velocity condition must be replaced by a mixed condition associating stress and velocity on top $\tau_{\text {top }}=\eta_{\text {weak }} \frac{u_{\text {top }}}{\delta h_{\text {weak }}}$, where $\eta_{\text {weak }}$ and $\delta h_{\text {weak }}$ are the viscosity and the width of the weak material layer, respectively. The serpentinite used in Gerya et al. (2002b), for $T=700^{\circ} \mathrm{C}$ and $\sigma=100 \mathrm{MPa}$, deforms between $10^{3}$ and $10^{5}$ times faster than unhydrated mantle (rheology from Ranalli (1995)), but its rheology is not well constrained by laboratory experiments.

For a given strain rate, rheological weakening results in stress decreasing, and the maximum stress applied under geologically realistic strain rates are all the lower as the material is weak. This consideration led us to model the weak layer not by a very unconstrained flow law, but by prescribing null stress within it.

\section{Results}

The velocity field and boundary stresses for various channel widths are shown on Fig. 18, with or without weak layer on top. The effect of the weak layer changes as channel width increases: For a narrow channel (small $\bar{h}$ ), there is less deformation in the crust, which is buried at a velocity close to the plate velocity $U$, and the downward flow is thus larger. For larger channel, when buoyancy forces overtake the viscous drag, the largest upward velocities are attained on the upper boundary, and the return flow is larger. Thus, if a weak layer enhances burial for narrow channels, it enhances exhumation for large channels. The transition occurs for $\bar{h}=\sqrt{\frac{2}{\alpha}}$ : the net flow without weak layer is larger than the one with for $\bar{h}>\sqrt{\frac{2}{\alpha}}$, and conversely (Fig. 18 bottom). This transition corresponds to a sign change in the stress at the channel top in the model without weak layer: for $\bar{h}<\sqrt{\frac{2}{\alpha}}$, the upward shear stress applied by the upper boundary restrains crust burial, while for $\bar{h}>\sqrt{\frac{2}{\alpha}}$ the upper shear stress is directed downward and restrains crust exhumation. The weak layer, which tends to 
decrease much the absolute value of the stress exerted by the upper boundary on the crust within the channel, has reverse effects, depending on the action of the upper boundary.

Maximum channel width for stable subduction regime -i.e., for $\bar{Q}=0$ - occurs in the model with weak layer for $\bar{h}=\sqrt{\frac{3}{\alpha}}$-i.e., for a narrower channel than without weak layer. The maximum velocity in this configuration, reached next to the weak layer, is

$u^{-\max }=-\frac{1}{2} \Rightarrow u^{\max }=-\frac{1}{2} U$

while average exhumation velocity is

$<u^{-e x}>=\frac{\bar{Q}^{e x}}{\bar{h}^{e x}} \approx-\frac{1}{3} \Rightarrow<u^{e x}>=-\frac{1}{3} U$

If the introduction of a weak layer changes the velocity profiles, it does not affect the qualitative relations between $\bar{h}, \bar{Q}$ and $\alpha$, or the order of exhumation rates in steady state subduction regime. The conclusions on the effect of eclogitization, based on the comparison of two materials affected by metamorphic reactions in a very different fashion, are therefore still valid whether a weak layer is present or not.

\section{Discussion}

\section{Model assumptions}

The simplicity of the channel-flow models enables to gather all relevant material properties into a single adimensionnal parameter $\alpha$, the exhumation number, and to describe the flow pattern with unidimensional variables $\bar{Q}(\bar{x})$ (or $\bar{h}(\bar{x})$ ). The assumptions underlying the model are nevertheless very strong and their relevance must be assessed.

\section{Unidimensional velocities}

All velocities in the channel-flow model are parallel to the subduction plane. This assumption requires that the $\vec{x}$ variations of the channel width are really smooth. The shape of $\alpha(x)$ profiles (not adimensional $\bar{x}$ ), which determine $\frac{\partial \alpha}{\partial x}$ gradients and consequently width gradients $\frac{\partial h}{\partial x}$, depends first on material properties involved in $\alpha$, but also on the actual $\vec{x}$-size of the partially eclogitized zone. This size depends on the rates at which metamorphic 
reactions progress in time and propagate in space. Metastable preservation of shallow parageneses into high pressure fields can be very efficient: igneous texture and mineralogy was largely preserved in metagranodiorite from the Brossasco-Isasca unit in the Dora-Maira massif in spite of its burial up to 24 kbars (Bruno et al. 2001), while the eclogitization of anhydrous granulite-facies rocks on Holsnøy or in the Flatraket Complex (Wain et al. 2001) was restricted to shear zones crosscutting virtually untransformed host granulite. These examples evidence that as for rheology, the rate of metamorphic transformation of a km-sized unit (large-scale kinetics) depend not only on mineral-scale reaction kinetics, but also on larger-scale physical processes such as fluid transport and deformation. Furthermore the size of the partially-eclogitized domain is the result of the competition between reaction kinetics and burial rates, both being highly variable in different geological settings.

All these uncertainties preclude to assess precisely the actual length of the partially eclogitized zone, and to estimate whether channel width variations are sufficiently smooth for the circulation to be unidimensional, as described in the model. Nevertheless, within the deep circulation $(>40 \mathrm{~km})$ the $\vec{y}$-directed circulation is of second-order with respect to $\vec{x}$-directed one, as attested by petrological data as well as orogen-scale numerical modelling. The shape of numerous high and ultra-high pressure P-T paths shows burial and exhumation along the same cold gradient (e.g. in Dora-Maira massif (Chopin \& Schertl 1999; Schertl et al. 1991; Simon et al. 1997) or in Kokchetav massif (Parkinson 2000)). These gradients prescribe movements near the subduction plane, which are in agreement with results from numerical modelling showing velocities in the high-pressure domain mainly parallel to subduction (Burov et al. 2001; Gerya et al. 2002b).

\section{Boundary conditions}

\section{Upper boundary velocity}

If the velocity condition at the bottom of the subduction channel ( $u=U_{\text {convergence }}$ ) is rather natural (plate velocity), kinematic boundary conditions on top are more difficult to prescribe. The null velocity condition implies that the the channel wall is rigid enough not to be dragged down by the subducting slab, resulting in the localization of all the deformation into the channel (heterogeneously if a weak layer is present). To assess this assumption we must model the flow within the whole orogen, whose complexity we precisely avoided by using the simple channel-flow model. The question of the behaviour of the hanging wall pertains to the existence of the subduction channel itself: if the hanging wall takes part to the deformation, 
the strain is much more distributed and the flow adopts more complex geometries than simple channel flow, or part of the hanging-wall is involved in the channel circulation. As discuted above, thermomechanical models as well as natural data support the view of the localization of the deep deformation within a channel and indirectly the relative strong behaviour of channel flanks. The balance is nevertheless very precise, if the mantle is stronger than the crust within the channel, it is flexible enough to deform according to channel geometry variations, as attested by the absence of tectonic overpressures (Burov et al. 2001).

\section{Material loss or gain}

In the channel flow model designed by Shreve \& Cloos (1986), underplating of sediments was accounted for by a loss term on the right handside of equation (2). Material loss occurred when shear stresses applied on the boundary exceeded a threshold. This criterion does not seem to be relevant, because the effect of shear stresses is ambiguous, as high shear stresses on the border may imply either channel loss or gain, depending on the material scraped off. It should be also noted that under prescribed velocity conditions, the intensity of shear stresses are absolutely not indicative of the movements within the channel: as $\bar{h}$ increases, upward net flow increases, as well as downward drag by the subducting slab (Fig. 18 left).

Another possible criterion for channel material gain or loss is the evolution of the pressure within the channel. For a prescribed geometry of the channel with variable width, the conservation of the flux determines pressure variations along $\vec{x}$ that much differ from lithostatic pressure variations (Mancktelow 1995). The resulting large overpressures are nevertheless at variance with models by Burov et al. (2001) that show that the strength of the rocks surrounding the channel is too low to maintain such channel geometries. In addition, the approach adopted here enables channel width to vary, but prescribes pressure variations and does not allow us to study tectonic over- and underpressures.

\section{Crust involved in the channel flow}

Before reaching the subduction channel, the crust on top of the subducting lithospheric plate is involved in shallow circulation. Depending on the internal coherence of the crust and the crust-sediments coupling, a variable upper fraction of this crust is scraped off and starts exhuming, while the rest reaches the deep channel-flow circulation.

On the other hand, the most abundant UHP rocks now at the surface are felsic rocks (Ernst 2001), indicative of upper crustal levels. The larger capacity of felsic rocks to exhume has certainly much to do with their greater buoyancy (e.g. petrogenetic grid in Bousquet et al. 
(1997)). An alternative reason lies in the upper crust structural position in the channel-flow: as the bottleneck created by partially eclogitized crust triggers return flow, incoming crust is divided between an upper portion that keeps on downward and the rest that is forced back. For real heterogeneous materials, this corresponds to the formation of large shear zones decoupling slivers on top of subducting crust, enabling their exhumation. The crustal depth reached by such shear zones, or equivalently the fraction of incoming crust involved in return flow, depends on the capacity of the bottleneck to let material through. The unusual exhumation of large tracts of lower crust such as on Holsnøy can be explained in our model by a very high $\alpha$, which highly decreases the capacity of the bottleneck and forces to exhume almost the totality of incoming crust, including lower levels.

\section{Heterogeneities modelling}

The channel flow model assumes for sake of simplicity that subducted crust is made of a single homogeneous material, and the resulting velocity field is rather smooth. The study of high pressure provinces shows on the contrary that high-pressure deformation is highly heterogenous at all scales. Heterogeneities whose size is largely inferior to the model smallest dimension -i.e., channel width-, are accounted for by averaging local material properties and using effective parameters. The conclusions drawn from this study are to be understood in the same "effective" meaning: the largest eclogite fraction, corresponding to the maximum of $\alpha$, is an average over the channel width. Effective properties, averaged over a few kilometers, can explain the exhumation of completely eclogitized km-sized mafic bodies embedded in a buoyant and little eclogitized felsic matrix in the WGR, such as Drøsdal body (Foreman et al. 2005), or the concomitant exhumation of light and weak serpentine with eclogitic rocks (De Sigoyer et al. 2004; Guillot et al. 2000; Guillot et al. 2001).

\section{Petrochronological constraints on subduction models}

\section{Exhumation rates}

Exhumation of many high- and ultrahigh-pressure terranes proceeded in 2 phases, with a rapid exhumation with little or no cooling from peak burial, followed by a much slower return to the surface (Duchêne et al. 1997). The rates of this deep exhumation, which we studied here through the channel flow model, are highly variable (see for example the review of exhumation rates in the WGR by Labrousse et al. (2004)), but there is a growing number of evidences for very high rates (Perchuk \& Philippot 2000), of the order of plate velocities (3.4 cm/yr, Dora Maira, (Rubatto \& Hermann 2001); 1-2.6 cm/yr, Zermatt-Saas, (Amato et al. 
1999); 1.5-3 cm/yr, Kokchetav, (Hacker et al. 2003); 1.7-5.1 cm/yr, eastern Papoua New Guinea, (Baldwin et al. 2004)). Such high rates are incompatible with steady state subduction -i.e., with positive net flow- but can occur in transient evolution of the system, when light and weak eclogitized crust is subducted after dense and strong one. The distribution of exhumation rates and in particular the abundance of very high rates in natural records can therefore provide useful information on deep processes. It must nevertheless be noted that: (i) some of these high rates are controversial (for example in the UHP unit of Kokchetav, exhumation rates estimated by Katayama et al. (2001) are $0.5 \mathrm{~cm} / \mathrm{yr}$, compared to $1.5-3 \mathrm{~cm} / \mathrm{yr}$ (Hacker et al. 2003)) and (ii) surface records are not necessary faithfull to the deep processes, as rapidly exhuming terranes are much more likely to preserve HP and UHP relics without complete retrograde overprinting, therefore rapidly exhuming units may be much more abundant on the surface than they are actually at depth.

\section{P-T paths}

The cold gradients leading to peak metamorphic conditions of most HP and UHP terranes is a strong argument in favor of burial in subduction context. P-T evolution on the retrograde path is on the other hand much more variable, from hair-pin like P-T paths with high cooling rates during exhumation (see the review by Chopin (2003)), to much more open clockwise P-T paths (Carswell \& Zhang 1999). Most HP and UHP units in western Norway show a deep exhumation with little cooling from peak conditions down to $600-650^{\circ} \mathrm{C} \sim 10 \mathrm{kbars}$ (Labrousse et al. 2004). The thermal field in the subduction zone may vary a lot with respect to the nature of buried material and convergence rates (Goffé et al. 2003; Peacock \& Wang 1999). Moreover, the dynamics of the subduction channel strongly affect the P-T evolution of involved crust. Cooling rates during uplift are the result of the balance between heat lost to adjacent units and exhuming rates. As argued by Ernst (1999) and Ernst (2001), the thinner the metamorphic unit, the more efficient the heat loss, therefore a large channel width, resulting in a large width of its exhuming fraction, reduces heat transfer to footwall and hanging wall and favors near-adiabatic decompression (e.g. thermal field evolution with increasing wedge width in Gerya et al. (2002b)). Concomitantly, within a large channel exhumation rates are high, also impeding heat transfer at depth. In the subduction channel model, exhumation rates and cooling during decompression are strongly related, both directly and indirectly through channel width.

Although viscous deformation has been considered as another main factor controlling temperature field through shear heating (Burg \& Gerya 2005), this hypothesis is difficult to 
assess on natural data. It must be noted that whatever model is considered to explain the deep organization of subduction zones, crustal units with the highest exhumation rates are by definition little deformed (velocity gradients -i.e., deformation rates- are null at velocity extrema) and little affected by shear heating. As these rapidly exhuming units are the most refractory to late overprinting, both deformation and thermal conditions deduced from them may not be faithfull to actual deep thermal and kinematic framework.

\section{Conclusion}

To study the structure and dynamics of subduction zones, large-scale rheology of rocks is necessary. As metamorphic reactions are neither instantaneous nor ubiquitous, most metamorphic rocks consist of juxtaposed volumes which equilibrated under different conditions. Large-scale rheology depends therefore on small-scale endmember rheology, but also on the spatial organization of the different metamorphic material.

Holsnøy protolith, which experienced pervasive granulite-facies metamorphism prior to its Caledonian burial, was almost completely anhydrous when it entered eclogite facies, therefore eclogitization reactions implied fluid transportation from external sources. The fluid was carried within a network of decameter-long fractures that cut through pristine granulite and were formed in response to both large-scale stresses and small scale metamorphic reactionsrelated stresses. Both mechanisms led to a highly anisotropic propagation of eclogitized zones resulting in the formation of narrow and elongated eclogitic shear zones continuous throughout the unit, separating large volumes of virtually pristine granulite. The critical rheological fraction (CRF), determined by large-scale transition from un- to eclogitized crustsupported rheology, occurring when eclogitized zones crosscut the whole unit, is in this anisotropic case relatively low. Alternatively, when eclogitization affects terranes richer in fluid, metamorphic reactions do not require fluid input and can occur simultaneously throughout the unit as soon as mineralogical assemblages step out of their stability field. Resulting eclogitized zones are much more isotropic and homogeneously distributed, and the CRF is higher. The variations of large-scale rheology vs eclogite fraction are therefore strongly controlled by the physical processes underlying the spatial and temporal propagation of eclogitization reactions.

The consequences for exhumation of progressive eclogitization and related evolution of physical properties of subducting crust are studied through the unidimensional channel flow model. Both density and large-scale rheology are integrated into a single parameter, the 
exhumation number $\alpha$, whose profile along subduction plane completely determines the flow pattern. The maximum possible net flow through a given section is conversely proportional to $\alpha$. For a very weak and relatively light eclogitic material (high exhumation number), the $\alpha$ profile within the partially eclogitized zone shows really high values, precluding the burial of large amount of crust, this zone act therefore as a bottleneck to the flow. For high incoming flow of crust, the excess material, which cannot flow through the bottleneck, is forced backward and starts exhuming. In the case of alternative subduction of crustal units with lowand high-exhumation numbers, we derive conditions for the exhuming zone, created during subduction of high exhumation number material, to expand and enable return flow to shallow levels. We show that really high exhumation rates, of the order of plate velocities, are incompatible with stable subduction regime, and are reached only at the transition from subduction of low to high $\alpha$ material. The presence of a weak layer on top of the channel favors burial for small channel widths, but enhances exhumation for large channel widths.

\section{Bibliography}

Amato, J.F., Johnson, C.M., Baumgartner, L.P. \& Beard, B.L., 1999. Rapid exhumation of the Zermatt-Saas ophiolite deduced from high-precision $\mathrm{Sm}-\mathrm{Nd}$ and $\mathrm{Rb}-\mathrm{Sr}$ geochronology, Earth and Planet Science Letters, 171, 425-438.

Austrheim, H., 1987. Eclogitization of lower crustal granulites by fluid migration through shear zones, Earth Planet. Sci. Lett., 81, 221-232.

Austrheim, H., 1990a. The granulite-eclogite facies transition : A comparison of experimental work and a natural occurrence in the Bergen Arcs, western Norway, Lithos, 25, 163 169.

Austrheim, H., 1990b. Fluid induced processes in the lower crust as evidenced by Caledonian eclogitization of Precambrian granulites, Bergen Arcs, Western Norway, PhD thesis, University of Oslo.

Austrheim, H., 1994. Eclogitization of the deep crust in continent collision zones, C. R. Acad. Sci. Paris, 319, serie II, 761-774. 
Austrheim, H. \& Engvik, A.K., 1995. Fluid transport, deformation and metamorphism at depth in a collision zone, in Fluid flow and transport in rocks : mechanisms and effects, pp. 123-137, ed. Jamtveit, B. \& Yardley, B.W.D., Chapman and Hall, London. Austrheim, H., Erambert, M. \& Engvik, A.K., 1996. Processing of crust in the root of the Caledonian continental collision zone : the role of eclogitization, Tectonophysics, $\mathbf{2 7 3}$, 129-153.

Austrheim, H. \& Griffin, W.L., 1985. Shear deformation and eclogite formation within granulite-facies anorthosites of the Bergen Arcs, Western Norway, Chemical Geology, 50, 267-281.

Austrheim, H. \& Mørk, M.B.E., 1988. The lower continental crust of the Caledonian mountain chain: evidence from former deep crustal sections in western Norway, Norges Geologiske Unders $\phi$ kelse, Special publication, 3, 102-113.

Baldwin, S.L., Monteleone, B.D., Webb, L.E., Fitzgerald, P.G., Grove, M. \& Hill, E.J., 2004. Pliocene eclogite exhumation at plate tectonic rates in eastern Papua New Guinea, Nature, 431, 263-267.

Bascou, J., Tommasi, A. \& Mainprice, D., 2002. Plastic deformation and development of clinopyroxene lattice preferred orientations in eclogites, Journal of Structural Geology, 24, 1357-1368.

Beaumont, C., Ellis, S., Hamilton, J. \& Fullsack, P., 1996. Mechanical model for subductioncollision tectonics of Alpine-type compressional orogens, Geology, 24, 8, 675-678.

Bingen, B., Austrheim, H., Whitehouse, M.J. \& Davis, W.J., 2004. Trace element signature and $\mathrm{U}-\mathrm{Pb}$ geochronology of eclogite-facies zircon, Bergen Arcs, Caledonides of W Norway, Contribution to Mineralogy and Petrology, 147, 671-683.

Bingen, B., Davis, G.A. \& Austrheim, H., 1998. Zircon growth during fluid induced Caledonian/Scandian eclogite-facies metamorphism of the Lindås Nappe, Caledonides of W Norway, Mineralogical Magazine, 62A, 161-162.

Bingen, B., Davis, W.J. \& Austrheim, H., 2001. Zircon U-Pb geochronology in the Bergen arc eclogites and their Proterozoic protoliths, and implications for the pre-Scandian evolution of the Caledonides in western Norway, Geological Society of America Bulletin, 113, 5, 640-649.

Birtel, S., Altenberger, U. \& Passchier, C.W., 1998. Polyphase structural and metamorphic evolution of the Rossland shear zone at Holsnøy, a ductile nappe boundary in the Middle Allochton of the Norwegian Caledonides, Zbl. Geol. Paläont. Teil I, 1-2, 1944. 
Bjørnerud, M.G., Austrheim, H. \& Lund, M.G., 2002. Processes leading to eclogitization (densification) of subducted and tectonically buried crust, Journal of Geophysical Research Solid Earth, 107, B10, 692-709.

Boundy, T.M., Fountain, D.M. \& Austrheim, H., 1992. Structural development and petrofabrics of eclogite facies shear zones, Bergen Arcs, Western Norway : implications for deep crustal deformational processes, Journal of Metamorphic Geology, 10, 127-146.

Boundy, T.M., Hall, C.M., Li, G., Essene, E.J. \& Halliday, A.N., 1997a. Fine-scale isotopic heterogeneities and fluids in the deep crust; a 40Ar/39Ar laser ablation and TEM study of muscovites from a granulite-eclogite transition zone, Earth and Planetary Science Letters, 148, 223-242.

Boundy, T.M., Mezger, K. \& Essene, E.J., 1997b. Temporal and tectonic evolution of the granulite-eclogite association of the Bergen Arcs, western Norway, Lithos, 39, 159178.

Bousquet, R., Goffé, B., Henry, P., Le Pichon, X. \& Chopin, C., 1997. Kinematic, thermal and petrological model of the Central Alps : Lepontine metamorphism in the upper crust and eclogitisation of the lower crust, Tectonophysics, 273, 105-128.

Bruno, M., Compagnoni, R. \& Rubbo, M., 2001. The ultra-high pressure coronitic and pseudomorphous reactions in a metagranodiorite from the Brossasco-Isasca Unit, Dora-Maira Massif, western Italian Alps: a petrographic study and equilibrium thermodynamic modelling, Journal of Metamorphic Geology, 19, 33-43.

Burg, J.-P. \& Gerya, T.V., 2005. The role of viscous heating in Barrovian metamorphism of collisional orogens: thermomechanical models and application to the Lepontine Dome in the Central Alps, Journal of Metamorphic Geology, 23, 75-95.

Burov, E., Jolivet, L., Le Pourhiet, L. \& Poliakov, A., 2001. A thermomechanical model of exhumation of high pressure (HP) and ultra-high pressure (UHP) metamorphic rocks in Alpine-type collision belts, Tectonophysics, 342, 1-2, 113-136.

Bystricky, M. \& Mackwell, S., 2001. Creep of dry clinopyroxene aggregates, Journal of Geophysical Research, 106, B7, 13443-13454.

Carson, C.J., Clarke, G.L. \& Powell, R., 2000. Hydration of eclogite, Pam Peninsula, New Caledonia, Journal of Metamorphic Geology, 18, 79-90.

Carson, C.J., Powell, R. \& Clarke, G.L., 1999. Calculated mineral equilibria for eclogites in CaO-Na2O-FeO-MgO-A12O3-SiO2-H2O: application to the Pouébo Terrane, Pam Peninsula, New Caledonia, Journal of Metamorphic Geology, 17, 9-24. 
Carswell, D.A. \& Zhang, R.Y., 1999. Petrographic characteristics and metamorphic evolution of ultra-high pressure eclogites in plate collision belts, International geology review, 41, 781-798.

Carswell, T., Cuthbert, S., O'Brien, P. \& Tucker, R., Eclogite Evolution and the timing of Ultra-High Pressure Metamorphism in Western Norway, pp. $\mathrm{n}^{\circ} 348$, Journal of Conference Abstracts, EUG XI, Strasbourg, France, 2001.

Castelli, D., Rolfo, F., Compagnoni, R. \& Xu, S., 1998. Metamorphic veins with kyanite, zoisite and quartz in the Zhu-Jia-Chong eclogite, Dabie Shan, China, The Island Arc, 7, 159-173.

Chemenda, A.I., Mattauer, M. \& Bokun, A.N., 1996. Continental Subduction and a Mechanism for Exhumation of High-Pressure Metamorphic Rocks: New Modeling and Field Data from Oman, Earth and Planet Sci. Lett., 143, 173-182.

Chemenda, A.I., Mattauer, M., Malavieille, J. \& Bokun, A.N., 1995. A mechanism for syncollision rock exhumation and associated normal faulting: results from physical modelling, Earth Planet. Sci. Lett., 132, 225-232.

Chi, W.-C., Reed, D.L., Moore, G., Nguyen, T., Liu, C.-S. \& Lundberg, N., 2003. Tectonic wedging along the rear of the offshore Taiwan accretionary prism, Tectonophysics, 374, 199-217.

Chopin, C., 1984. Coesite and pure pyrope in high-grade blueschists of the western Alps: A first record and some consequences, Contributions to Mineralogy and Petrology, 86, 107-118.

Chopin, C., 2003. Ultrahigh-pressure metamorphism: tracing continental crust into the mantle, Earth and Planet Science Letters, 212, 1-14.

Chopin, C. \& Schertl, H.P., 1999. The UHP Unit in the Dora-Maira massif, western Alps, International geology review, 41, 765-780.

Cohen, A.S., O'Nions, R.K., Siegenthaler, R. \& Griffin, W.L., 1988. Chronology of the pressure-temperature history recorded by a granulite terrain, Contribution to Mineralogy and Petrology, 99, 303-311.

Compagnoni, R. \& Rolfo, F., 1999. Characteristics of UHP pelites, gneisses and other unusual rocks, International geology review, 41, 6, 552-570.

De Sigoyer, J., Guillot, S. \& Dick, P., 2004. Exhumation of the ultrahigh-pressure Tso Morari unit in eastern Ladakh (NW Himalaya): a case study, Tectonics, 23, doi:10.1029/2002TC001492. 
Dimanov, A., Lavie, M.P., Dresen, G., Ingrin, J. \& Jaoul, O., 2003. Creep of polycrystalline anorthite and diopside, Journal of Geophysical Research, 108, B1, doi:10.1029/2002JB001815.

Dobrzhinetskaya, L.F., Eide, E.A., Larsen, R.B., Sturt, B.A., Trønnes, R.G., Smith, D.C., Taylor, W.R. \& Posukova, T.V., 1995. Microdiamond in high-grade metamorphic rocks of the Western Gneiss Region, Norway., Geology, 23, 597-600.

Doin, M.-P. \& Henry, P., 2001. Subduction initiation and continental crust recycling : the roles of rheology and eclogitization, Tectonophysics, 342, 163-191.

Duchêne, S., Lardeaux, J.M. \& Albarède, F., 1997. Exhumation of eclogites : insights from depth-time analysis, Tectonophysics, 280, 125-140.

England, P.C. \& Holland, T.J.B., 1979. Archimedes and the Tauern eclogites: the role of buoyancy in the preservation of exotic eclogite blocks, Earth Planet. Sci. Lett., 44, 287-294.

Erambert, M. \& Austrheim, H., 1993. The effect of fluid and deformation on zoning and inclusion patterns in poly-metamorphic garnets, Contributions to Mineralogy and Petrology, 115, 204-214.

Ernst, W.G., 1999. Metamorphism, partial preservation, and exhumation of ultrahigh-pressure belts, The Island Arc, 8, 125-153.

Ernst, W.G., 2001. Subduction, ultrahigh-pressure metamorphism, and regurgitation of buoyant crustal slices-implications for arcs and continental growth, Physics of the Earth and Planetary Interiors, 127, 253-275.

Faure, M., Lin, W., Shu, L., Sun, Y. \& Schärer, U., 1999. Tectonics of the Dabieshan (eastern China) and possible exhumation mechanism of ultra high-pressure rocks, Terra Nova, 11, 251-258.

Foreman, R., Andersen, T.B. \& Wheeler, J., 2005. Eclogite facies polyphase deformation of the Drøsdal eclogite, Western Gneiss Complex, Norway, and implications for exhumation, Tectonophysics, in press.

Fossen, H., 1992. The role of extensional tectonics in the Caledonides of south Norway, Journal of structural geology, 14, 8-9, 1033-1046.

Fossen, H., 2000. Extensional tectonics in the Caledonides : Synorogenic or postorogenic ?, Tectonics, 19, 2, 213-224.

François, D., Pineau, A. \& Zaoui, A., 1995. Comportement mécanique des matériaux, tome I: Elasticité et plasticité, p. 508, Hermes, Paris. 
Gerya, T.V. \& Stöckhert, B., 2002a. Exhumation rates of high-pressure metamorphic rocks in subduction channels: the effect of rheology, Geophysical research letters, 29, 8, doi:10.1029/2001GL014307.

Gerya, T.V., Stöckhert, B. \& Perchuk, A.L., 2002b. Exhumation of high-pressure metamorphic rocks in a subduction channel: a numerical simulation, Tectonics, 21, 6, doi:10.1029/2002TC001406.

Godard, G. \& van Roermund, H.L.M., 1995. Deformation-induced clinopyroxene fabrics from eclogites, Journal of Structural Geology, 17, 10, 1425-1443.

Goffé, B., Bousquet, R., Henry, P. \& Le Pichon, X., 2003. Effect of the chemical composition of the crust on the metamorphic evolution of orogenic wedges, Journal of Metamorphic Geology, 21, 123-141.

Griffin, W.L., Austrheim, H., Brastad, K., Bryhni, I., Krill, A.G., Krogh, E.J., Mørk, M.B.E., Qvale, H. \& Tørudbakken, B., 1985. High-pressure metamorphism in the Scandinavian Caledonides, in The Caledonide Orogen-Scandinavia and Related Areas, pp. 783-801, ed. Gee, D.G. \& Sturt, B.A., John Wiley \& Sons Ltd, Chichester, UK.

Guillot, S., Hattori, K.H. \& de Sigoyer, J., 2000. Mantle wedge serpentinization and exhumation of eclogites: insights from eastern Ladakh, northwest Himalaya, Geology, 28, 199-202.

Guillot, S., Hattori, K.H., de Sigoyer, J., Nägler, T. \& Auzende, A.-L., 2001. Evidence of hydration of the mantle wedge and its role in the exhumation of eclogites, Earth and Planet Science Letters, 193, 115-127.

Hacker, B.R., Calvert, A., Zhang, R.Y., Ernst, W.G. \& Liou, J.G., 2003. Ultrarapid exhumation of ultrahigh-pressure diamond-bearing metaedimentary rocks of the Kokchetav Massif, Kazakhstan, Lithos, 70, 61-75.

Jamtveit, B., Bucher-Nurminen, K. \& Austrheim, H., 1990. Fluid controlled eclogitization of granulites in deep crustal shear zones, Bergen arcs, Western Norway, Contribution to Mineralogy and Petrology, 104, 184-193.

Jin, Z.M., Zhang, S., Green II, H.W. \& Jin, S., 2001. Eclogite rheology : Implications for subducted lithosphere, Geology, 29, 8, 667-670.

Jolivet, L., Faccenna, C., Goffe, B., Burov, E. \& Agard, P., 2003. Subduction tectonics and exhumation of high-pressure metamorphic rocks in the Mediterranean orogens, American Journal of Science, 303, 5, 353-409. 
Katayama, I., Maruyama, S., Parkinson, C.D., Terada, K. \& Sano, Y., 2001. Ion micro-probe $\mathrm{U}-\mathrm{Pb}$ zircon geochronology of peak and retrograde stages of ultrahigh-pressure metamorphic rocks from the Kokchetav massif, northern Kazakhstan, Earth and Planet Science Letters, 188, 185-198.

Kolderup, C.F. \& Kolderup, N.H., 1940. Geology of the Bergen Arc System, p. 137.

Krogh, E.J., 1977. Evidence of Precambrian continent-continent collision in Western Norway, Nature, 267, 17-20.

Kühn, A., 2002. The influence of fluid on the granulite to eclogite and amphibolite facies transition: a study in the anorthositic rocks from the Lindås Nappe, Bergen Arcs, West Norway, PhD Thesis thesis, University of Oslo.

Labrousse, L., Jolivet, L., Andersen, T.B., Agard, P., Maluski, H. \& Schärer, U., 2004. Pressure-temperature-time-deformation history of the exhumation of ultra-highpressure rocks in the Western Gneiss Region, Norway, GSA special paper, 380, 155183.

Lapen, T.S., Johnson, C.M., Baumgartner, J., Mahlen, N.J., Beard, B.L. \& Amato, J.F., 2003. Burial rates during prograde metamorphism of an ultra-high-pressure terrane: an example from Lago di Cignana, western Alps Italy, Earth and Planet Science Letters, 215, 57-72.

Le Pichon, X., Bergerat, F. \& Roulet, M.J., 1988. Plate kinematics and tectonics leading to the Alpine belt formation, Geological Society of America, Special Paper, 218, 111-131.

Lighthill, M.J., Whitham, F.R.S. \& Whitham, G.B., 1955a. On kinematic waves I. Flood movement in long rivers, Proceedings of the Royal Society of London, Series A, 229, 281-316.

Lighthill, M.J., Whitham, F.R.S. \& Whitham, G.B., 1955b. On kinematic waves II. A theory of traffic flow on long crowded roads, Proceedings of the Royal Society of London, Series A, 229, 317-345.

Mancktelow, N.S., 1995. Nonlithostatic pressure during sediment subduction and the development and exhumation of high pressure metamorphic rocks, Journal of geophysical research, 100, B1, 571-583; 1.

Mattey, D., Jackson, D.H., Harris, B.W. \& Kelly, S., 1994. Isotopic constraints on fluid infiltration from an eclogite facies shear zone, Holsnøy, Norway, Journal of Metamorphic Geology, 12, 311-325. 
Mauler, A., Godard, G. \& Kunze, K., 2001. Crystallographic fabrics of omphacite, rutile and quartz in Vendée eclogites (Armorican Massif, France). Consequences for deformation mechanisms and regimes, Tectonophysics, 342, 81-112.

Nemat-Nasser, S. \& Hori, M., 1993. Micromechanics: overall properties of heterogeneous materials, p. 687, Elsevier Science Publishers B.V., North-Holland-Amsterdam, London, New York, Tokyo.

Oh, C.W. \& Liou, J.G., 1998. A petrogenetic grid for eclogite and related facies under highpressure metamorphism, The Island Arc, 7, 36-51.

Parkinson, C.D., 2000. Coesite inclusions and prograde compositional zonation of garnet in whiteschist of the HP-UHPM Kokchetav massif, Kazakhstan: a record of progressive UHP metamorphism, Lithos, 52, 215-233.

Peacock, S.M. \& Wang, K., 1999. Seismic consequences of warm versus cool subduction metamorphism: examples from southwest and northeast Japan, Science, 286, 937-939.

Perchuk, A.L. \& Philippot, P., 2000. Geospeedometry and Time Scales of High-Pressure Metamorphism, International Geology Review, 42, 3, 207-223.

Piepenbreier, D. \& Stöckhert, B., 2001. Plastic flow of omphacite in eclogites at temperatures below $500^{\circ} \mathrm{C}$ - implications for interplate coupling in subduction zones, International Journal of Earth Sciences, 90, 197-210.

Ragnhildsveit, J. \& Helliksen, D., Geologisk kart over Norge, begrunnskart Bergen, 1:250000, Norges Geologiske Undersøkelse, 1997.

Raimbourg, H., Goffe, B. \& Jolivet, L., submitted. Garnet reequilibration in the eclogite facies : differential behavior of $\mathrm{Ca}, \mathrm{Fe}$ and $\mathrm{Mg}$.

Raimbourg, H., Jolivet, L., Labrousse, L., Leroy, Y.M. \& Avigad, D., in press. Kinematics of syn-eclogite deformation in the Bergen Arcs, Norway, implications for exhumation mechanisms, in Deformation mechanisms, rheology and tectonics, Special Publications of the Geological Society of London.

Ranalli, G., 1995. Rheology of the Earth, p. 2nd ed., 413, Chapman and Hall, New York.

Regard, V., Faccenna, C., Martinod, J., Bellier, O. \& Thomas, J.-C., 2003. From subduction to collision: control of deep processes on the evolution of convergent plate boundary, Journal of Geophysical Research, 108, B4, doi:10.1029/2002JB001943.

Reinecke, T., 1998. Prograde high- to ultrahigh-pressure metamorphism and exhumation of oceanic sediments at Lago di Cignana, Zermatt-Saas Zone, western Alps, Lithos, 42, 147-189. 
Roberts, D., 2003. The Scandinavian Caledonides: event chronology, palaeogeographic settings and likely modern analogues, Tectonophysics, 6848, 1-17.

Rubatto, D. \& Hermann, J., 2001. Exhumation as fast as subduction?, Geology, 29, 1, 3-6.

Rubio, E., Torné, M., Vera, E. \& Diaz, A., 2000. Crustal structure of the southernmost Chilean margin from seismic and gravity, Tectonophysics, 323, 39-60.

Schertl, H.P., Schreyer, W. \& Chopin, C., 1991. The pyrope-coesite rocks and their country rocks at Parigi, Dora-Maira Massif, western Alps: Detailed petrography, mineral chemistry and P-T paths, Contributions to Mineralogy and Petrology, 108, 1-21.

Schwartz, S., Allemand, P. \& Guillot, S., 2001. Numerical model of the effect of serpentinites on the exhumation of eclogitic rocks: insights from the Monviso ophiolitic massif (western Alps), Tectonophysics, 342, 193-206.

Shreve, R.L. \& Cloos, M., 1986. Dynamics of sediment subduction, melange formation, and prism accretion, Journal of Geophysical Research, 91, 10, 10.229-10.245.

Simon, G., Chopin, C. \& Schenk, V., 1997. Near-end-member magnesiochloritoid in prograde-zoned pyrope, Dora-Maira Massif, western Alps, Lithos, 41, 37-57.

Smith, D.C., 1984. Coesite in clinopyroxene in the Caledonides and its implications for geodynamics, Nature, 310, 641-644.

Stöckhert, B., 2002. Stress and deformation in subduction zones - insight from the record of exhumed high pressure metamorphic rocks, in Deformation Mechanisms, Rheology, and Tectonics: Current Status and Future Perspectives, pp. 255-274, ed. al., S.d.M.e., Geological Society Special Publications.

Stöckhert, B., Wachmann, M., Kuster, M. \& Bimmermann, S., 1999. Low effective viscosity during high pressure metamorphism due to dissolution precipitation creep: the record of HP-LT metamorphic carbonates and siliciclastic rocks from Crete, Tectonophysics, 303 (1-4), 299-319.

Stockhert, B.S.o.c., Massone, H.-J. \& U, N.E., 1997. Low differential stress during highpressure metamorphism : The microstructural record of a metapelite from the Eclogite Zone, Tauern Window, Eastern Alps, Lithos, 41, 103-118.

Toussaint, G., Burov, E. \& Avouac, J.-P., 2004. Tectonic evolution of a continental collision zone: a thermomechanical numerical model, Tectonics, 23, doi:10.1029/2003TC001604.

Trotet, F., Jolivet, L. \& Vidal, O., 2001. Tectono-metamorphic evolution of Syros and Sifnos islands (Cyclades, Greece), Tectonophysics, 338, 179-206. 
Vigneresse, J.L., Barbey, P. \& Cuney, M., 1996. Rheological Transitions During Partial Melting and Crystallization with Application to Felsic Magma Segregation and Transfer, Journal of Petrology, 37, 6, 1579-1600.

Wain, A., 1997. New evidence for coesite in eclogite and gneisses : Defining an ultra-high pressure province in the Western Gneiss region of Norway, Geology, 25, 10, 927-930.

Wain, A., Waters, D.J. \& Austrheim, H., 2001. Metastability of granulites and processes of eclogitisation in the UHP region of western Norway, Journal of Metamorphic Geology, 19, 607-623.

Wei, C.J., Powell, R. \& Zhang, L.F., 2003. Eclogites from the south Tianshan, NW China: petrological characteristic and calculated mineral equilibria in the $\mathrm{Na} 2 \mathrm{O}-\mathrm{CaO}-\mathrm{FeO}-$ MgO-A12O3-SiO2-H2O system, Journal of Metamorphic Geology, 21, 163-179.

\section{Figure Caption}

Figure 1 : (a) Geological map of Holsnøy by Birtel et al. (1998), Boundy et al. (1997b), Kühn (2002) and Ragnhildsveit \& Helliksen (1997). Location of figure 1b. Coordinates correspond to UTM grid, zone $32: 22=6722000,81=281000$.

(b) Northwestern Holsnøy from Austrheim et al. (1996), Boundy et al. (1992), Boundy et al. (1997a) and Raimbourg et al. (in press), with heterogeneous distribution of eclogitic overprint on granulite. Eclogite, Breccia and Granulite corresponds respectively to degrees of eclogitic metamorphism $>80 \%, 40 \%-80 \%,<40 \%$. Structural data are given for the large-scale eclogitic shear zones.

Figure 2: Localization of deep deformation and rheological differences between eclogite and granulite. The granulitic foliation, which is undeformed in the core of the granulite, bends to merge into the eclogitic foliation. This foliation deflection, either on the granulite boudin rim (left picture), or on the border of a narrow eclogitic shear zone (right picture), is used to deduce the sense of shear.

Figure 3: The extent of eclogitization is highly variable throughout the granulitic unit. In little transformed areas, eclogite is present only in scarce and narrow shear zones cutting through a rigid granulitic skeleton. In the most transformed areas, granulite is preserved only in rare boudins embedded in an eclogitic skeleton. The rheology difference between strong granulite 
and weak eclogite results in the localization of all the deformation in the eclogite fraction. The disruption of the granulitic skeleton with eclogitization progress is marked by the increase in the misorientation of adjacent granulite volumes. In the most transformed zones, the independent rigid rotation of granulite boudins results in the random orientation of their foliations.

Figure 4: Two possible mechanisms for propagation of eclogitized zones into granulite. In the highly anhydrous granulite, fluid input is necessary to trigger eclogitization, and the sharp front between light granulite and dark eclogite coincides with the hydration front. Left: Fluid input is achieved by the combination of channelized flow within meter-scale fractures and subsequent diffusion from the fracture into host rock. Right: Microscopic diffusion is in charge of meter-scale flow, as no macroscopic hydrous fracture is visible. The finger-like eclogitized zone is roughly parallel to the granulitic foliation. This sort of structure is much less abundant than the eclogite band with a central hydrous fracture. Note in both structures the presence of "dry" fractures (as opposed to eclogitic fractures, filled with hydrous eclogitic minerals) crosscutting the eclogite volume and its boundary, whose origin is unclear.

Figure 5: The partially eclogitized granulitic unit can be schematically divided into three distinct zones. Within the highly transformed "eclogite", the stress supporting matrix is eclogite, and granulite is preserved only in boudins. Within the other endmember "granulite", granulite is virtually unaffected by eclogitization. Within the damage zone surrounding "eclogite", macroscopic fractures enables fluid input and eclogitization inception. The size and geometry of this fractured zone depends on the physical mechanisms causing macroscopic fracturation.

Figure 6: The mechanical consequences of eclogitization result first from the rheology difference and second from the volume reduction induced by the metamorphic reactions. Both phenomena are accounted for in a inclusion/matrix problem, where eclogite is confined into an ellipsoidal inclusion embedded in an infinite granulitic matrix, undergoing stress/strain at infinity. The reaction-induced volume reduction is modelled by prescribing a field $\varepsilon^{*}(x)$ of residual deformation, constant within the inclusion and null outside. Both rheology difference $\left(\underline{\underline{\underline{\underline{C_{g}}}}} / \underline{\underline{\underline{C_{e}}}}\right)$ and volume reduction result in higher stress concentration near the sharp tip of the 
inclusion, resulting in anisotropic geometry of the fractured zone in granulite and propagation of the eclogite volume.

Figure 7: Possible evolutions of the granulitic unit under eclogite-facies conditions. The propagation of eclogitized zones is constrained by the geometry of fractured zones, itself dependent on the physical mechanism underlying fracturation. In particular the strong weakening associated to the "percolation" of an eclogite volume through the granulitic unit occurs for a variable eclogite fraction, depending on the anisotropy of fractured zones. Both volume reduction or rheology difference associated to eclogitization lead to an anisotropic geometry of fractured zones and eventually of eclogitic zones (A and B). While the volume reduction-related stress concentrations induce self propagation of eclogitized zones (A), the rheological difference cause fracturing only under applied external stress (B). In the latter case, the stress drop linked to the weakening of the unit causes a strong decrease in stress concentration, fracturing and eclogitized zones propagation, as stated by Bjørnerud et al. (2002).

Figure 8: Subduction channel model. The material within the channel is the crust belonging to the subducting slab. The channel is bounded at the bottom by the lithospheric mantle, at the top by the crust or the mantle of the overriding plate, depending on the depth and the subduction zone considered. Bottom velocity is the plate convergence rate, top velocity is zero. The velocity field within the channel is the sum of a linear field, related to basal dragging, and a parabolic field related to buoyancy of buried crust.

Figure 9: Top: Velocity fields for various positive $\alpha$, for a fixed channel width $\bar{h}$. The increase in $\alpha$ results in the decrease in the downward flow and eventually in the formation of a return flow in the upper portion of the channel.

Middle: Velocity fields for various channel widths $\bar{h}$, for fixed positive $\alpha$. For $\bar{h} \leq \sqrt{\frac{2}{\alpha}}$, everywhere in the channel velocities are directed downward, while for $\bar{h} \geq \sqrt{\frac{2}{\alpha}}$ in the upper section of the channel the crust is moving upward (note that the diagrams are not at scale). The particular channel width $\bar{h}=\sqrt{\frac{2}{\alpha}}$ corresponds also to the maximum net flow $\bar{Q}$. 
Bottom left: $\bar{Q}(\bar{h})$ curve for a positive $\alpha . \bar{h}=\sqrt{\frac{2}{\alpha}}$ separates regimes with and without return flow, $\bar{h}=\sqrt{\frac{6}{\alpha}}$ separates positive and negative net flow domains.

Bottom right: For a given pair $(\bar{Q}, \bar{h})$, the velocity average over the channel width is slope of the chord and the velocity of the wave carrying $\bar{Q}$ is the slope of the tangent to the curve.

Figure 10: The morphology of the channel, i.e. the $\bar{h}(\bar{x})$ profile, is completely determined by the $\alpha(\bar{x})$ profile under steady state conditions (constant $\bar{Q}$ over channel length). In the completely eclogitized zone, $\alpha$ is largely negative, resulting in a narrow channel. For the same net flow, in shallower domains where the exhumation number is higher, the channel is wider.

Figure 11: $\alpha$ variations versus eclogitization extent (proportion of eclogite in the granulite unit) for three different rocks. $\Delta \rho$, positive when crust is lighter than mantle and conversely, changes as crust is partially eclogitized. While the density changes are proportional to eclogite fraction, the rheology variations are much more difficult to constrain. The effective viscosity and resulting $\alpha$ of the mixture must nevertheless lie between Reuss and Voigt endmembers, corresponding to prescribed macrostress $\left(\underline{\underline{\sigma}}(\underline{x})=\underline{\underline{\sigma}}^{0}\right)$ and macrostrain $\left(\underline{\underline{\varepsilon}}(\underline{x})=\underline{\underline{\varepsilon}}^{0}\right)$, respectively. All curves were computed for a weak eclogite with $\frac{\mu_{\xi=0}}{\mu_{\xi=1}}=100$.

Figure 12: Evolution of effective viscosity and parameter $\alpha$ for the eclogitizing granulitic unit. For a low proportion of weak eclogitic material (1-2), the stress supporting matrix is the strong granulite and the effective viscosity under the prescribed shear is close to the Voigt estimate. For an eclogite proportion larger than the critical rheological fraction (CRF), an eclogite volume cuts through the granulitic unit and strongly decreases the effective viscosity of the unit (3-4), as all the strain localizes into the eclogite fraction. The resulting $\alpha$-curve (solid line) shows a maximum near Reuss estimate maximum for $f_{e} \approx 0.5$. For higher CRF 
(dashed line), the maximum of $\alpha$ is located near the rheological transition, for $f_{e}>0.5$. The curves were computed with $\frac{\mu_{\xi=0}}{\mu_{\xi=1}}=100$.

Figure 13: $\alpha$ variations versus eclogitization extent for a mafic crust previously equilibrated under amphibolite facies.

(A): Effect of viscosity contrast on $\alpha$ variations. For $\Delta \eta>0$ (eclogite stronger than uneclogitized crust), $\alpha$-curves are concave upward, for $\Delta \eta<0$ convex and for $\Delta \eta=0$ it is a straight line. Note that all $\alpha$-curves are arbitrary scaled through width $h^{*}$, so only evolution within a single curve with varying $\xi$ should be considered. Reuss and Voigt mechanical bounds, bracketing the effective $\alpha$-curve, are shown for $\frac{\eta_{e}}{\eta_{g}}=0,1$.

(B): For a low weakening effect of eclogitization, Voigt and Reuss estimates are close, the main factor determining $\alpha$ evolution is the density increase and the rheological weakening at the critical rheological fraction (CRF) has little influence on $\alpha$. Maximum of $\alpha$ occurs for $\xi=0$ (uneclogitized crust).

(C): For a larger rheology contrast, the rheological weakening at the CRF induces a variable increase in $\alpha$. The overall maximum value of $\alpha$ depends on the position of the CRF: For a low CRF (dashed line), the maximum of $\alpha$ is located slightly after the CRF, while for high CRF (solid line), the maximum of $\alpha$ occurs for $\xi=0$.

Figure 14: Consequences on the flow within the subduction channel of the material properties of partially eclogitized crust. On the left, for the crust 1 whose eclogitization induces little weakening and a large density increase, the $\alpha$ profile shows a constant increase in the partially eclogitized domain (ge1). The corresponding $\bar{Q}(\bar{h})$ curves are intermediate between uneclogitized (g) and completely eclogitized (e), and at steady state flow $\bar{Q}_{e q}^{1}$, the width $\bar{h}$ smoothly decreases from $\bar{h}_{g}$ to $\bar{h}_{e}$ within the (ge1) zone. In this configuration there is no return flow anywhere.

For the subsequently subducted crust 2, whose eclogitization induces less density increase and more rheological weakening, such as the granulite on Holsnøy, the $\alpha$ evolution in the partially eclogitized domain (ge2) shows a maximum for a given transformation extent $\xi$. The 
maximum net flow $\bar{Q}_{2}$ for this maximum $\alpha$ is is incompatible with the incoming flow $\bar{Q}_{1}$ from domain $(\mathrm{g})$, determined by the previous steady state flow of crust 1 (middle diagram). In the final stable regime, the equilibrium flow $\bar{Q}_{e q}^{2}$ is determined by the maximum flow at the bottleneck (i.e., the maximum of $\alpha$ ), and upstream of the bottleneck the large channel width enables material exhumation. The match between $\bar{Q}_{e q}^{2}$ and incoming flow $\bar{Q}_{1}$ in the domain (g) is made by a shock wave, also moving upward.

Figure 15: Space-time diagram describing the wave trajectories for successive subduction of low- and high- $\alpha$ material, respectively ge 1 and ge 2 (material properties on the middle figure). The instantaneous material property changes, from ge1 to ge 2 and conversely, lead to a variation in the flow carried by a given wave $\left(\bar{Q}_{-} \rightarrow \bar{Q}_{+}\right)$, for constant $\bar{h}$ (bottom left diagram). Everywhere else waves carry a constant $\bar{Q}$, and change velocity depending on the material crossed. The introduction of high- $\alpha$ material triggers the formation of a bottleneck, localized at the maximum of $\alpha$ within the partially eclogitized domain ge2, which determines the maximum net flow possible $\bar{Q}_{g e 2}^{\max }$ (c-d). Waves carrying this net flow move backward and converge with incoming waves carrying $\bar{Q}_{g}^{i n}$, leading to the formation of a shock wave that also moves backward with a velocity $V_{w}$ as shown on bottom right diagram. When low- $\alpha$ material is again subducted, the flow $\bar{Q}_{g}^{\max }$, carried by a null velocity wave (e-f), is maximum within the partially eclogitized domain. The decreasing backward velocity of waves feeding the shock wave makes it reverse movement and propagate forward (see the evolution from negative shock wave velocity $V_{w}$-points 1 and 2- to positive $V^{\prime}{ }_{w}$-points 1 ' and 2'- on bottom middle diagram). The backward and forward movements of the shock wave correspond respectively to extension and shrinkage of the exhuming domain, shown in bottom right figure.

Figure 16: Consequences of the alterning subduction of high and low exhumation number crust. Sketches in (B) show the schematic evolution in the morphology of the channel around the zone of progressive eclogitization. When high- $\alpha$ material is subducted, the low capacity of the partially eclogitized zone triggers upwards the formation of an "exhuming zone" (sketch 2), that is, a wide-channel zone whose upper portion is moving upward (zone of upward 
velocity). This "exhuming zone" expands upwards continuously (2-3), until the provision of the system with low- $\alpha$ crust leads to its shrinkage (3-4-5). The possibility of complete exhumation -i.e., up to the surface or at least to shallow levels, depends on the respective length of high- and low- $\alpha$ crust to be subducted.

Figure 17: Short- and long-term flow pattern in the channel after instantaneous introduction of high- $\alpha$ material in the zone of partial eclogitization. The left figure shows the evolution of the waves crossing the material properties change line: for constant $\bar{h}$, the flow they carry suddenly drops $\left(\bar{Q}_{i n} \rightarrow \bar{Q}_{\text {out }}\right)$, and the wave velocity is reversed $\left(V_{1} \rightarrow V_{2}\right)$. When these waves move back into domain $(\mathrm{g})$, they keep their flow $\bar{Q}_{\text {out }}$ onto the $\bar{Q}(\bar{h})$ curve of $(\mathrm{g})$, and thus change velocity.

After a long time, waves moving within domain (ge2) have a velocity close to zero and carry $\bar{Q}_{\text {out }}$, which they keep into domain $(\mathrm{g})$ with velocity $V_{B}$. The shock wave has a constant backward velocity constrained by incoming and outcoming flows $\bar{Q}_{i n}$ and $\bar{Q}_{\text {out }}$.

The bottom figure shows the limit solution, when there is no flow through the high- $\alpha$ material $\left(\bar{Q}_{\text {out }}=0\right)$ and all incoming crust must flow backward, which is the most favorable configuration to exhumation in steady state subduction. The absolute exhumation velocities within the exhuming domain -i.e., for $\bar{h}=\bar{h}_{\text {out }}, \bar{Q}_{\text {out }}=0$ - are smaller than the ones reached during the transient evolution of the system, where outcoming net flow can be negative.

Figure 18: Consequences on the flow pattern and shear stress distribution of the presence of a weak layer on top of the subduction channel. The velocity fields for varying channel widths $\bar{h}$ 's are shown with or without the weak layer. The shear stresses at the base and top of the channel are represented by arrows at scale, when no arrow stress is zero. For $\bar{h} \leq \sqrt{\frac{2}{\alpha}}$, shear stresses exerted by the hanging wall at the top of the channel without weak layer are directed upward, and the net flow without weak layer is smaller than with it (thus average burial rates are smaller), and conversely for $\bar{h} \geq \sqrt{\frac{2}{\alpha}}$. 
Tables

Table 1: Measured density of granulite- and eclogite-facies samples 

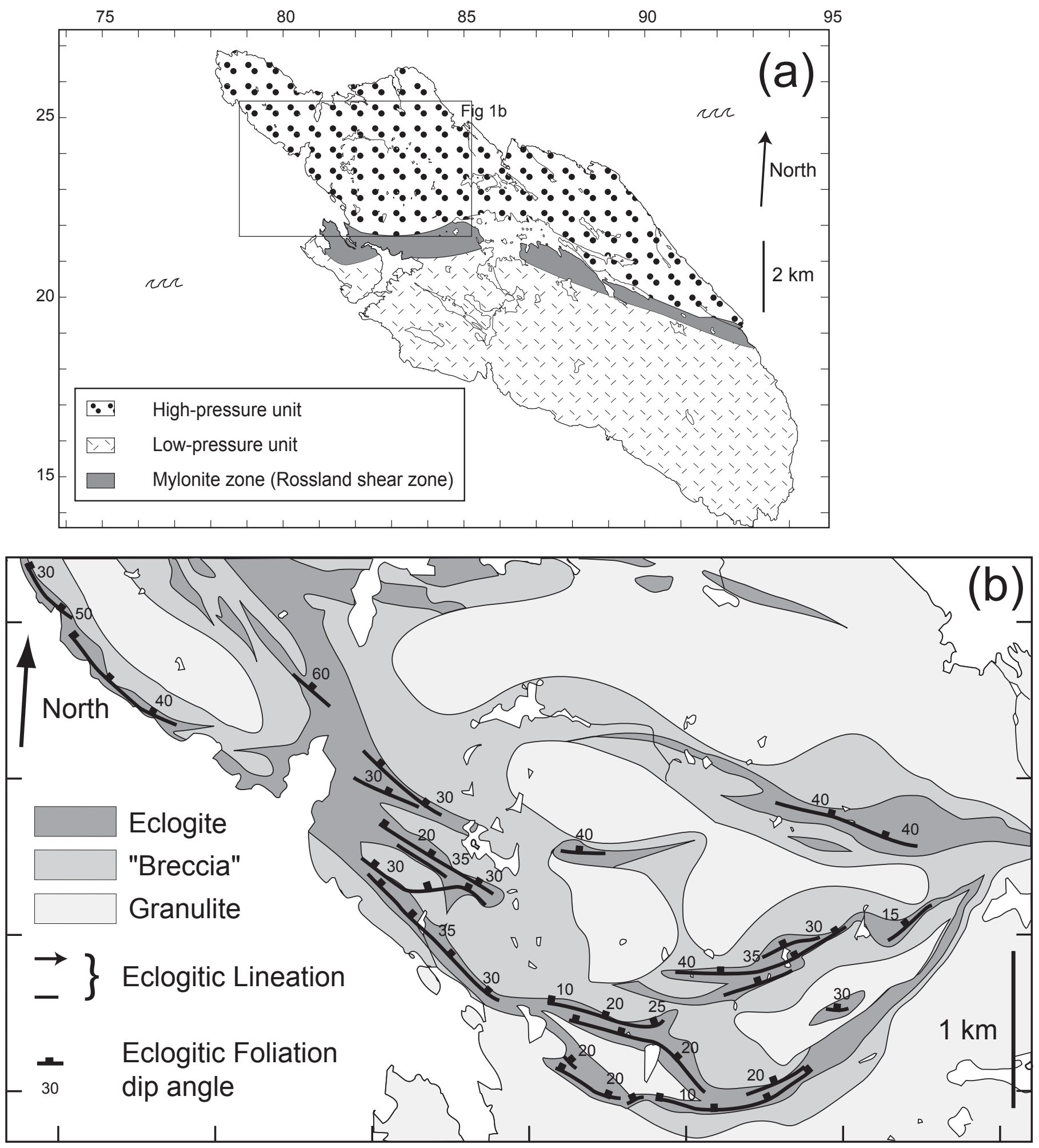

Figure 1 

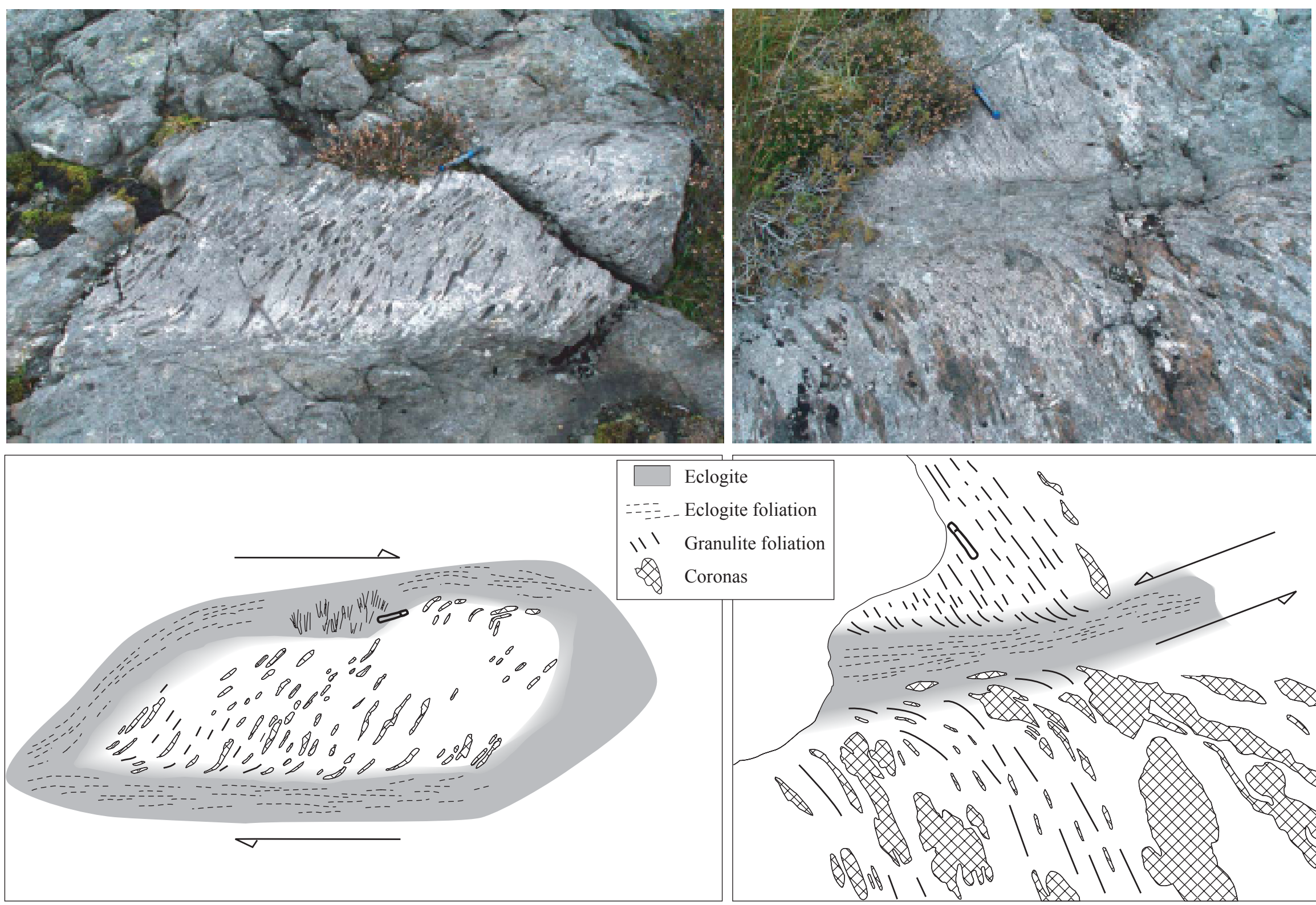

e

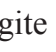

gite foliation

Granulite foliation

onas
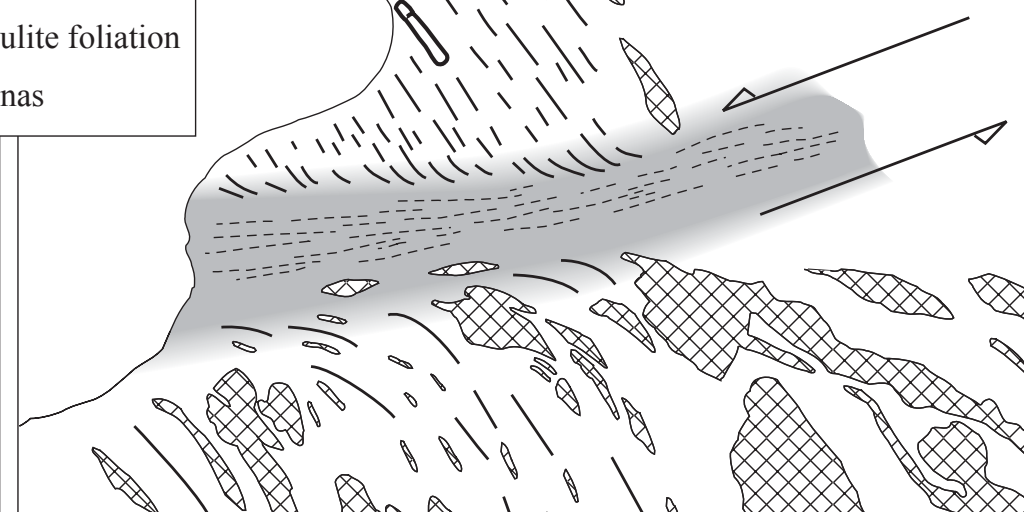

$$
\int
$$

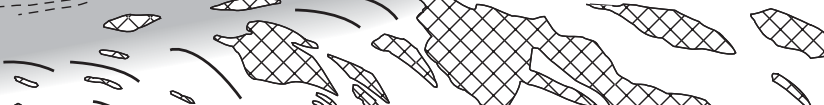
1 200111 18 1

1018

Figure 2 
A few narrow shear zones little deformation no granulitic foliation rotation

Eclogite

Anastomosing shear zones Increasing deformation small granulitic foliation rotation

Wide shear zones High deformation Large granulitic foliation rotation

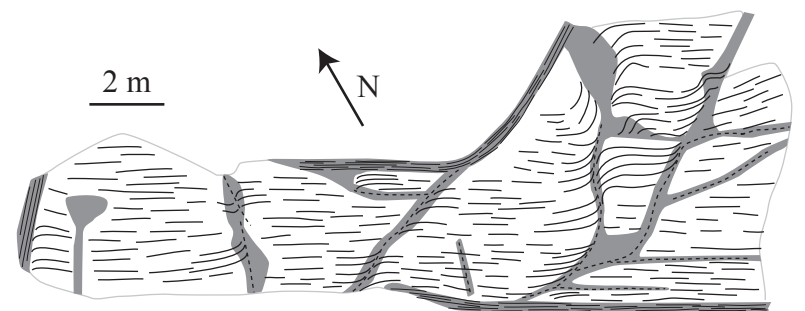

\section{Granlulitic skeleton}
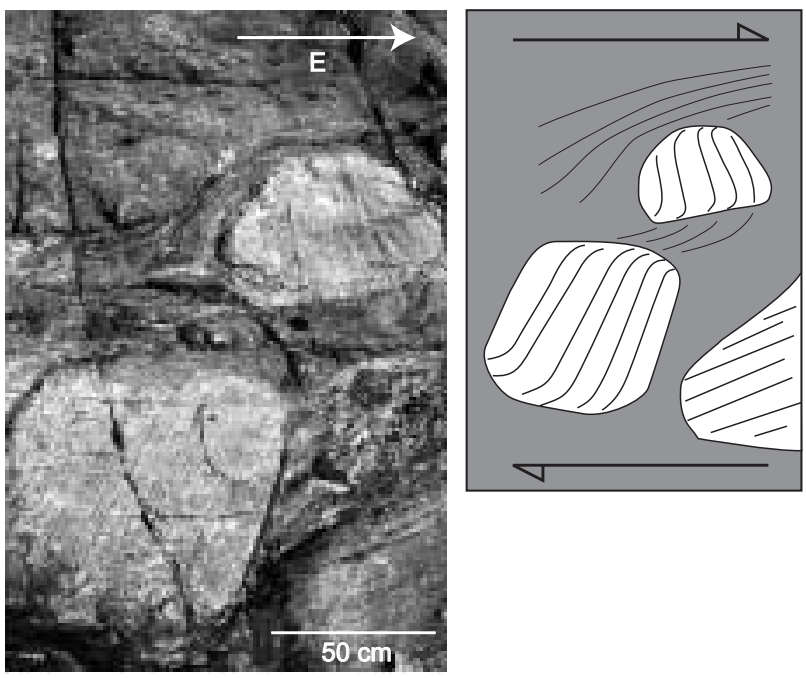

\section{Increasing transformation}

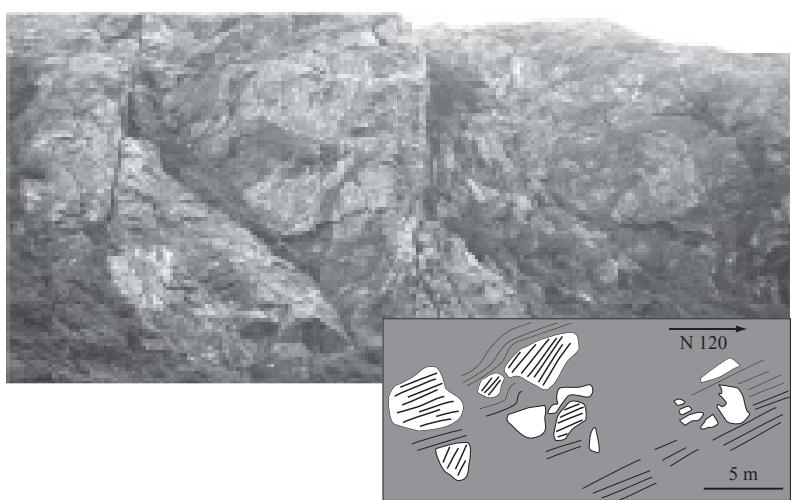



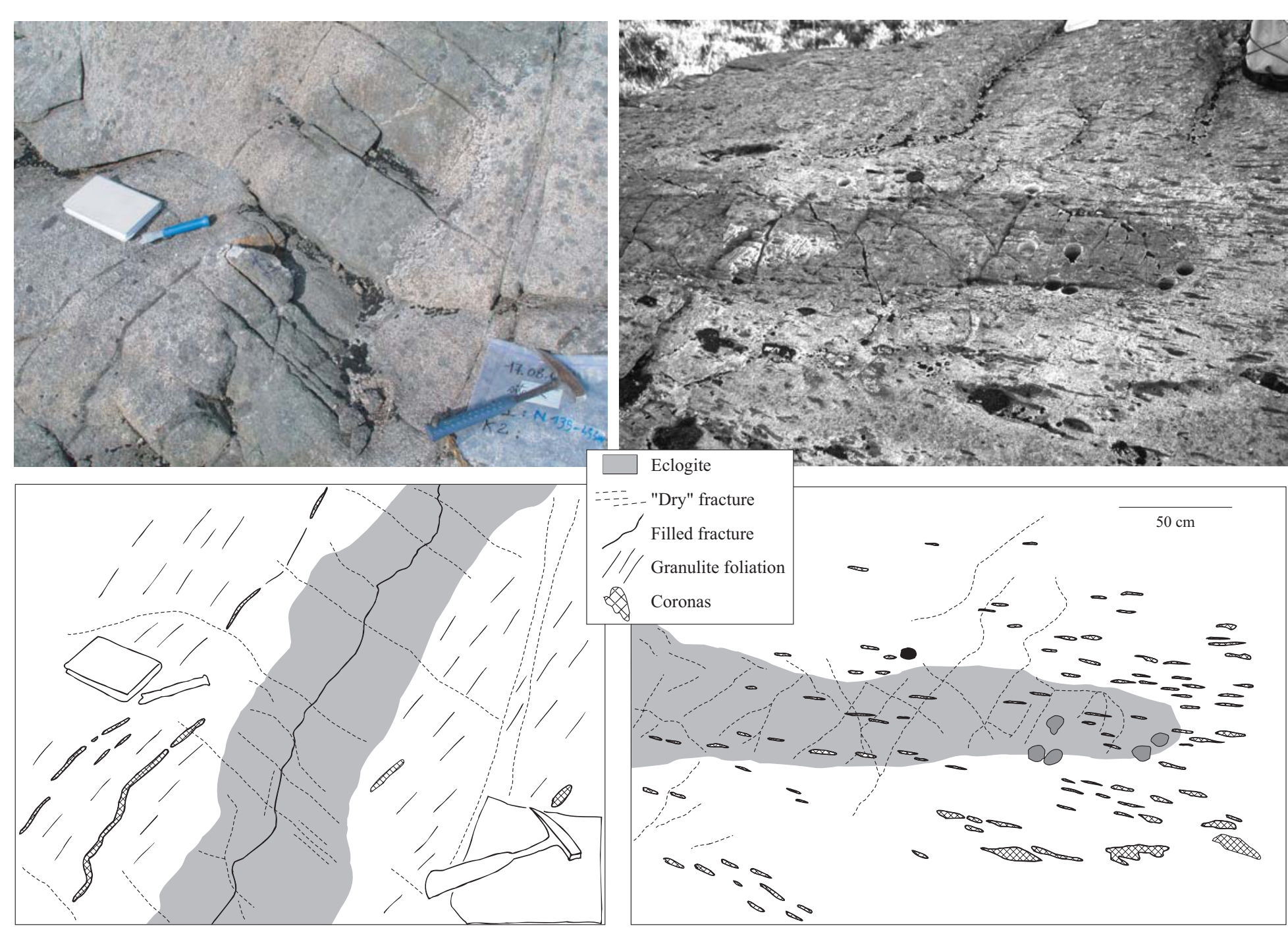

Eclogite

sines.

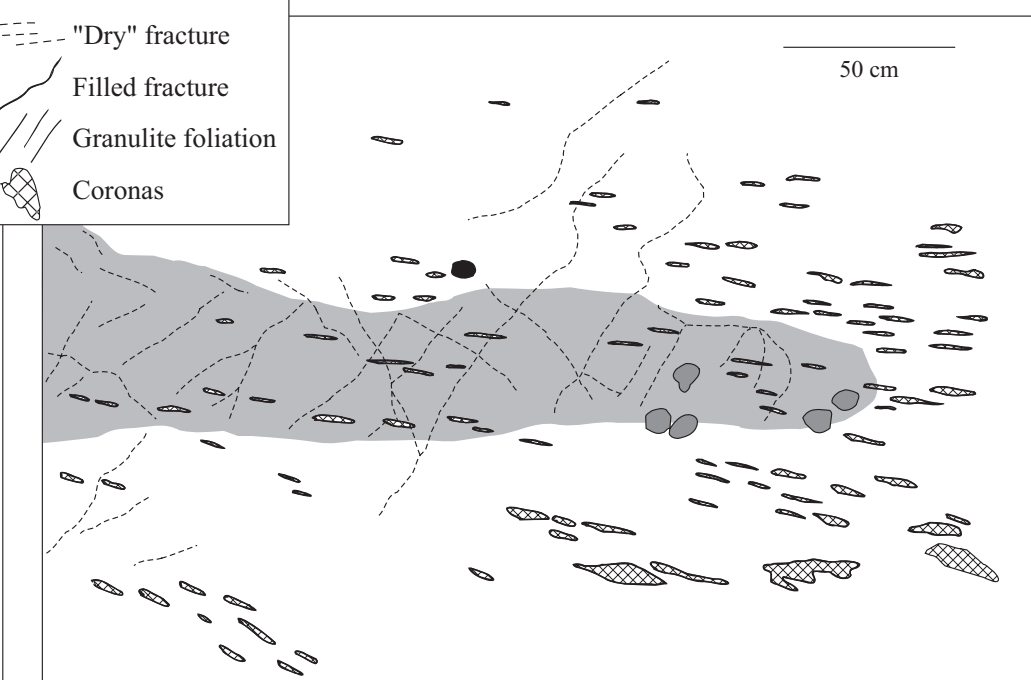

centimeter-scale
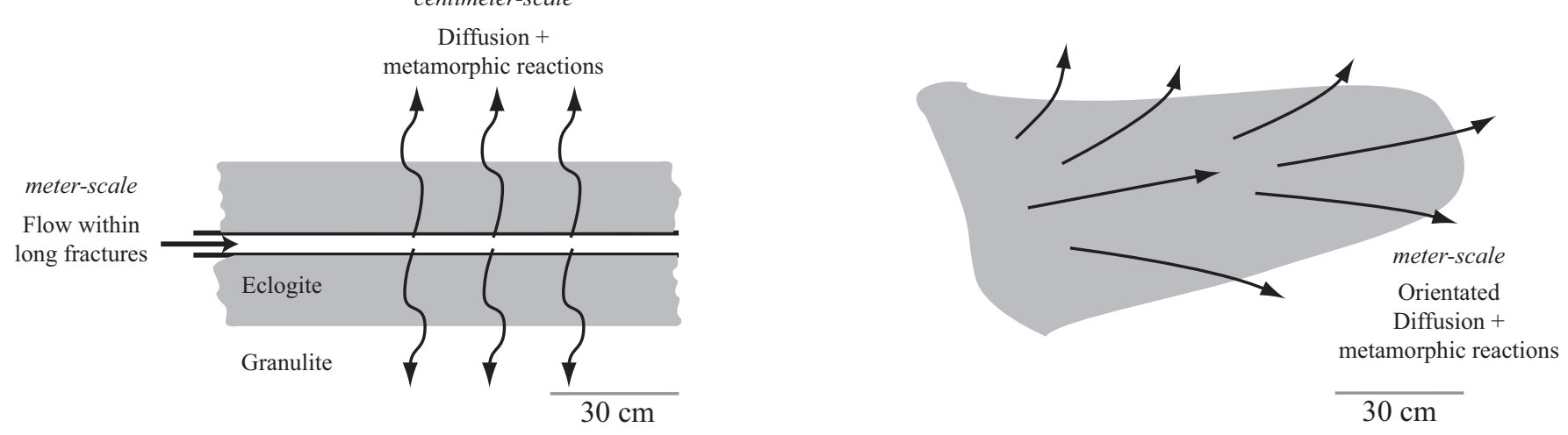

$30 \mathrm{~cm}$

\section{Figure 4}


$5 \mathrm{~km}$

$10 \mathrm{~m}$

\section{Granulite-supported}

pristine granulite
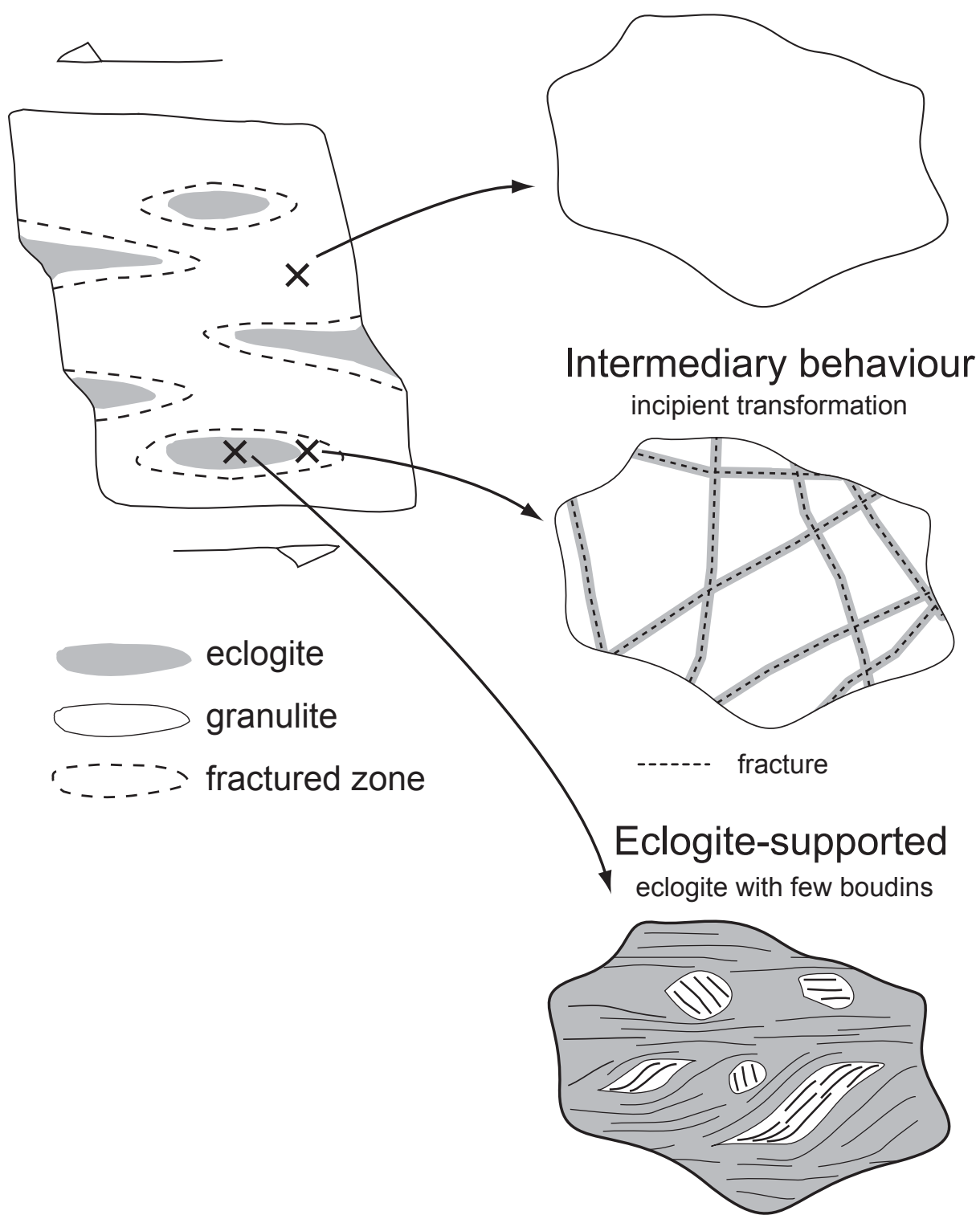

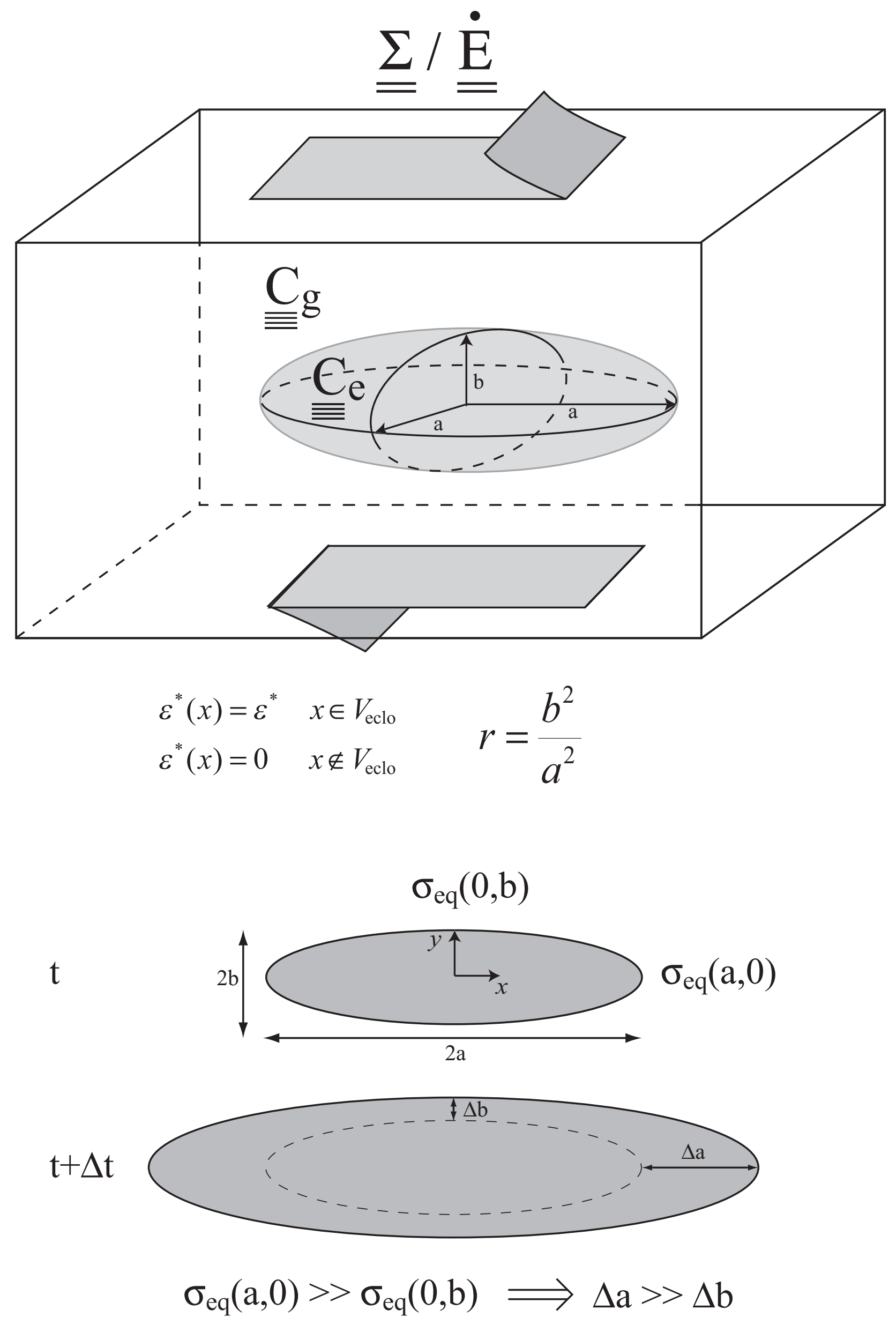

Figure 6 


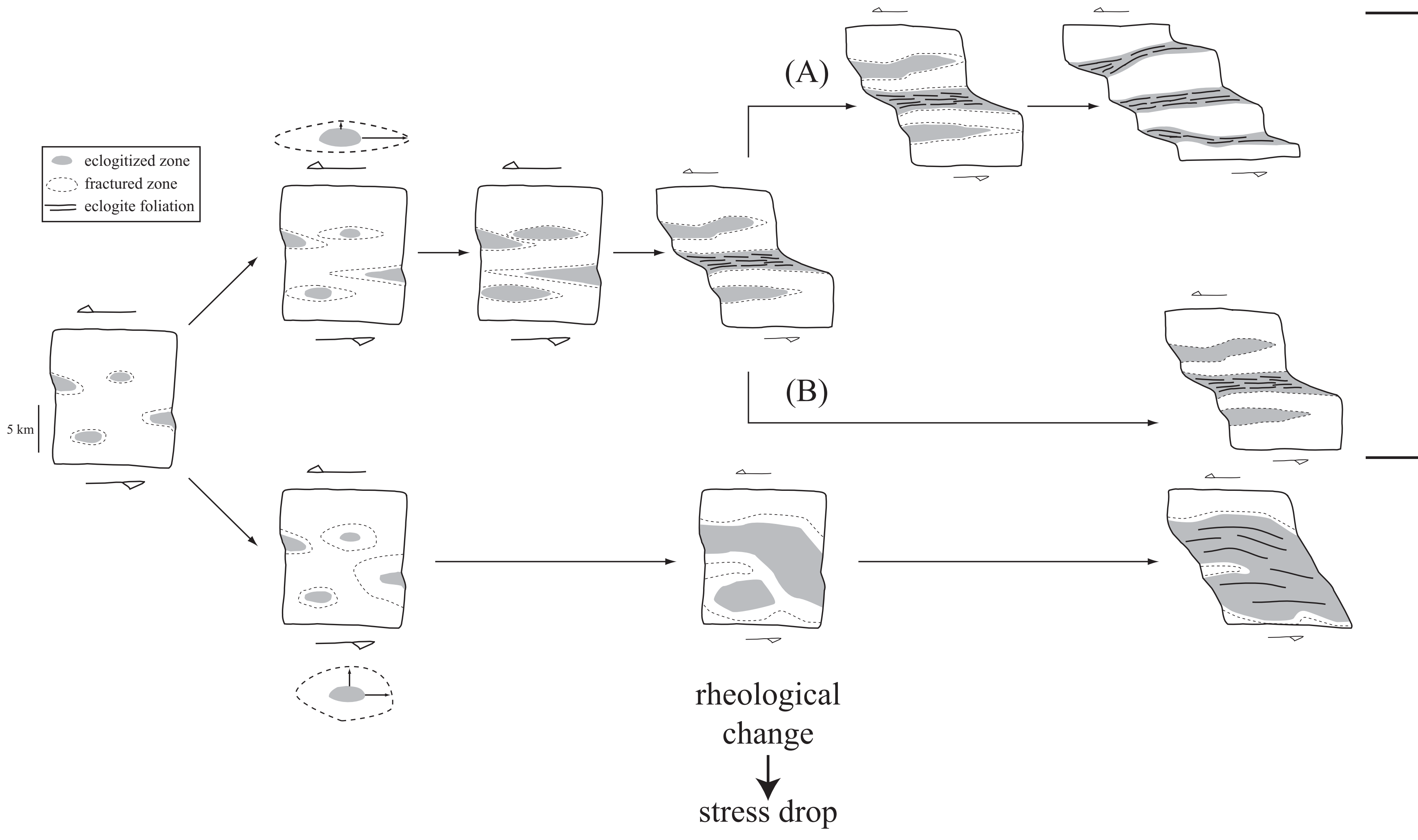

anisotropic

propagation

isotropic

propagation

Figure 7 


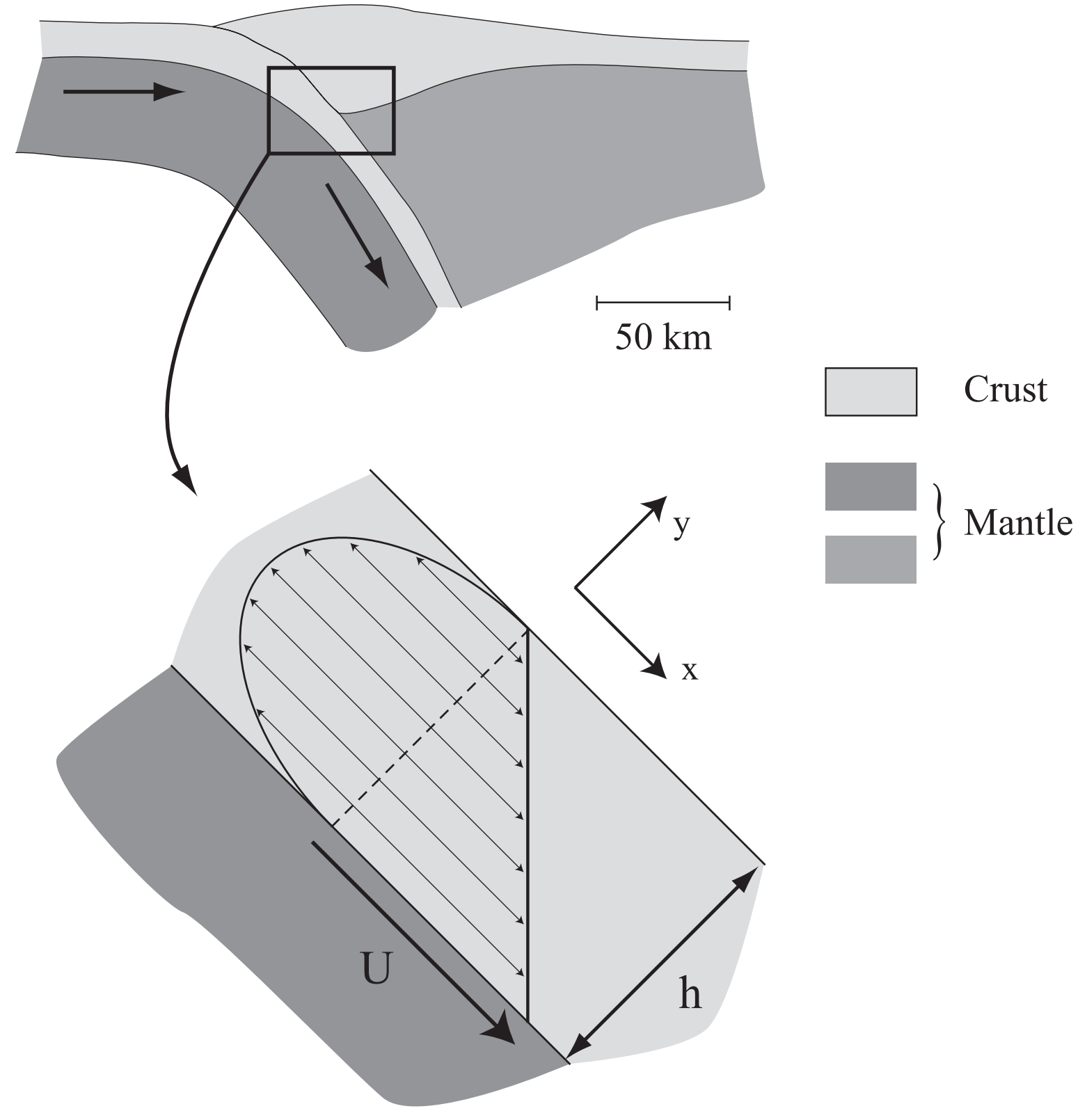

Figure 8 


$$
\alpha=\frac{1}{2 \bar{h}^{2}} \quad \alpha=\frac{2}{\bar{h}^{2}} \quad \alpha=\frac{6}{\bar{h}^{2}}
$$
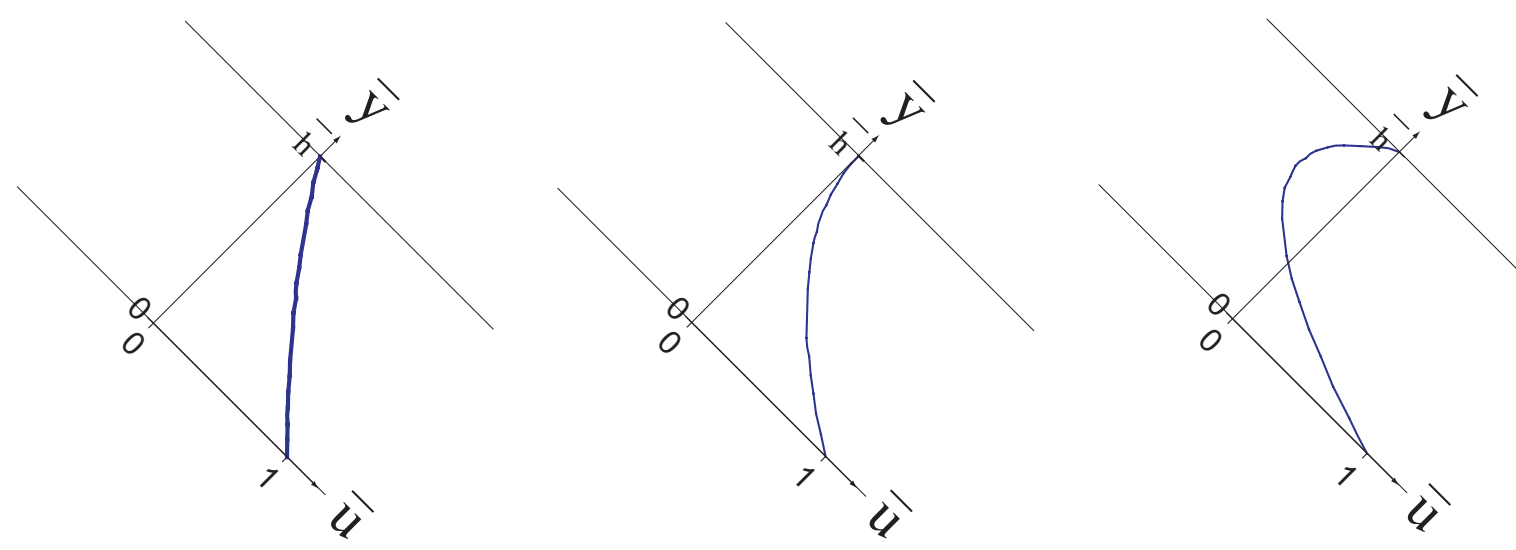

Increasing $\overline{\mathrm{h}} \quad$ (fixed $\alpha$ )

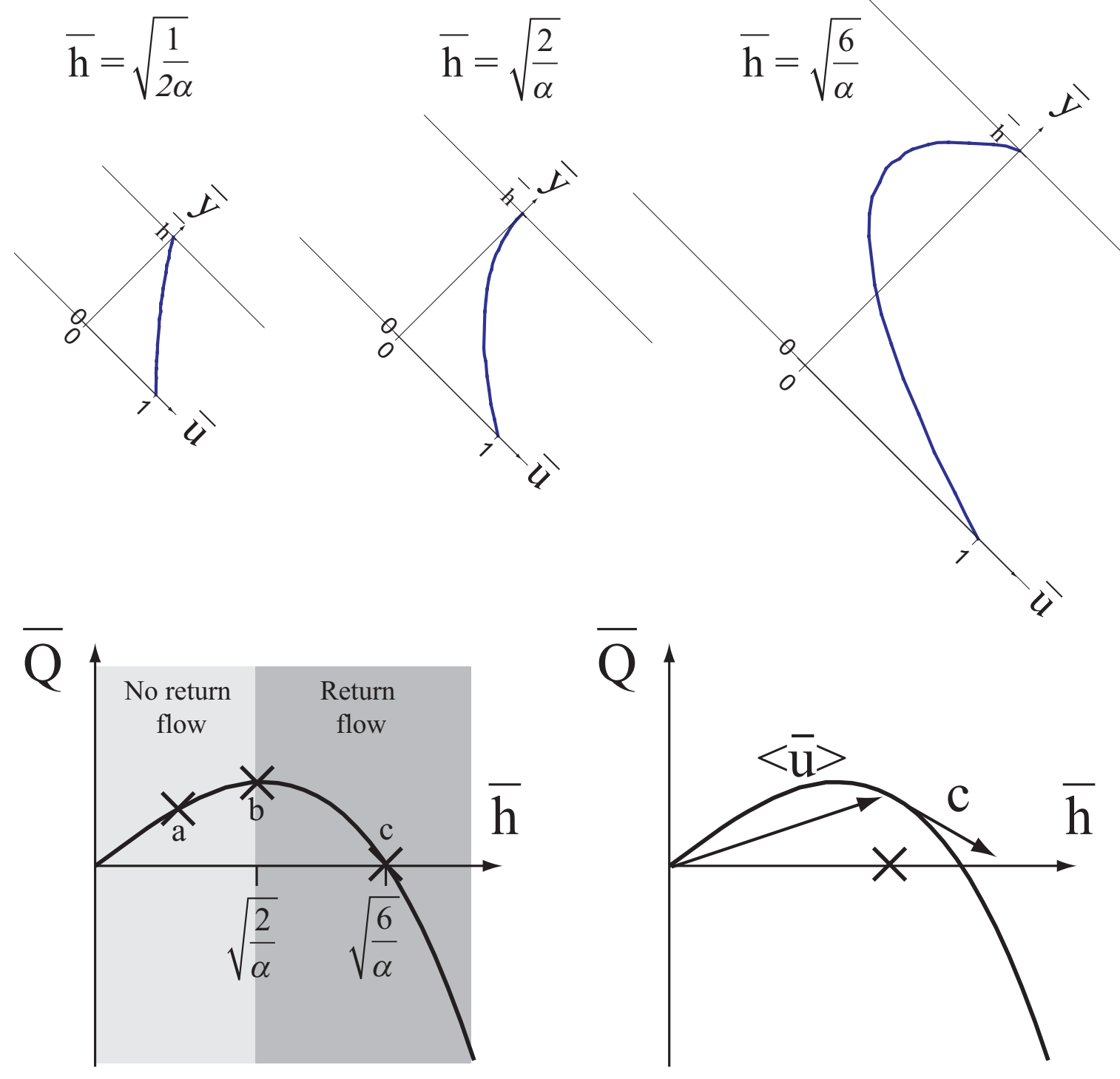

Figure 9 


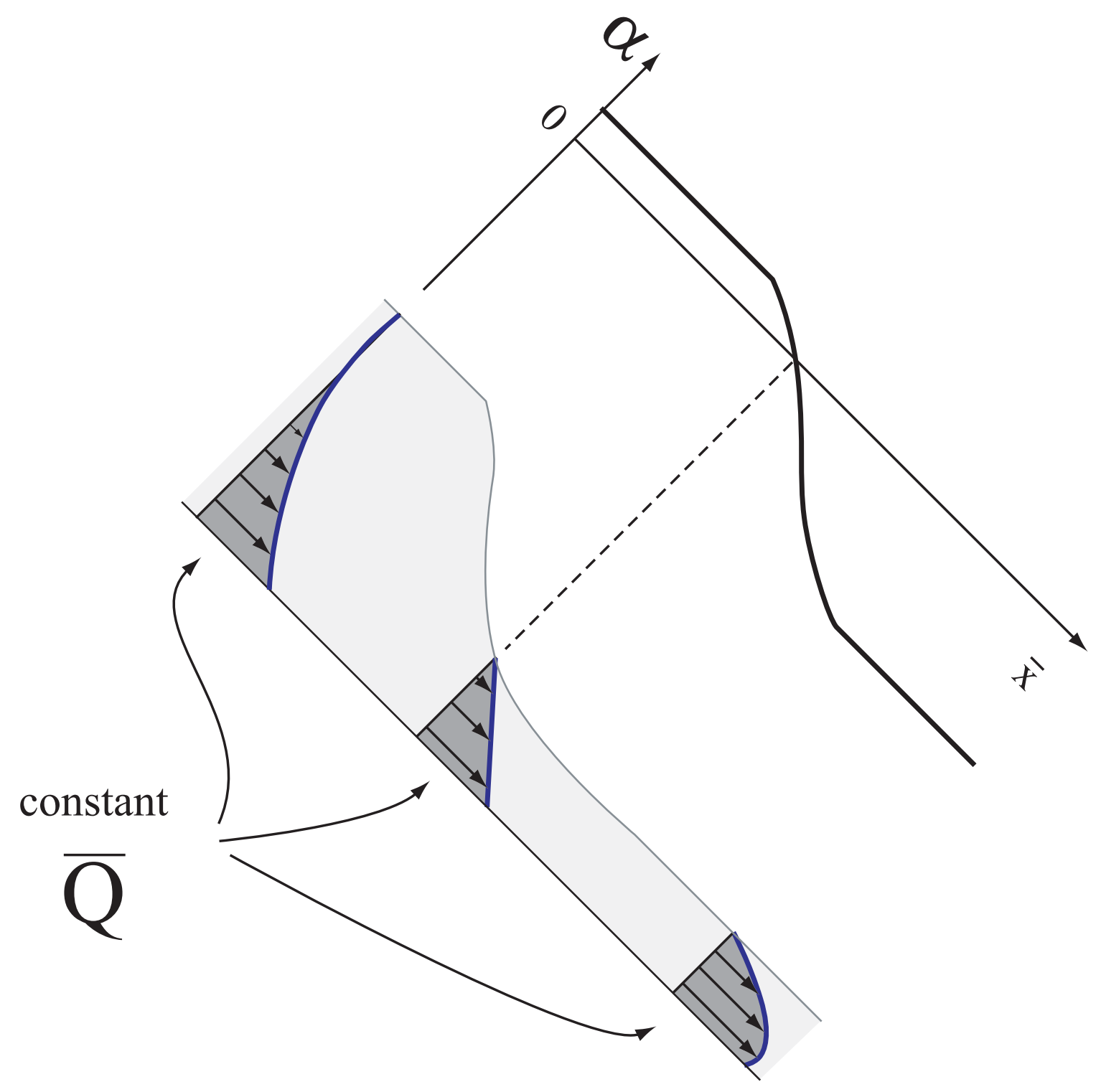

Figure 10 

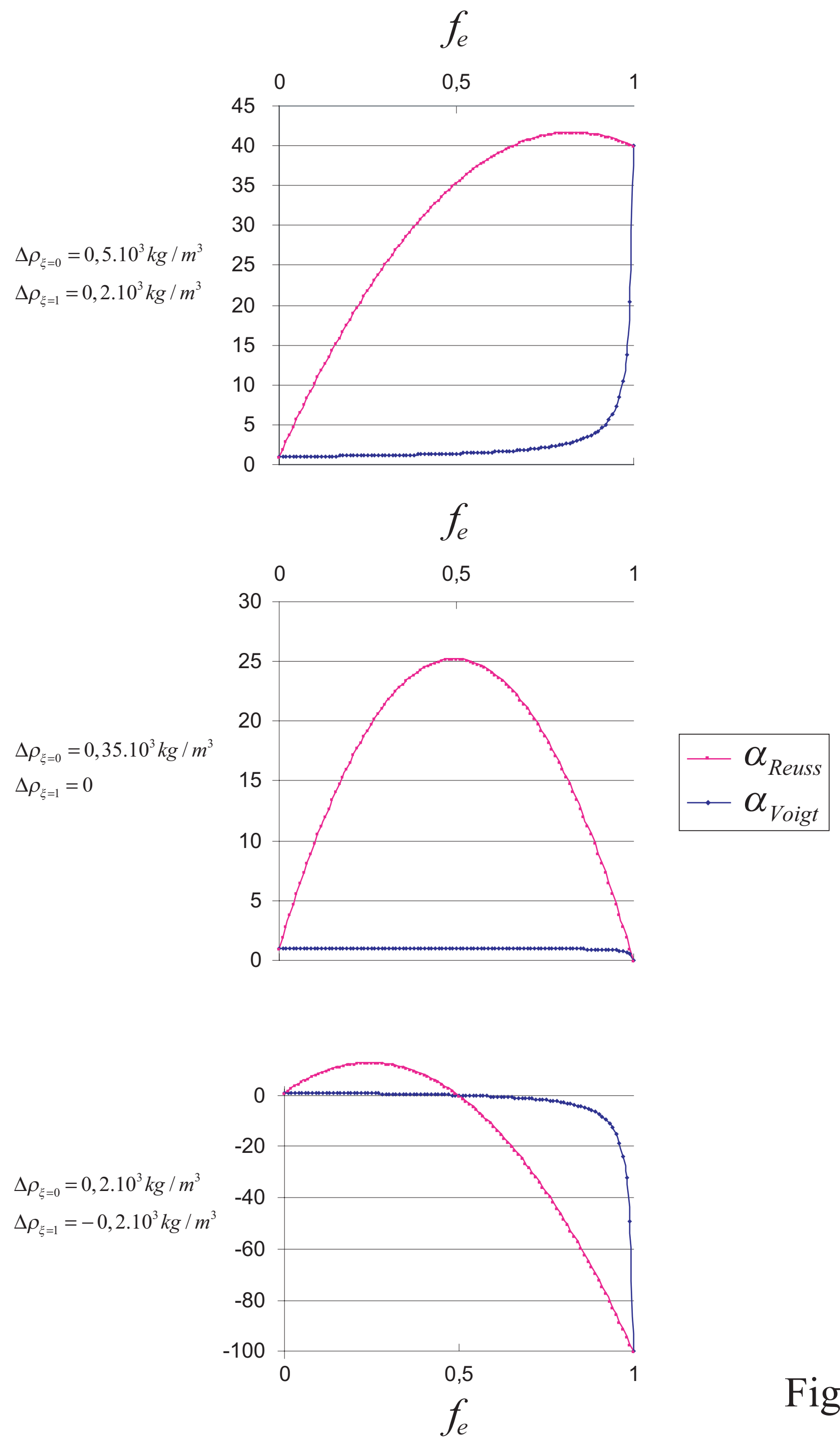

Figure 11 


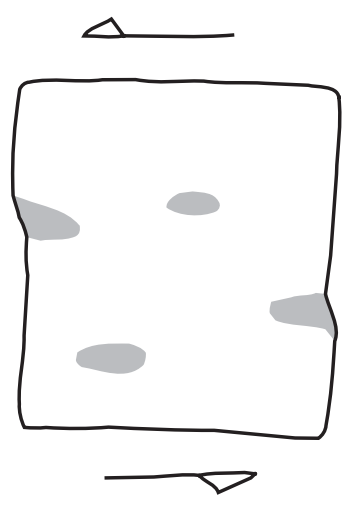

(1)

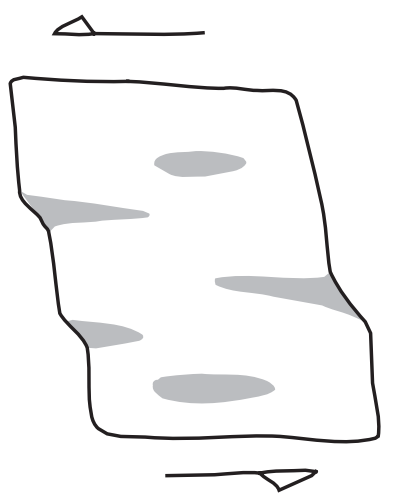

(2)

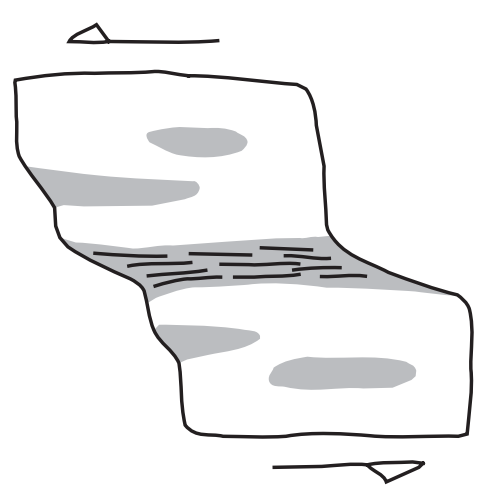

(3)

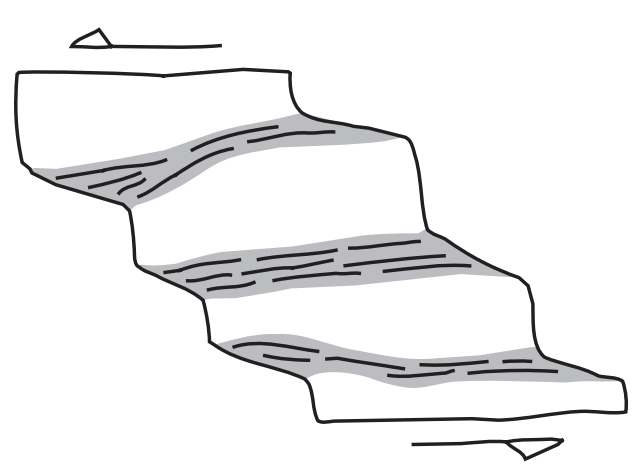

(4)

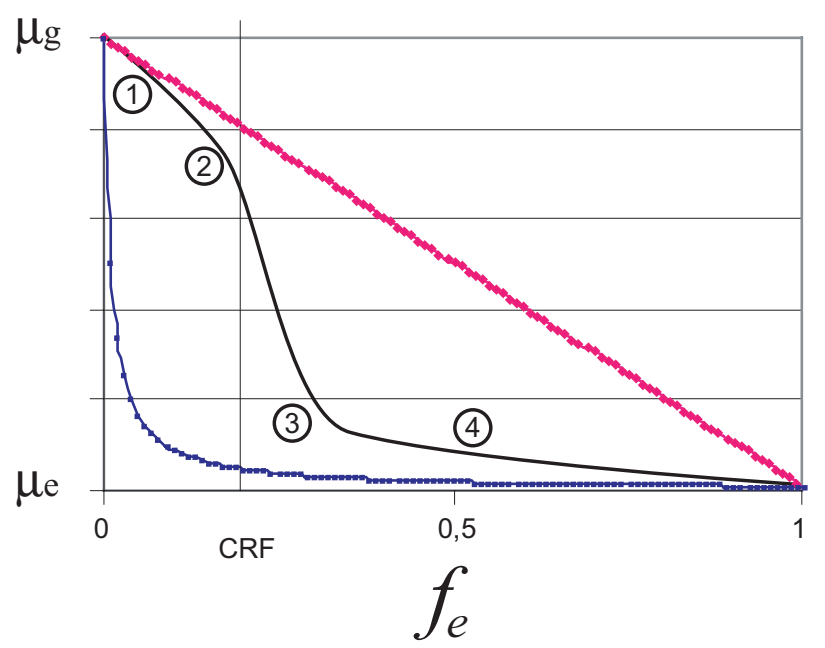

\section{$\ldots \mu_{\text {Reuss }}$ \\ $\longleftrightarrow \mu_{\mathrm{Voigt}}$ \\ $\longrightarrow \mu_{\text {eff }}$}

CRF $1 \quad$ CRF 2

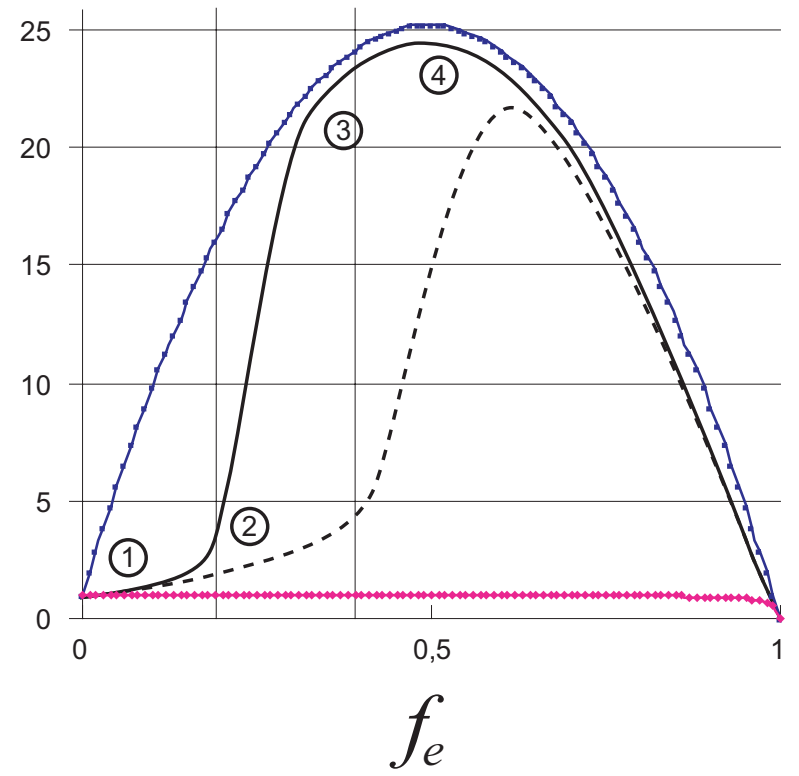

$\Delta \rho_{\xi=0}=0,35 \cdot 10^{3} \mathrm{~kg} / \mathrm{m}^{3}$

$\Delta \rho_{\xi=1}=0$

$\ldots \alpha_{\text {Reuss }}$

$\because \alpha_{\text {Voigt }}$

$-\alpha_{\text {eff }}$

$\ldots \alpha_{\text {eff }}$ (high CRF)

Figure 12 


$$
\begin{aligned}
& \Delta \rho_{\xi=0}=0,2 \cdot 10^{3} \mathrm{~kg} / \mathrm{m}^{3} \\
& \Delta \rho_{\xi=1}=-0,2 \cdot 10^{3} \mathrm{~kg} / \mathrm{m}^{3}
\end{aligned}
$$

Figure 13
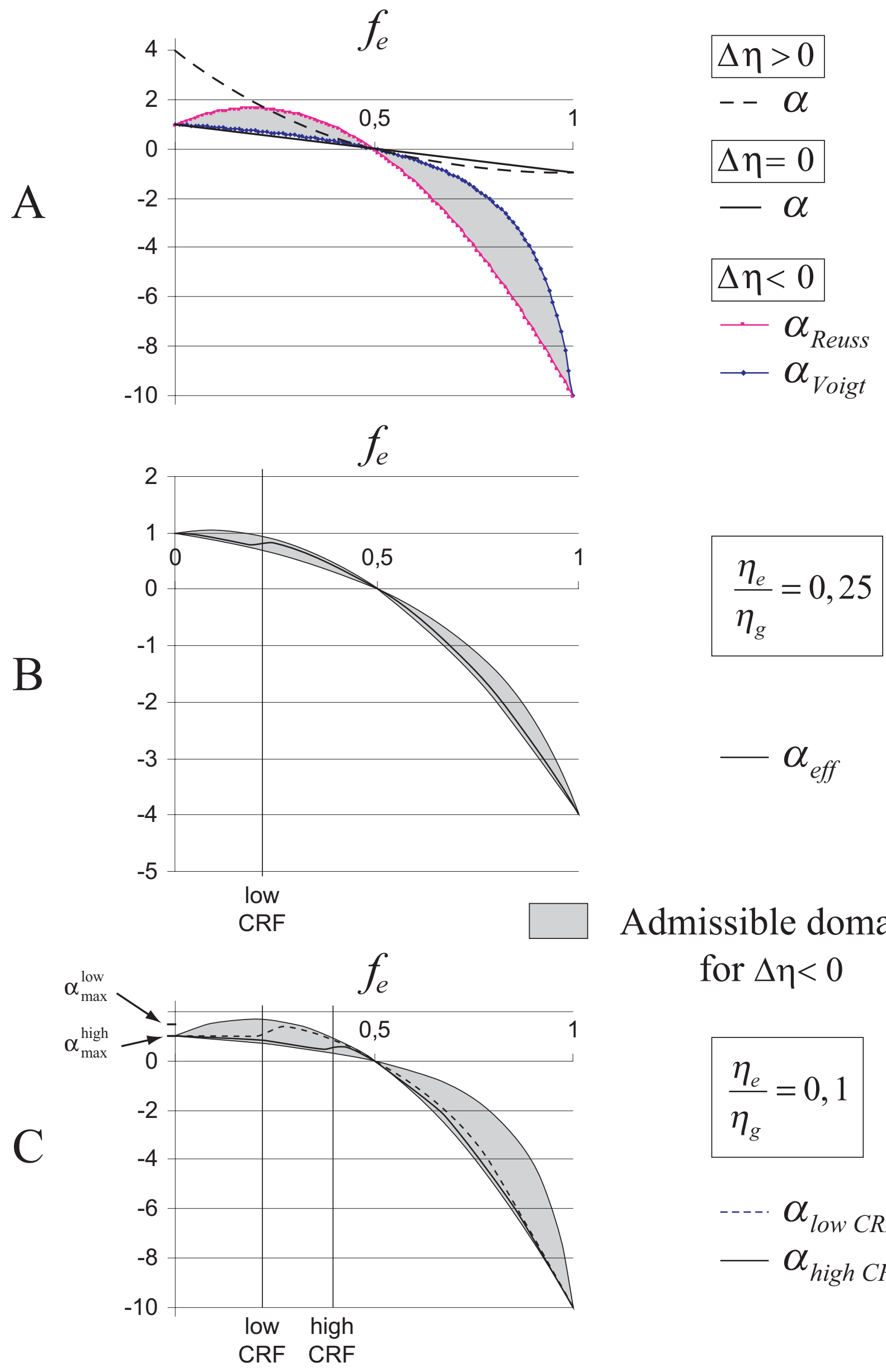

Admissible domain for $\Delta \eta<0$

$$
\frac{\eta_{e}}{\eta_{g}}=0,1
$$

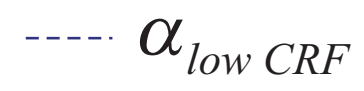

$-\alpha_{\text {high } C R F}$ 
Figure 14

Untransformed crust

Partially eclogitized crust

Completely eclogitized crust

Crust 1 (ge1)

Crust 2 (ge2)

- Eclogite-facies upper boundary (fixed depth)

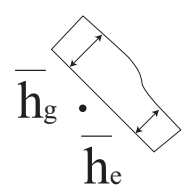

$t_{0}$

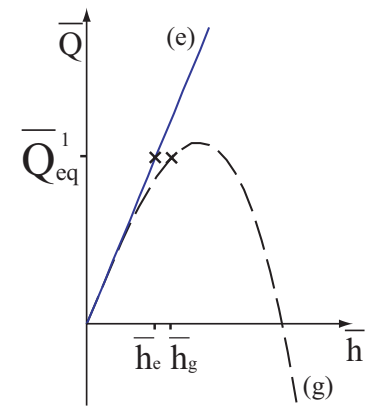

Metamorphic reactions distribution

\section{Material} distribution

h.

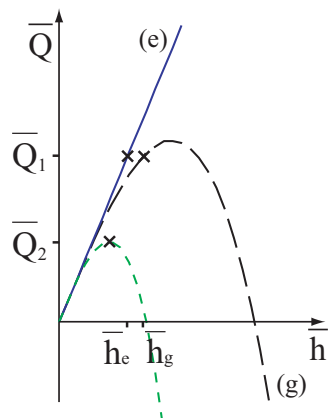

(ge 2)

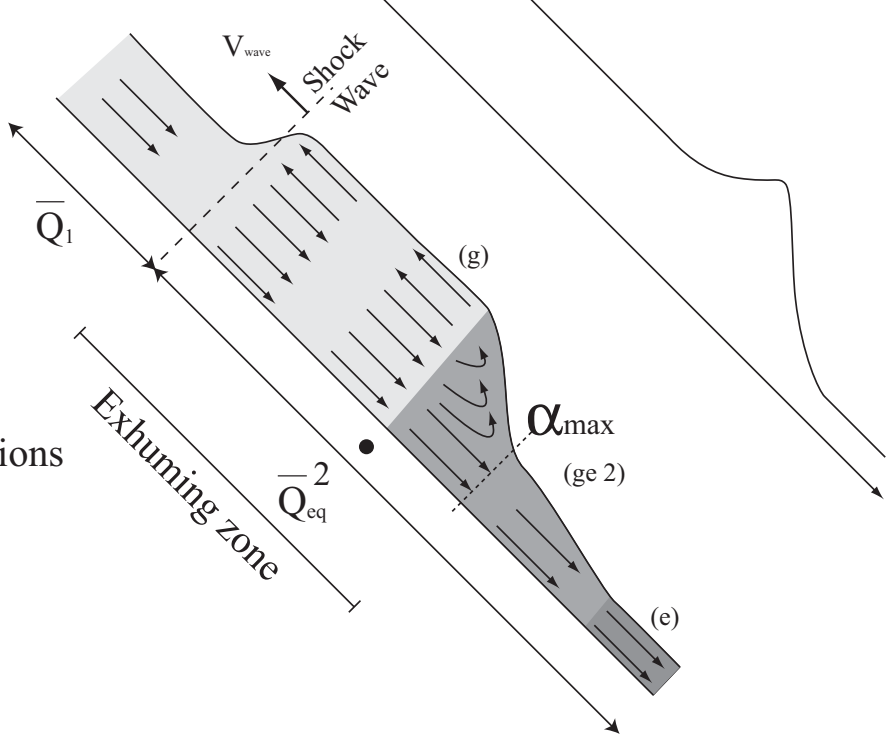

$\mathrm{h}_{\mathrm{s}}$
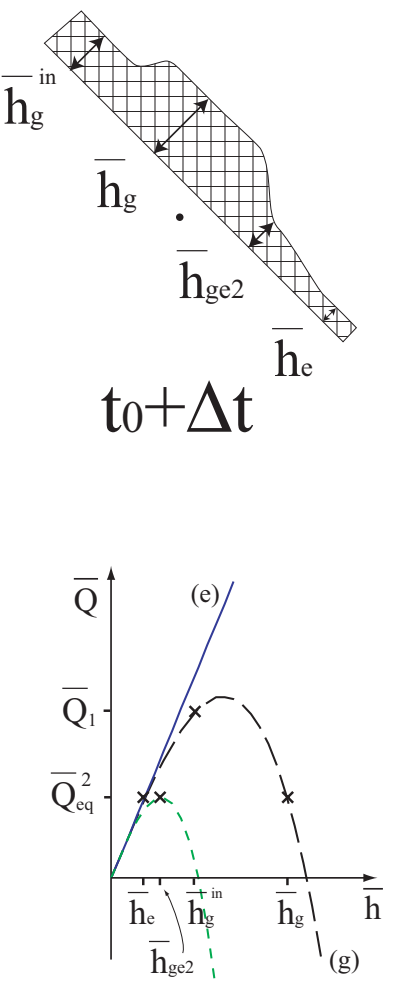

(ge 2) 


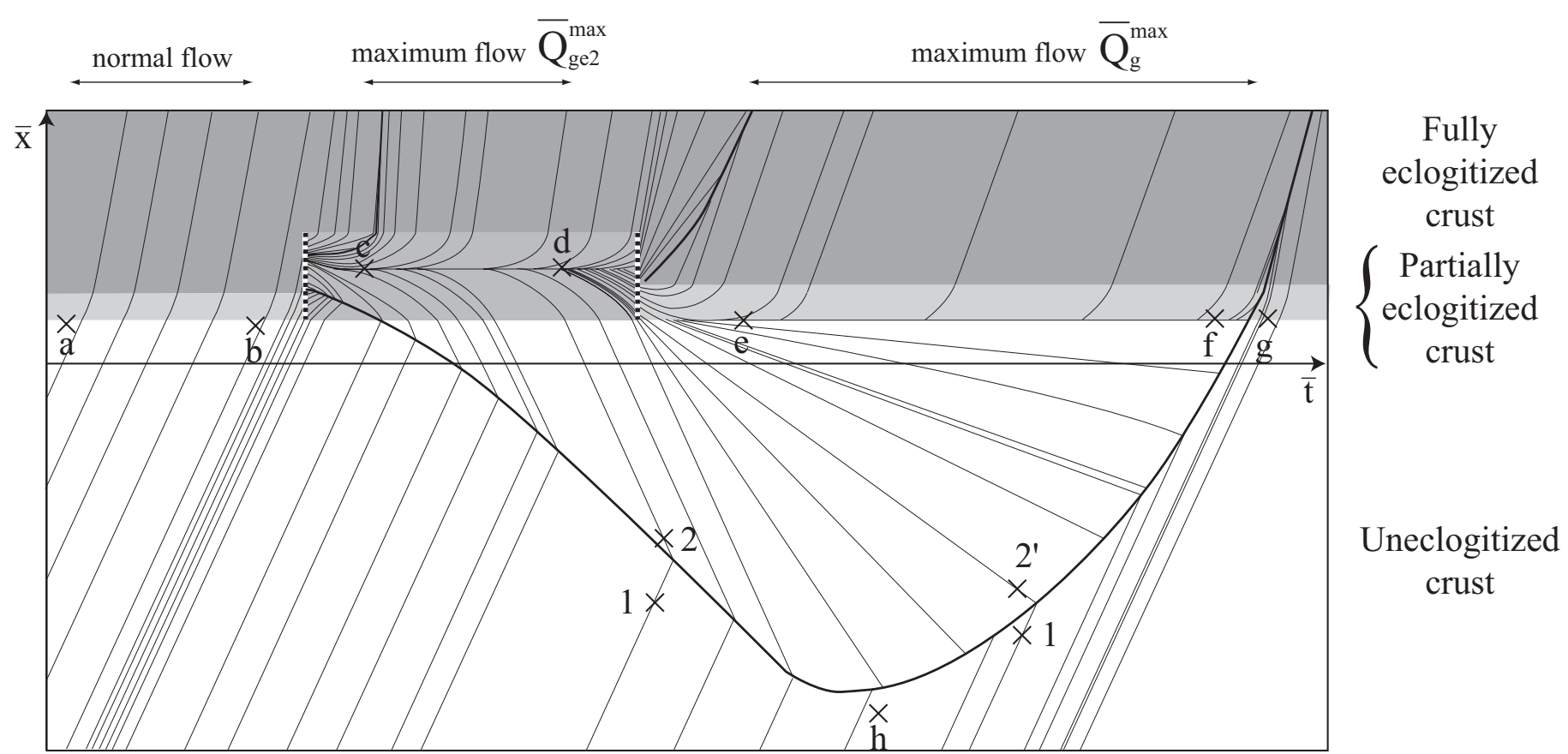

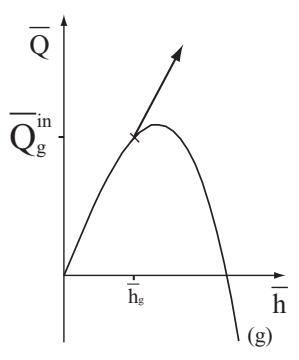

(a-b)

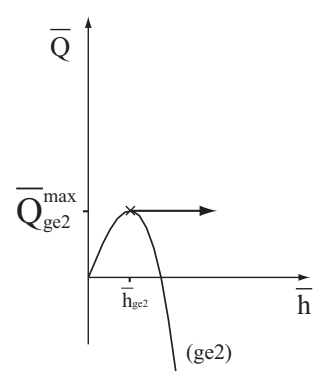

(c-d)

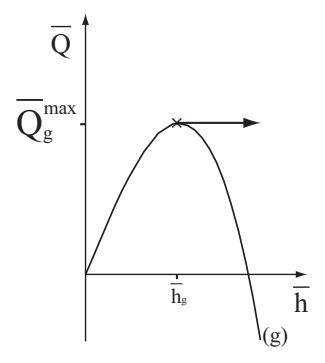

(e-f)
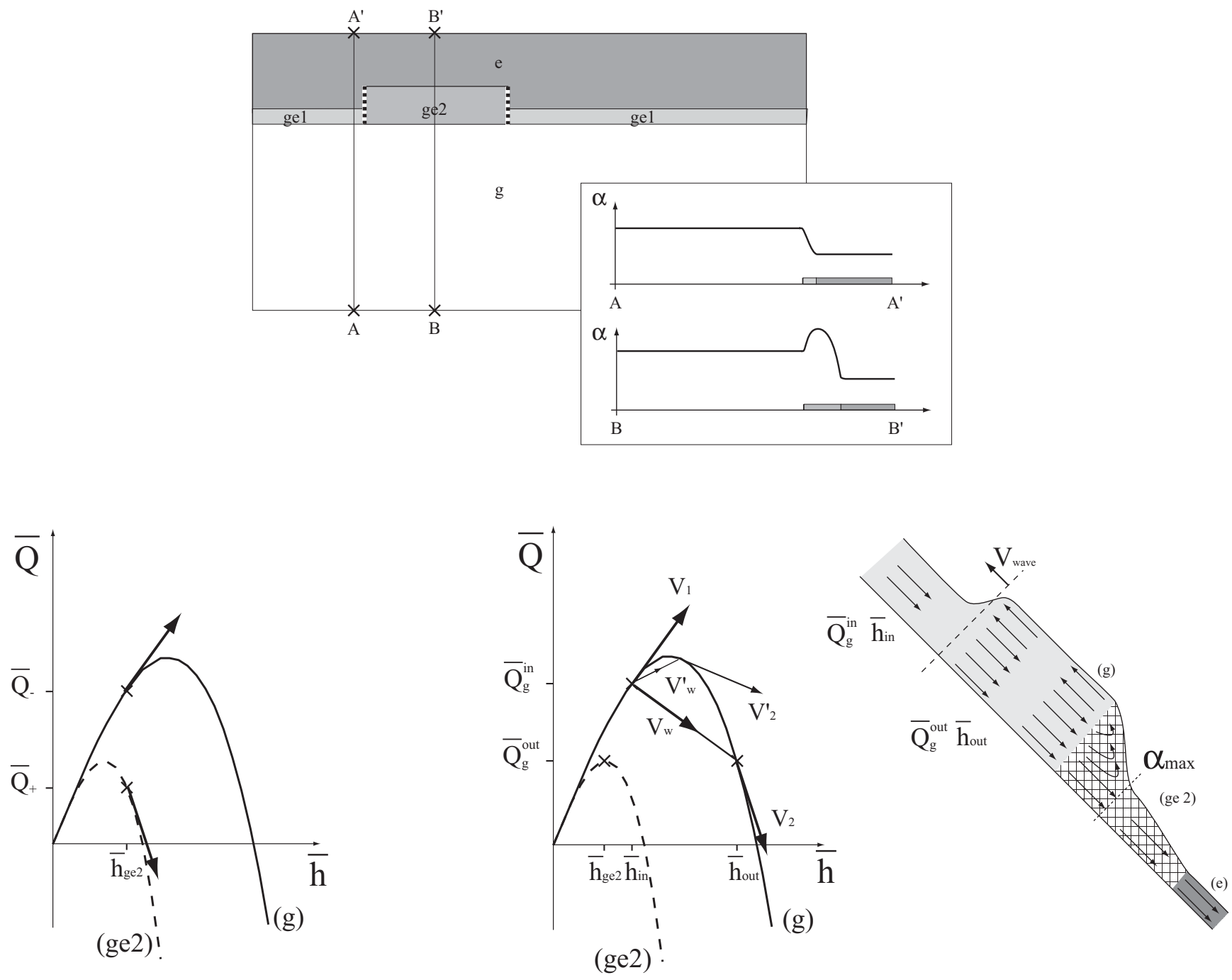

Figure 15 


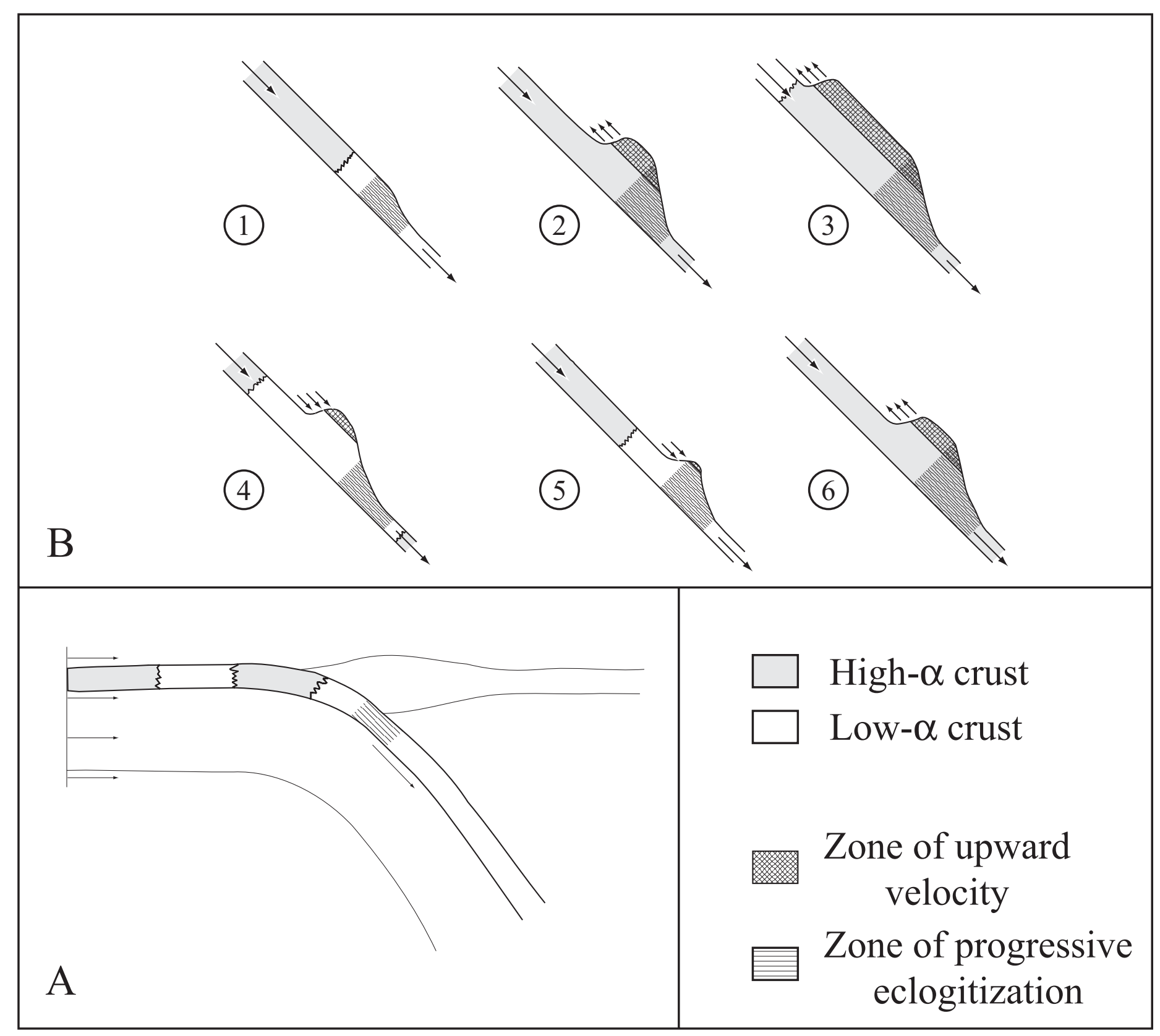

Figure 16 


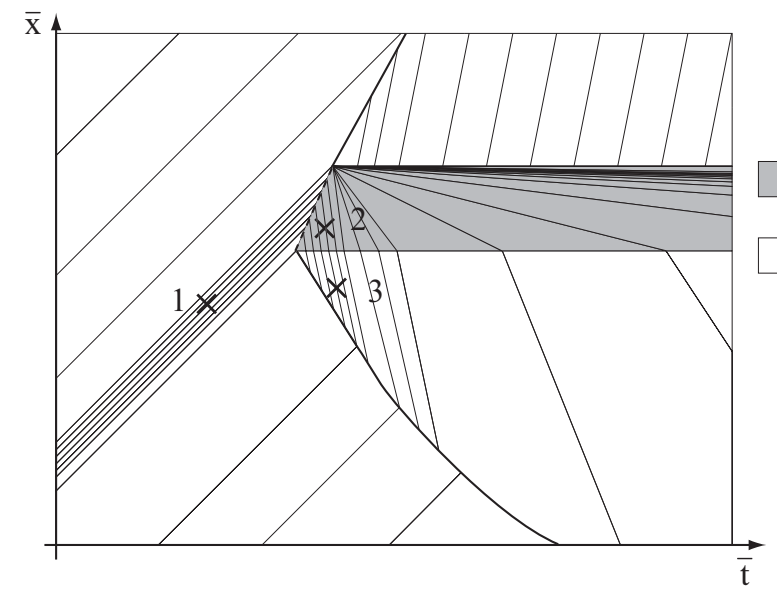

high- $\alpha$ material (ge2) low- $\alpha$ material (g)
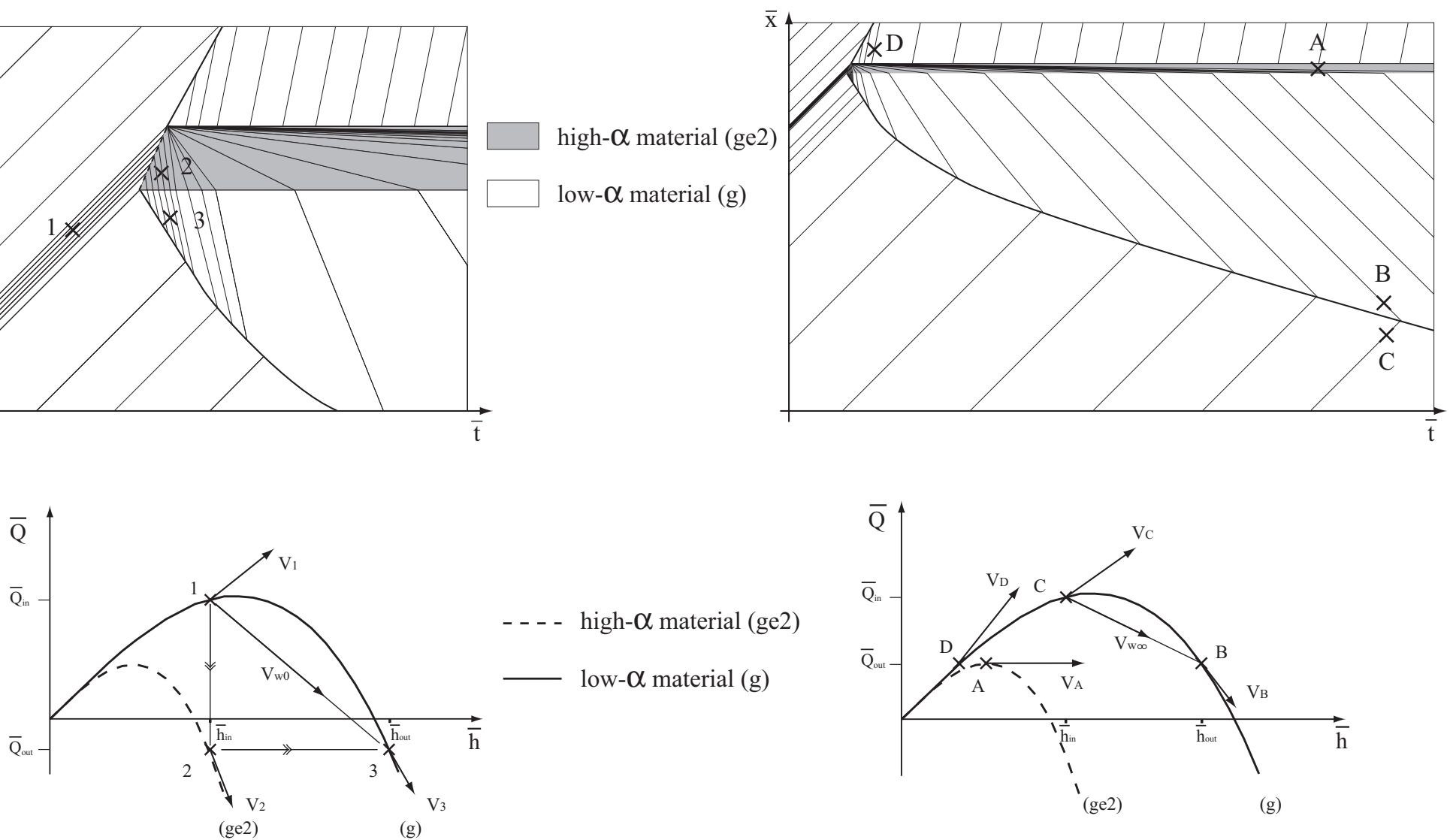

- - - high- $\alpha$ material (ge2)

— low- $\alpha$ material (g)
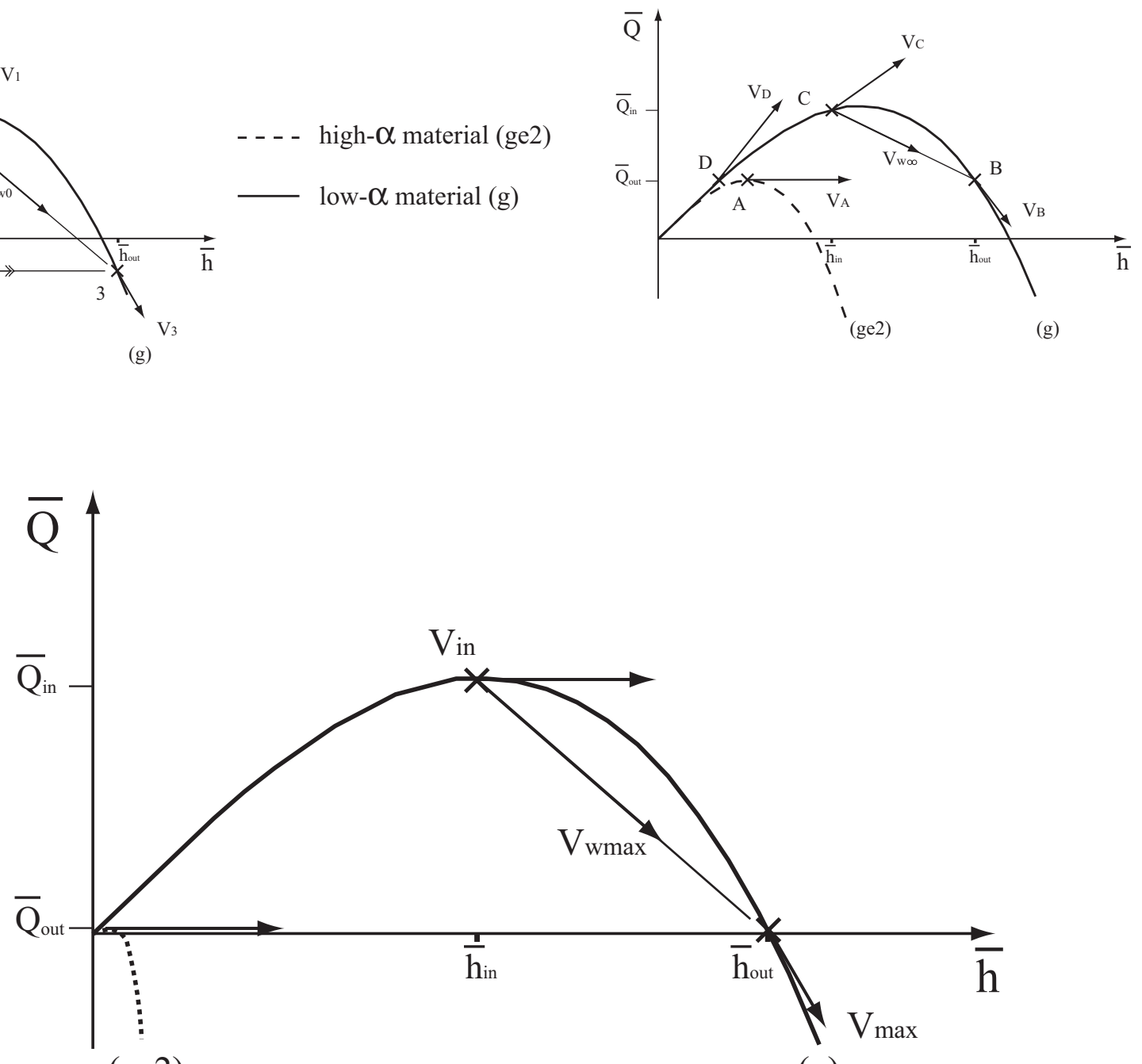

(ge2)

(g) 


\section{Velocity Field}

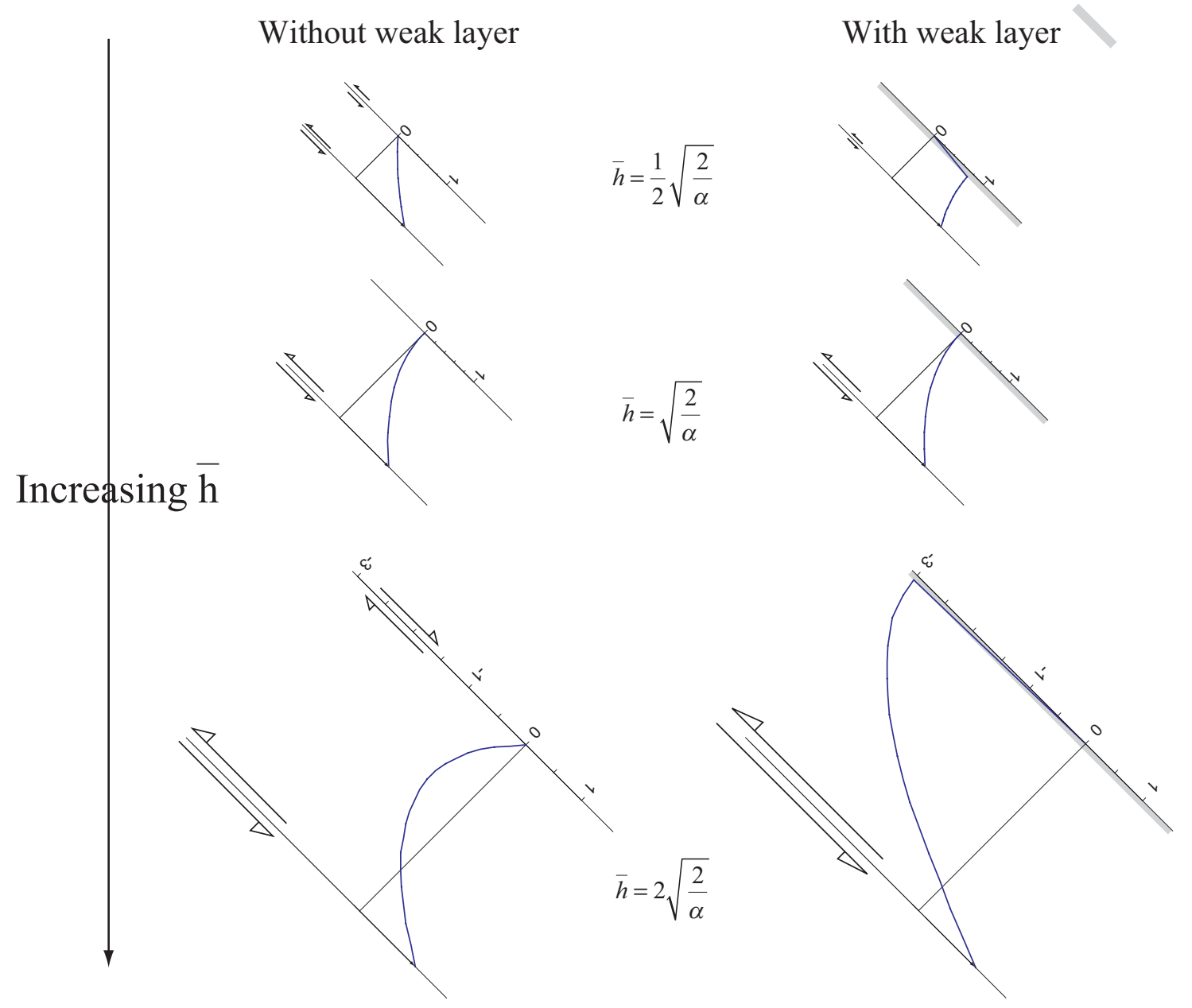

Net flow

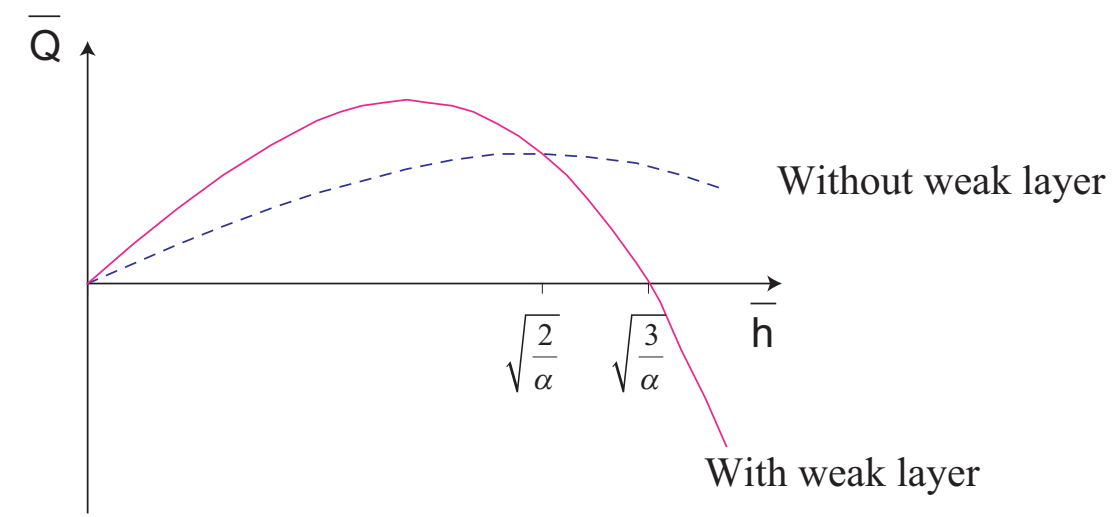

Figure 18 


\begin{tabular}{|c|c|c|}
\hline sample & density & type \\
\hline $\mathrm{H} 30 \mathrm{a}$ & 3,34 & eclo \\
$\mathrm{H} 30 \mathrm{~b}$ & 3,32 & eclo \\
$\mathrm{H} 26$ & 3,22 & eclo \\
$\mathrm{K} 02$ & 3,22 & eclo \\
$\mathrm{G} 03$ & 3,37 & eclo \\
$\mathrm{H} 01$ & 3,29 & eclo \\
$\mathrm{N} 03$ & 3,27 & eclo \\
$\mathrm{H} 14$ & 3,40 & eclo \\
$\mathrm{H} 14$ & 3,39 & eclo \\
\hline $\mathrm{M} 02 \mathrm{~b}$ & 2,76 & gran \\
$\mathrm{A} 04$ & 2,98 & gran \\
$\mathrm{G} 01$ & 2,96 & gran \\
$\mathrm{M} 02 \mathrm{a}$ & 2,75 & gran \\
$\mathrm{N} 01$ & 3,10 & gran \\
\hline
\end{tabular}

Table 1 